\title{
Review of Literature on the Testing of Point-Velocity Current Meters
}

\author{
By KIRK G. THIBODEAUX
}




\title{
U.S. DEPARTMENT OF THE INTERIOR BRUCE BABBITT, Secretary
}

\author{
U.S. GEOLOGICAL SURVEY
} GORDON P. EATON, Director

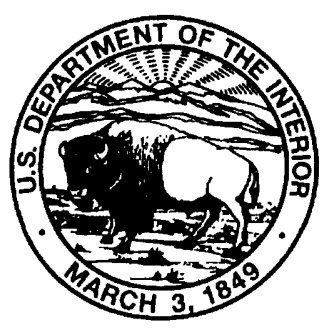

Any use of trade, product, or firm names in this publication is for descriptive purposes only and does not imply endorsement by the U.S. Geological Survey.

For additional information write to:

Chief, Hydraulic Laboratory Facilities

U.S. Geological Survey

Office of Surface Water

Building 2101

Stennis Space Center, MS 39529
Copies of this report can be purchased from:

U.S. Geological Survey

Earth Science Information Center

Open-File Reports Section

Box 25286, MS 517

Denver Federal Center

Denver, CO 80225 


\section{CONTENTS}

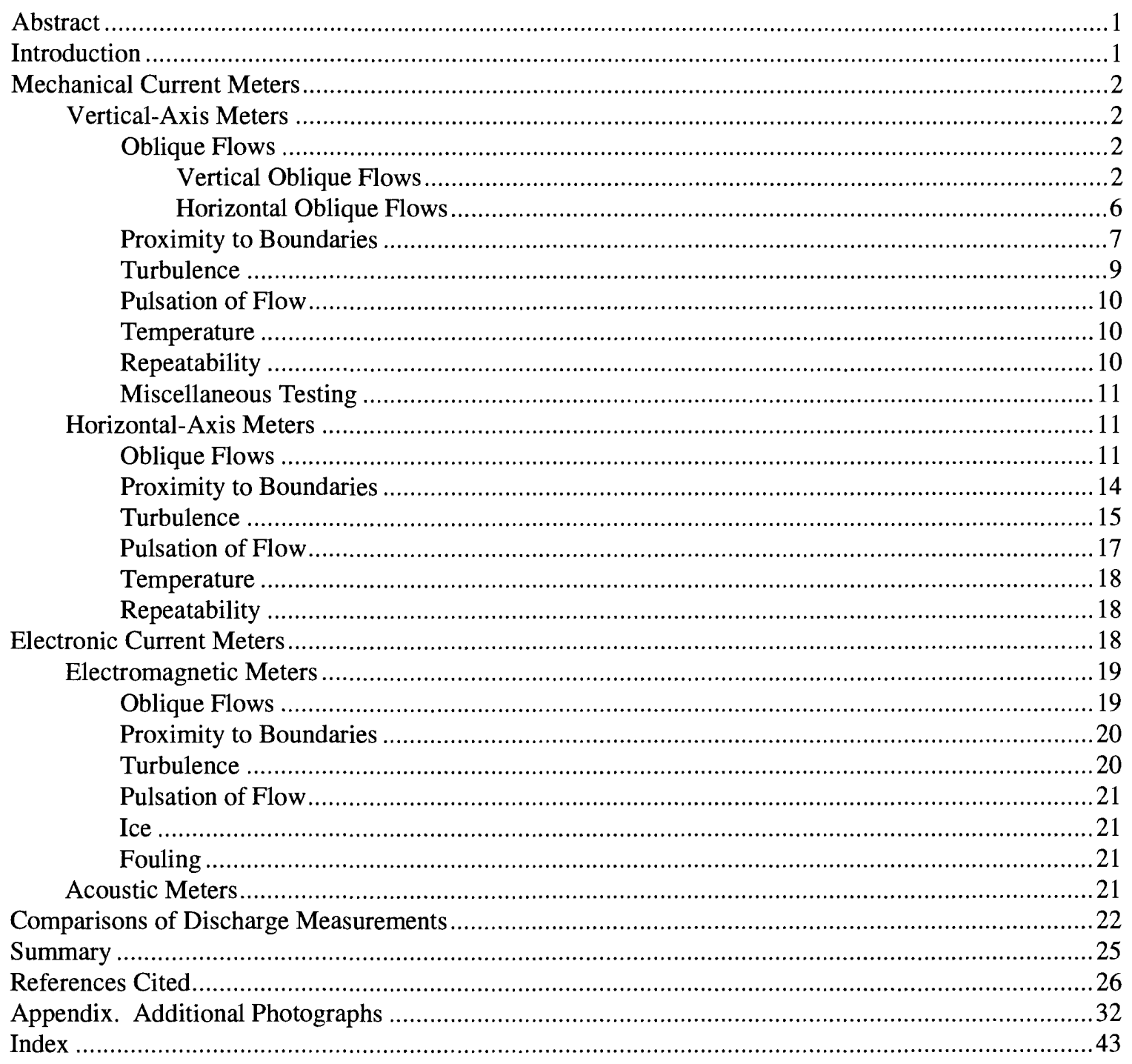




\section{FIGURES}

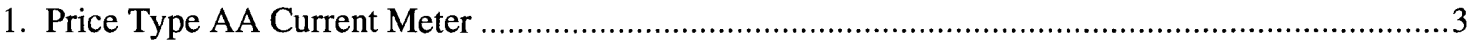

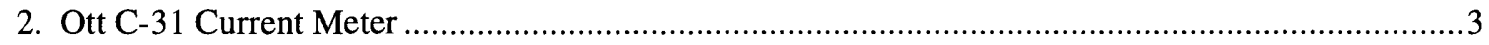

3. Collection of Price-Type Current Meters from the Early 1900's...................................................33

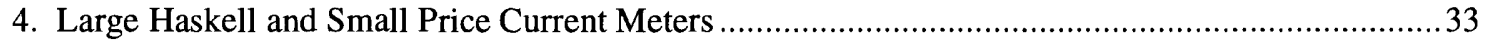

5. Collection of Haskell Current Meters from the Early 1900's ....................................................... 34

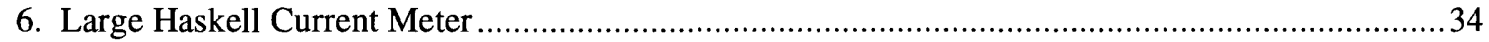

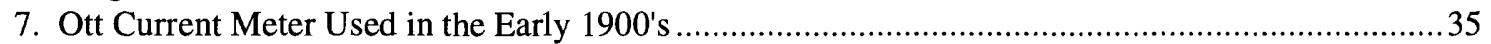

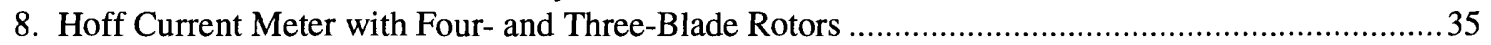

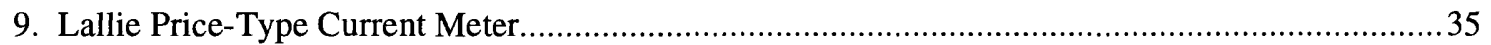

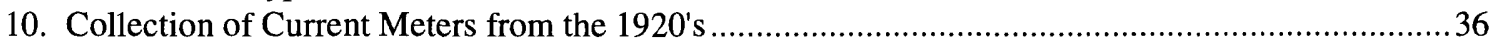

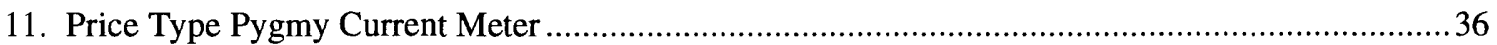

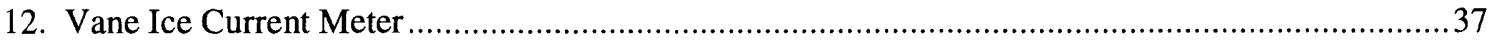

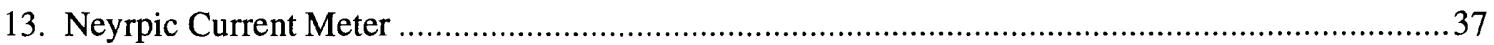

14. EG\&G (Neil Brown) Two-Dimensional Acoustic Current Meter................................................38

15. Marsh-McBirney One-Dimensional Electromagnetic Tear-Drop Probe …...................................38

16. Marsh-McBirney Two-Dimensional Electromagnetic Spherical Probe ........................................ 39

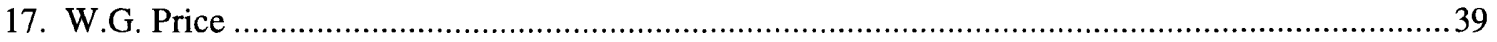

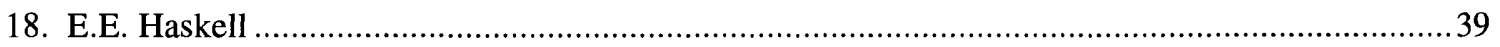

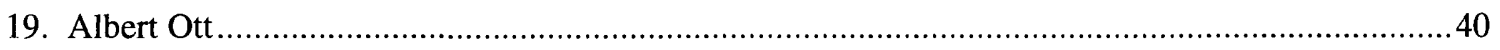

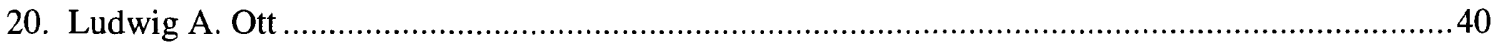

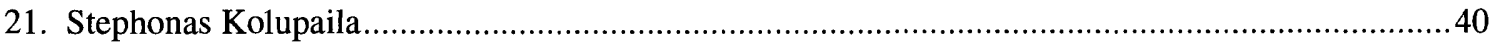

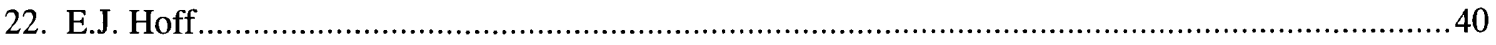

23. Small Price Current Meter Being Tested under Vertical-Oblique Flow Conditions ........................ 41

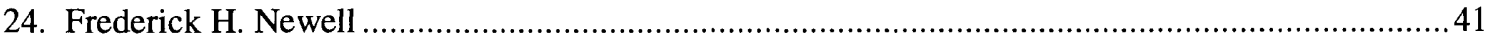

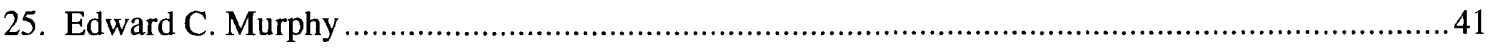

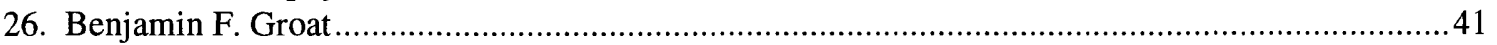

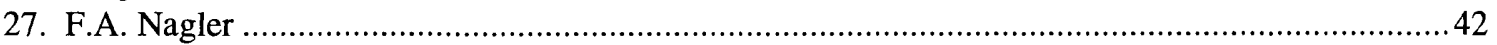

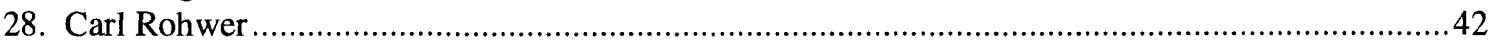

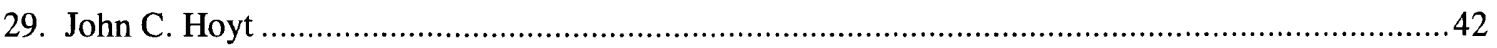

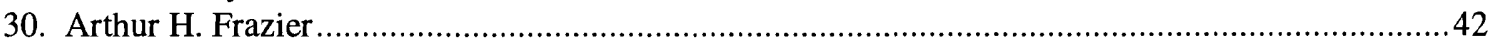




\section{CONVERSION FACTORS}

\begin{tabular}{rcl}
\hline Multiply & By & To obtain \\
\hline inch (in.) & 25.4 & millimeter \\
foot (ft) & 0.3048 & meter \\
foot per second (ft/s) & 0.3048 & meter per second \\
ounce, avoirdupois (oz) & 28.35 & gram \\
degree Fahrenheit $\left({ }^{\circ} \mathrm{F}\right)$ & ${ }^{\circ} \mathrm{C}=5 / 9 \times\left({ }^{\circ} \mathrm{F}-32\right)$ & degree Celsius \\
millimeter $(\mathrm{mm})$ & 0.03937 & inch \\
meter $(\mathrm{m})$ & 3.281 & foot \\
millimeter per second $(\mathrm{mm} / \mathrm{s})$ & 0.03937 & foot per second \\
meter per second $(\mathrm{m} / \mathrm{s})$ & 3.281 & foot per second \\
gram $(\mathrm{g})$ & 0.03527 & ounce, avoirdupois \\
degree Celsius $\left({ }^{\circ} \mathrm{C}\right)$ & ${ }^{\circ} \mathrm{F}=1.8 \times{ }^{\circ} \mathrm{C}+32$ & degree Fahrenheit \\
\hline
\end{tabular}




\title{
Review of Literature on the Testing of Point-Velocity Current Meters
}

\author{
By Kirk G. Thibodeaux
}

\section{Abstract}

The U.S. Geological Survey is in the process of evaluating point-velocity current meters. As part of this evaluation process, a review of the literature pertaining to the testing of pointvelocity current meters was conducted. A listing of current-meter testing found in the literature was compiled and is grouped according to the type of meter tested and the type of test conducted. Meter types included in the review were vertical- and horizontal-axis mechanical current meters and electromagnetic and acoustic electronic current meters. Laser current meters are not included in the review because there are no practical laser meter designs for field velocity measurements. The results of the literature review indicated that there has not been a comprehensive testing of the commonly available current meters since the 1920's.

\section{INTRODUCTION}

Many types and makes of point-velocity current meters are available for use in taking velocity measurements and making discharge measurements. How well these current meters work under varying and adverse conditions has been a concern since the beginning of their widespread use for velocity and discharge measurements. How well the current meters in use around the world today work under varying conditions is of concern to the U.S. Geological Survey (USGS).

The development of new instrumentation technology, such as the acoustic and electromagnetic current meters, and renewed interest in the performance of older instrumentation prompted the USGS in 1990 to create a committee to investigate current meters. As part of the initial investigations, the committee performed two tasks: a review of literature from previous current meter studies and a survey of the characteristics of discharge measurements made by the USGS. This paper presents the results of the first task, the review of literature from previous current meter studies. The second task, a survey of the characteristics of discharge measurements made by the USGS for water year 1990 (October 1, 1989 to September 30,1990) has been completed and is reported on by Fulford (1992).

The review of the literature on the testing of point-velocity current meters was undertaken to determine what kinds of tests were conducted on these meters and how the tests were conducted. The reanalysis of the data presented in the literature was not conducted as part of the literature review. Those tests that were conceived, planned, and executed with great care and understanding of the physical properties of the meters being tested will be evaluated by the USGS for use in its ongoing test of point-velocity current meters. Those tests that were ill conceived, poorly planned, or not executed with care will be studied by the USGS so as not to repeat the mistakes made in earlier testing.

The results of the literature review will be given under two major groups: mechanical current meters and electronic current meters. The mechanical current meter section will cover the testing of verticaland horizontal-axis meters. The electronic current meter section will cover the testing of electromagnetic meters and acoustic meters. Laser current meters will not be covered in the literature review because there are no practical laser meter designs for field velocity measurements.

Literature covering the history of current-meter design and use includes works by Murphy (1904), Hoyt (1910), Kolupaila (1960), and Frazier (1967 and 1974). Papers that contain extensive lists of references covering current-meter testing include Kolupaila (1961), Dickinson (1967), and Pelletier (1988). These works are mentioned because the reader may be interested in aspects of current meters other than the testing of meters. 


\section{MECHANICAL CURRENT METERS}

Mechanical current meters fall into two categories, vertical-axis current meters and horizontal-axis current meters. Both of these meter types use mechanical means to determine the water velocity. Common examples of the mechanical current meters are the Price-type meter, a vertical-axis meter, and the Ott-type meter, a horizontal-axis meter. A Price type AA current meter is shown in figure 1 and an Ott model C-31 current meter is shown in figure 2. Additional photographs of current meters and current meter developers and researchers can be found in the appendix.

\section{Vertical-Axis Meters}

In all but a few of the papers reviewed, the meter associated with the vertical-axis label is the Price-type current meter. Some of the early testing of vertical-axis meters include meters other than the Price-type.

The Price type current meters used in the testing outlined in this section fall into three general size categories. These are the large Price meter with a 7.5 in. $(190.5 \mathrm{~mm})$ diameter rotor with 5 cups, the small Price type meter (including the present version of this meter) with a 5 in. $(127 \mathrm{~mm})$ diameter rotor with 6 cups, and a Price pygmy meter with a 2 in. $(51 \mathrm{~mm})$ diameter rotor with 6 cups.

\section{Oblique Flows}

The concern about the effects of oblique flows on the performance of the vertical-axis current meter has been around for quite some time. The earliest documented study located in the USGS literature review was in 1899 (Newell, 1899) where the effects of vertical oblique flows on the calibration of a Price meter were determined. Because a vertical-axis meter will respond differently to oblique flows in the vertical and horizontal planes, tests using the two types of oblique flows will be addressed separately.

\section{Vertical Oblique Flows}

The testing of vertical-axis current meters subjected to oblique flows in the vertical direction can generally be lumped into two groups. The first group of tests are those where the meter is fixed at a vertical angle and is then towed or placed in flowing water to determine the meter's performance. This method was used by the Newell (1899), Brown and Nagler (1914), Scobey (1914), Yarnell and Nagler (1931), Nagler (1931), Rohwer (1933), Hjalmarson (1967), Engel and DeZeeuw (1979), and Fulford (1990). The second group of tests are those where the meter is moved vertically when it is being towed or placed in flowing water. This method was used by Lippincott (1902), Miller (1902), Groat (1913 and 1916), Scobey (1914), Leach (1931), Rohwer (1933), Chappell (1939), Kallio (1966a), Thibodeaux and Futrell (1987), Engel (1990), and Fulford (1990).

The results of tests using the first method are presented in the Nineteenth Annual Report of the U.S. Geological Survey (Newell, 1899). This work determines the effects of not holding the meter in a vertical position when taking discharge measurements. Without giving the type of meter used in the tests, large Price meter or small Price meter, the results presented are calibration curves for the meter tilted at various angles. A table derived from the calibration curves is also presented for tilt angles of $5,15,25,35$, and 45 degrees. No analysis of the data is presented in the report.

Brown and Nagler (1914) present the results of tests on a large Price meter. The meter was mounted on an assembly that would rotate in the vertical direction around the meter rotor's center. Little information is given on the testing. The information that is given covers the test setup. The meter was tested in a 42-inch-diameter $(1.1 \mathrm{~m})$ pipe flowing partially full, the depth of flow was kept at approximately 13 in. $(0.3 \mathrm{~m})$ deep with a velocity of $4 \mathrm{ft} / \mathrm{s}(1.2 \mathrm{~m} / \mathrm{s})$. During the tests the meter was rotated to angles of \pm 90 degrees. No quantitative results are given in the paper; but, from the description of the test setup, the results were affected by the proximity of the meter to the invert of the pipe and the water surface.

The work reported on by Scobey (1914) consists, in part, of the results of tests on a small Price meter tilted at angles of $\pm 5,15$, and 30 degrees and towed in a flume. The results are presented in graphical form with the results of 13 experiments on 1 graph. With the exception of a few data points, the graph is too cluttered to be of much value.

As part of an extensive set of tests, Yarnell and Nagler (1931) conducted vertical oblique flow tests on three types of vertical-axis meters; a small Price, 


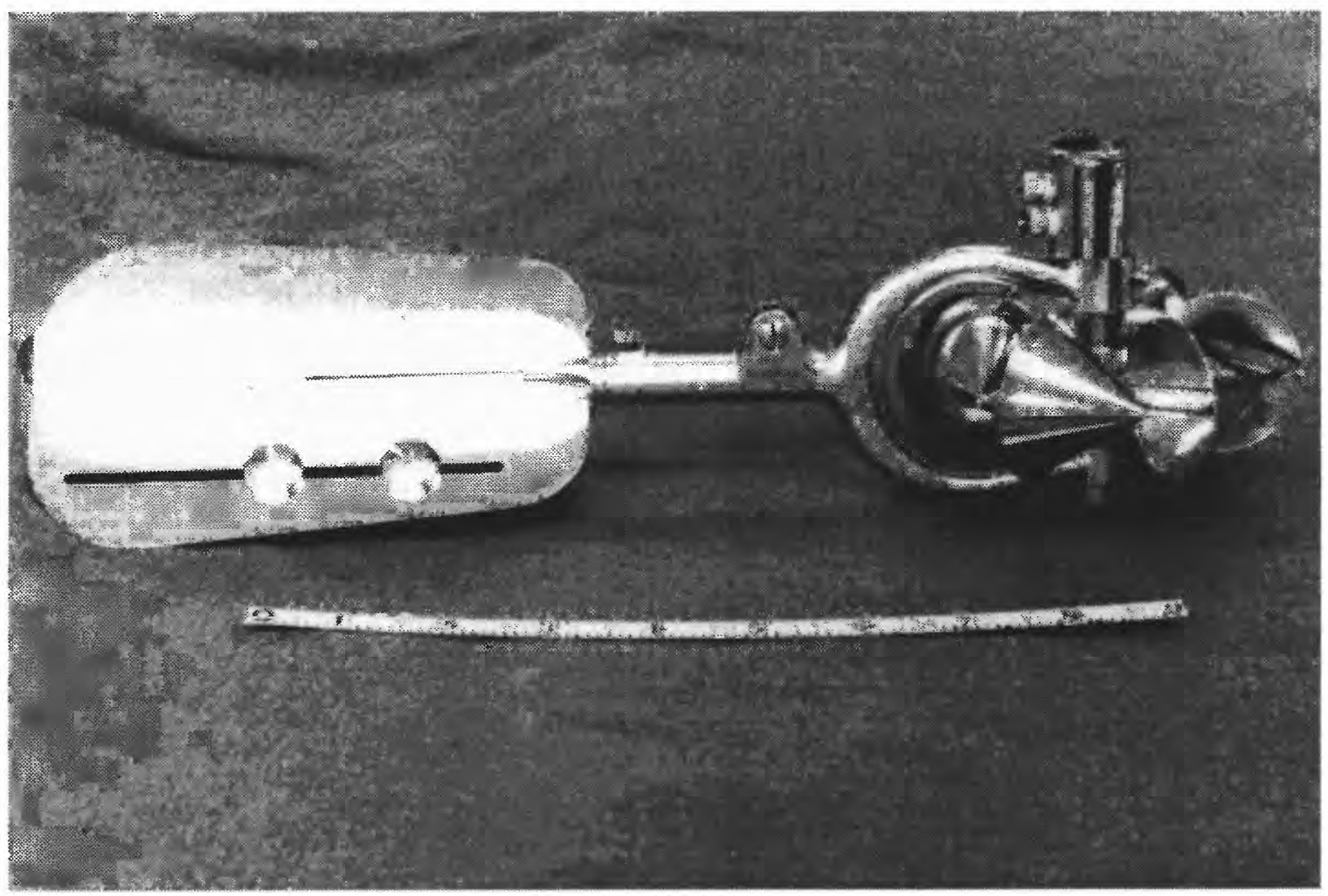

Figure 1. Price type $A A$ current meter.

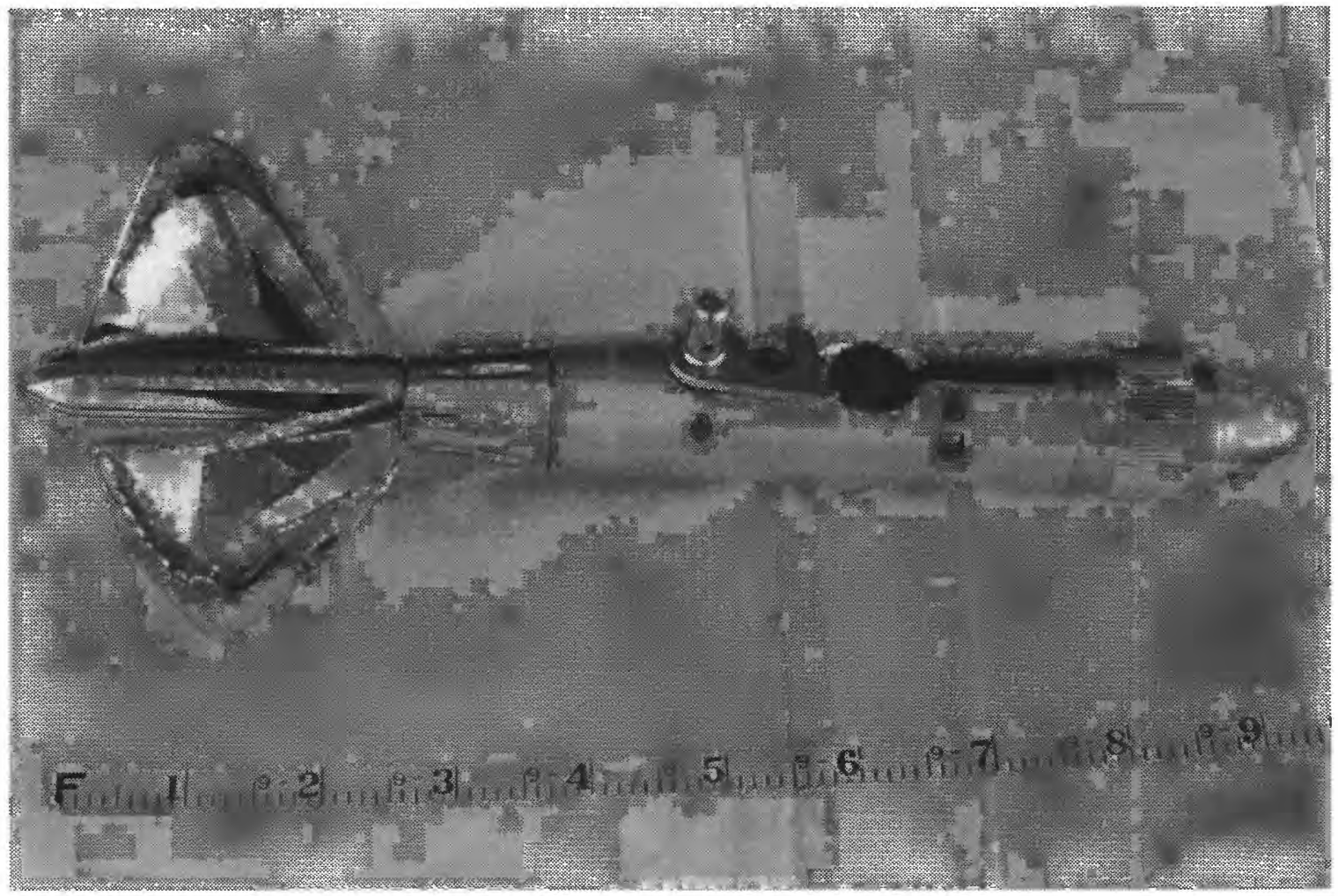

Figure 2. Ott C-31 current meter. 
an acoustic Price, and the USGS-improved Price (later designated as the 622-type meter). These tests were conducted in a flowing flume for meter angles ranging to \pm 30 degrees in 5-degree increments. The results of the tests are presented graphically where the meter outputs are plotted against a theoretical cosine response. This is the first paper to present the results in a manner in which the meter's registered velocity is plotted against the theoretical cosine response line. For angles producing an upward current on the meters, all three meters registered less than the theoretical response. For angles producing a downward current on the meters, the small Price meter underregistered, the USGS-improved Price meter overregistered; and the acoustic Price meter fluctuated between overregistering at angles less than 20 degrees and underregistering at angles greater than 20 degrees. The authors contend that, at the time of the tests (1931), the Price-type meters were as good as could be used.

Accompanying the paper by Yarnell and Nagler is an extensive collection of discussion letters by other people. Most of these discussions are comments about the work done by Yarnell and Nagler with a few presenting results of their own experiments. The discussion by Nagler (1931) is one that covers the results of experiments on various meters including a large Price meter and a small Price meter. These tests were conducted in a pipe flowing partially full in the same manner as the tests described by Brown and Nagler (1914). The results are presented in graphical form and are of little value because of the difficulty in interpreting the data.

In his paper, Rohwer (1933) presents the results of a comprehensive set of tests to determine the flowmeasuring characteristics of most of the current meters available in the United States in the late 1920 's. A portion of the testing conducted in a tangential (straight) tow tank covered vertical oblique flows for vertical-axis meters. The results presented by Rohwer are in graphical form and consist of three plots for the small Price meters used. The plots presenting the data are arranged so that the number of revolutions of the meter's rotor per foot of travel is plotted against the tow vehicle's speed; the percent error between the meter's registered velocity and the axial velocity is plotted against the angle of the approaching flow (meter tilt angle); and the percent error between the meter's registered velocity and the cosine of the axial velocity is plotted against the angle of the approaching flow.

Testing of the present incarnation of the Pricetype meter, the 622AA-type or just Price type AA, are reported on by Hjalmarson (1967), Engel and DeZeeuw (1979) and Fulford (1990). In his article, Hjalmarson briefly presents the results of a test where a Price type AA meter was rotated at various vertical angles ranging from 0 to 90 degrees in a stream flowing at $0.4 \mathrm{ft} / \mathrm{s}(0.12 \mathrm{~m} / \mathrm{s})$. The results, shown graphically, indicate that for angles of 20 degrees or less, the meter tested deviated little from the theoretical cosine response.

Engel and DeZeeuw (1979) tilt the Price type AA meter they tested in a vertical plane. The meter was tilted to angles of $\pm 5,10$ and 15 degrees and towed at velocities ranging from $0.06 \mathrm{~m} / \mathrm{s}(0.20 \mathrm{ft} / \mathrm{s})$ to $3.0 \mathrm{~m} / \mathrm{s}(9.8 \mathrm{ft} / \mathrm{s})$. The data from the tests are presented in both tabular and graphical form. The tables are presented in three types. The first type of table gives values for the tow carriage velocity, $V_{o}$, and the revolutions per second, $N$, for all angles tested. The second type of table gives the $V_{o}$ and the meter efficiency, $N / V_{o}$, values for all of the angles tested. The third type of table gives the percent error of the meter response between no angle and turned angles. As with the tables, there are three types of graphs presented. The first type of graph has the $V_{o}$ plotted against the ratio of $N$ at various angles to $N$ at an angle of zero degrees. The second type of graph has $V_{o}$ plotted against the percent error of the meter's response at the tested angles. The third type of graph has the angle of alignment plotted against the percent error of the meter response for various velocities. Tables and graphs for all angles above and below the horizontal are given.

The work presented by Fulford (1990) covers testing where the Price type AA meter with two types of rotors is subjected to oblique flows by two methods. The first method used falls into the category of tilting the meter in the vertical plane and then towing the meter. The meters tested were rotated \pm 90 degrees in 10-degree increments. Two types of rotors were used in the testing: the standard open metal rotor and the solid polymer rotor. The results are presented graphically and show the characteristic response of the Price-type meter with the open metal rotor and the solid polymer rotor. The second method of testing, moving the meter vertically while towing the meter, will be discussed below. 
The earliest papers containing details of the second method of testing, in which the meter is moved vertically while it is being towed or placed in flowing water, are by Lippincott (1902) and Miller (1902). Both of these papers are discussions of a paper by Murphy (1902).

In his discussion, Lippincott (1902) gives little information on his tests. Lippincott's tests were conducted to determine how the discharge measured in a stream with a large Price meter would differ if the discharge was taken by moving the meter up and down in the vertical direction in each vertical (integration method). The only information given is that the meter determined discharge was between 1 percent more to 2.4 percent less when the meter was moved at a vertical rate of motion of $0.5 \mathrm{ft} / \mathrm{s}$ $(0.15 \mathrm{~m} / \mathrm{s})$ as compared to the discharge obtained with three velocity measurements at the top, middepth, and bottom of the stream. No actual comparisons of the meter velocity measurements are given.

In his discussion, Miller (1902) states that a large Price meter will overregister when rocked in a vertical direction when placed in a flowing stream. The very brief description of the testing indicates that a Price meter and a Haskell meter were suspended from a skiff in a stream with a current between 2 and $3 \mathrm{ft} / \mathrm{s}(0.6$ to $0.9 \mathrm{~m} / \mathrm{s})$ and rocked in the vertical direction a distance of 1 to $2 \mathrm{ft}(0.3$ to $0.6 \mathrm{~m})$ by rocking the skiff. No quantitative data are given.

Groat (1913 and 1916) discusses testing on two types of Price current meters, a large Price meter in 1913 and a small Price meter in 1916. The 1913 tests described by Groat (1913) have the meter moving in the vertical direction by rocking the boat being used to calibrate the meter. Without any information on the rate of vertical movement, Groat states that the large Price meter's rate of rotation increased by 15 percent over the rate of rotation with no vertical oscillations. There are no quantitative data given in this paper regarding meter testing.

In his second paper, Groat (1916) briefly describes the testing of a small Price current meter. These tests consisted, in part, of oscillating the meter in the vertical direction while it was being towed in a towing tank. The results are given in graphical form and show the deviation of the number of revolutions per foot of travel that the meter's rotor revolves when different vertical distances and rates of travel are imparted on the meter. Although cluttered, the figure does show that the small Price meter tested overregistered to varying degrees when various vertical oscillations were induced on the meter.

In addition to the work done by Scobey (1914) of tilting a small Price meter in the vertical direction while towing the meter, he also oscillated, by hand, a meter in the vertical direction in still water. The results of this test, which covers various rates of vertical motion, are given in both tabular and graphical form. These results show that the rotor of the small Price meter tested will rotate in the direction of normal rotation when the meter is oscillated in the vertical direction.

The paper by Leach (1931) is a discussion paper to the Yarnell and Nagler (1931) paper. In this discussion, Leach re-presents the data presented by Groat (1916) and Yarnell and Nagler (1931). Leach replots Groat's data in the graphical form used by Yarnell and Nagler to determine if the data from the two tests yield the same results. For relative vertical angles of flow less than 15 degrees, the data from both tests plot close together. At angles greater than 20 degrees, however, the data points from the two tests diverge. Leach also gives a better description of Groat's test setup than Groat presented.

As part of an extensive set of tests on current meters, Rohwer (1933) tested a pair of small Price meters in a tow tank to determine the effect on the ratings of the meters when a constant vertical motion of $0.25 \mathrm{ft} / \mathrm{s}(0.08 \mathrm{~m} / \mathrm{s})$ was applied. This test was conducted to simulate taking an integration discharge measurement. The vertical velocity was obtained by hand cranking the meter mount upwards while the tow vehicle traveled along the tank. Rohwer presents his data graphically with the data from five meters and ten calibration runs plotted on the same graph creating a cluttered plot. In describing the results, Rohwer points out that the two small Price meters tested consistently rotated slower, underregistered, when moving in a combined vertical and horizontal direction as compared to moving only in a horizontal direction.

The paper by Chappell (1939) covers testing conducted on a Price meter to determine what effects vertical motion had on the meter. The vertical motion induced on the meter was to simulate the vertical motion that may be found when making boat and cableway discharge measurements. The meter was tested at one horizontal velocity by raising and lowering the meter a distance of $2 \mathrm{ft}(0.6 \mathrm{~m})$ by hand crank at various vertical velocities. The vertical 
velocities of the test ranged from approximately. $0.3 \mathrm{ft} / \mathrm{s}(0.09 \mathrm{~m} / \mathrm{s})$ to $2.2 \mathrm{ft} / \mathrm{s}(0.66 \mathrm{~m} / \mathrm{s})$ with the horizontal velocity of approximately $2.4 \mathrm{ft} / \mathrm{s}(0.73 \mathrm{~m} / \mathrm{s})$. The results are given graphically with Chappell concluding that for vertical velocities less than a quarter of the horizontal velocity, the meter's error in registration was "slight." The graphs show that the Price meter tested underregistered for vertical velocities by less than a quarter of the horizontal velocity (approximately 15 degrees) and overregistered for vertical velocities larger than one quarter of the horizontal velocity.

Kallio's (1966a) tests, like Chappell's, were conducted to determine the effects of vertical motion on current meters. The vertical motion in these tests simulated the bobbing boat and cableway motions. Two of the three meters tested by Kallio were the vertical-axis type, a Price standard current meter and a vane-type current meter (see appendix for photo of vane-type current meter). For the testing, vertical motion was induced on the meters by manually raising and lowering the meters a distance of $\pm 0.1 \mathrm{ft}$ $(0.03 \mathrm{~m})$ to $\pm 2.0 \mathrm{ft}(0.6 \mathrm{~m})$ at vertical velocities of $0.4 \mathrm{ft} / \mathrm{s}(0.12 \mathrm{~m} / \mathrm{s})$ to $1.5 \mathrm{ft} / \mathrm{s}(0.46 \mathrm{~m} / \mathrm{s})$. The horizontal velocities were generated by towing the meters through a tow tank and suspending the meters into a river. Results are given in both tabular and graphical form. Results of the Price meter tests show that for vertical velocities less than 40 percent of the horizontal velocity (approximately 20 degrees), the Price meter will usually underregister the true horizontal velocity. At higher vertical velocities, the meter usually overregisters the horizontal velocity to varying degrees. Results of the tests on the vane-type meter show that this type of meter almost always overregisters the horizontal velocity when subjected to vertical motion.

Like Chappell (1939) and Kallio (1966a), Thibodeaux and Futrell (1987) report on vertical motion tests on current meters. The two meters tested and reported on by Thibodeaux and Futrell are the Price type AA current meter with a standard metal rotor and Price type OAA current meter with a solid polymer rotor. (The Price type OAA current meter is a Price type AA current meter with the cat whisker counting head replaced with an optic counting head.) The vertical distance traveled during the tests were $1,2,3$, and $4 \mathrm{ft}(0.3,0.6,0.9$, and $1.2 \mathrm{~m})$ with vertical velocities of $0.33,0.66,1.00$, and $1.2 \mathrm{ft} / \mathrm{s}(0.10,0.20,0.31$, and $0.37 \mathrm{~m} / \mathrm{s})$. All vertical motions were generated using a hydraulic cylinder for steady motions. The horizontal velocities were obtained by towing the meter in a tow tank at velocities ranging from 0 to $8 \mathrm{ft} / \mathrm{s}(0$ to $2.4 \mathrm{~m} / \mathrm{s})$. The results of these tests are given in graphical form and show that for the Price type AA meter, the results are similar to those obtained by Kallio. For vertical velocities below 40 percent of the horizontal velocity (approximately 20 degrees), the meter underregistered the horizontal velocity. For vertical to horizontal velocity ratios larger than 40 percent, the meter generally overregistered the horizontal velocity. The results of the OAA meter with polymer rotor tests show that this meter generally always underregistered the horizontal velocity. Only at very high vertical to horizontal velocity ratios did the OAA meter not underregister.

The paper by Engel (1990) covers mostly the theoretical side of the integration method of determining the average velocity in a vertical. A group of limited tests with a Price pygmy type meter in a laboratory flume is also presented. The results from the limited tests indicate that the vertical velocity a meter should travel during an integration velocity determination should not exceed the average horizontal velocity divided by 80 .

The second part of the paper by Fulford (1990) covers the testing of Price type AA meters by moving the meters in the vertical direction while being towed in a tow tank. The meters were moved either up or down by means of a hydraulically controlled cable reel assembly. The equivalent oblique angles obtained by this method were \pm 40 degrees. The results of these tests are presented graphically.

\section{Horizontal Oblique Flows}

The testing of vertical-axis meters subjected to oblique flows in the horizontal direction has not been conducted as extensively as testing in vertical oblique flows. The results of this type of testing are reported on by Rumpf (1914), Groat (1916), Yarnell and Nagler (1931), Nagler (1931), Rohwer(1933), Frazier (1941), Kulin and Compton (1975), and Engel and DeZeeuw (1978).

The horizontal oblique flow testing by Rumpf (1914) consisted of testing a small Price meter under two types of conditions. The first consisted of rotating the meter in the horizontal plane to the left and right in 10-degree increments for \pm 90 degrees and 
towing the meter in a tow tank. The results of these tests are presented graphically and are difficult to interpret because of the size of the graph. The second set of tests consisted of moving the meter back and forth in the lateral horizontal direction as the meter was being towed. Rumpf limits his discussion on the results of the second set of tests to saying that the meter overregistered the true horizontal velocity.

The horizontal oblique flow testing by Groat (1916) consisted of moving a small Price meter back and forth (oscillating) in the lateral horizontal direction as the meter was being towed in a tow tank. The purpose of these tests was to determine the effects of pulsating horizontal velocities on the meters being tested. The results of these tests are of little value because they are presented in a very cluttered graph.

As with the vertical oblique flow tests, Yarnell and Nagler (1931) conducted horizontal oblique flow tests on three types of vertical-axis meters, the small Price, the acoustic Price, and the USGS-improved Price current meters. These tests were conducted in a flowing flume at four velocities and seven horizontal angles of 10, 20, 25, 30, 35, 40, and 45 degrees. The results of these tests are presented in tabular and graphical form and show that for all angles tested, the meters tested overregistered from the theoretical cosine response of the meter.

In a discussion of the Yarnell and Nagler (1931) paper, Nagler (1931) covers results of tests on horizontal oblique flows conducted on a large Price meter and a small Price meter. As with the vertical oblique flow tests, these tests were conducted in a pipe flowing partially full. The results are presented in graphical form and are of little value because of the difficulty in interpreting the data.

Rohwer (1933) presents the results of testing of horizontal oblique flows on small Price meters. The tests presented in this paper consisted of rotating the meters being tested to angles of 5, 10, 15, 45, and 90 degrees in both the clockwise and counterclockwise directions. All of the results are shown graphically. In order to interpret the data in a meaningful manner, the reader will have to re-analyze the data to determine the deviation of the meter reading from the theoretical cosine response of the meter.

Tucked away in an article about a horizontalaxis meter, Frazier (1941) presents a table listing the percent errors of readings of a small Price meter subjected to oblique flows of 5, 10 and 15 degrees. Frazier presents the table to show the relative difference in the response of the horizontal-axis meter being described to the small Price meter. For the angles listed, 5, 10, and 15 degrees, the Price meter measured velocities with smaller errors to the ideal cosine response than the horizontal-axis meter described in the paper.

When dealing with oblique flows in the horizontal direction, Kulin and Compton (1975) rely on referencing Yarnell and Nagler (1931) to make the point of the reaction of the Price type AA and Price pygmy type current meters to horizontal oblique flows. In regard to lateral horizontal motions, the authors point out that a Price-type meter, in general, will overregister. The amount of overregistration will be totally dependent on the rate of lateral motion.

Engel and DeZeeuw (1978) report on tests conducted on a Price type AA current meter being towed at rotated angles of $10,15,20,30$, and 40 degrees to the left and right in the horizontal plane. The towing speeds ranged from $0.06 \mathrm{~m} / \mathrm{s}(0.20 \mathrm{ft} / \mathrm{s})$ to $3.0 \mathrm{~m} / \mathrm{s}$ $(9.8 \mathrm{ft} / \mathrm{s})$. The results of the tests are presented in both tabular and graphical form. The results that are given indicate that, for the meter tested, the meter will give the correct cosine response for angles less than 10 degrees to within 1 percent accuracy. For angles greater than 10 degrees, the meter's cosine response deteriorates until an error greater than 10 percent occurs at angles of 40 degrees.

\section{Proximity to Boundaries}

The testing of vertical-axis current meters to determine the effect of placing this type of meter in close proximity to boundaries, whether side, surface, or bottom boundaries, has been reported on by Murphy (1902 and 1904), Rumpf (1914), Scobey (1914), Rohwer (1933), USGS (1933a), Pierce (1941), Kulin (1977), and Engel (1983). With the exception of the work by Murphy (1902), Kulin (1977), and Engel (1983), the tests reported by the authors should be considered as flawed because of the methods used in the testing, the lack of a true reference velocity, or both.

Murphy (1902 and 1904) reports on a set of tests in which he compared the velocity measurements made with a small Price meter and those made with a 6-inch $(152 \mathrm{~mm})$ cubical float in the upper $1 \mathrm{ft}$ $(0.3 \mathrm{~m})$ of an irrigation canal. Murphy's conclusion is that when a small Price meter is positioned within 
$1 \mathrm{ft}(0.3 \mathrm{~m})$ of the surface of a stream the velocity obtained from the meter will be less than the velocity obtained by the float (meter underregisters). Murphy assumes that the float velocity is correct and that the small Price meter is always fully submerged.

The results of the tests reported on by Rumpf (1914) show the same results as those reported by Murphy (1902 and 1904) for a small Price meter placed within $1 \mathrm{ft}(0.3 \mathrm{~m})$ of the water surface.

Rumpf's test differ from Murphy's in that Rumpf was towing the meter he used in a tow tank while

Murphy's tests were conducted in a flowing channel. In addition, Rumpf also towed the small Price meter close to the side walls of the tow tank. The results of this test are of little value because towing a meter next to a stationary boundary is not the same as placing a meter next to a side boundary in a flowing stream. In a flowing stream, there will be a boundary development zone that is not present when both the water and the boundary are stationary as in a towing tank.

Scobey (1914) reports on two sets of tests in which a small Price meter was placed in close proximity to boundaries. The first set of tests has the meter being towed close to the water surface, next to side walls, and close to the channel's bottom. Most of the results are given in a cluttered graph with very little in the way of a description of the results. When towing the meter near the water surface, Scobey claims that the meter's recorded velocity is accurate when the meter is below $0.3 \mathrm{ft}(0.09 \mathrm{~m})$ from the surface. This does not match the results presented by Murphy (1902 and 1904) and Rumpf (1914). The results of towing the small Price meter next to the side walls and the bottom of the channel, like the side wall results of Rumpf (1914), should be taken with skepticism. The second set of tests reported by Scobey took place in a flowing flume. Without stating what he used as a reference velocity, Scobey contends that velocities obtained with a small Price meter $0.3 \mathrm{ft}(0.09 \mathrm{~m})$ below the stream surface and below are correct.

Rohwer (1933) reports on tests that are almost identical to the first set of tests reported by Scobey (1914). As with Scobey's results, the results presented by Rohwer should not be considered good because the data were obtained by towing the meters next to fixed boundaries in still water.

The data presented in the USGS (1933a) paper show the performance of a Price-type meter located
$0.5 \mathrm{ft}(0.15 \mathrm{~m})$ from the stream surface. Because there is no reference velocity, it is not known how much, or if, the meter is deviating from the true velocity.

As part of a study to develop discharge coefficients for shallow streams, Pierce (1941) obtained data on the performance of a Price type A meter in close proximity to the test flume's water surface and sides. All of the current meter's velocity data were compared to velocity data collected with a Pitot static tube. Results of obtaining velocity measurements in close proximity to the flume's surface are given graphically and show that the Price type A meter's velocity readings start deviating from the Pitot tube velocity readings at approximately $0.4 \mathrm{ft}(0.12 \mathrm{~m})$ below the water surface. The average velocity in the flume as determined by the Pitot tube was $1.0 \mathrm{ft} / \mathrm{s}$ $(0.3 \mathrm{~m} / \mathrm{s})$ with a depth of $1.25 \mathrm{ft}(0.38 \mathrm{~m})$. For the same flume conditions, velocities were obtained near the walls of the test flume with a Price type A meter and a Price pygmy meter. Using velocities obtained from a Pitot tube to compare the meter velocities, Pierce points out that when a vertical-axis meter is placed where the velocity is not uniformly distributed across the width of the meter rotor, as next to side boundaries, the meter will not give the correct velocity reading. The Price-type meter, with its rotor rotating in a counterclockwise direction, will overregister when placed close to the left side of the flume and underregister when placed close to the right side of the flume (left and right are determined by an observer looking downstream).

The work reported on by Kulin (1977) is a combination of theoretical and experimentally derived results. Kulin uses a theoretical basis to determine that a Price-type meter will either overregister or underregister when subjected to a nonuniform velocity field such as that found near the side of a flowing flume or stream. Added to the effects of the nonuniform velocity field are the effects caused by the physical presence of the wall. The effect caused by the proximity of the wall without the effects due to nonuniform velocity fields can be obtained by towing a meter next to a wall. Kulin concludes that the purely wall effect is eliminated if a Price type AA meter is placed with a clearance between the rotor and the wall of $1.5 \mathrm{in} .(38.1 \mathrm{~mm})$ and $1.0 \mathrm{in}$. $(25.4 \mathrm{~mm})$ for the Price type pygmy meter. Using a similar methodology, Kulin recommends that a Price type AA meter be placed no closer than 6 in. 
$(152 \mathrm{~mm})$ from the bottom of a stream or flume and a pygmy meter be placed no closer than 3 in. (76 mm).

The paper by Engel (1983) is much like Kulin's (1977) in that it is a combination of theoretical and experimental work dealing with the effects of a nonuniform velocity field on a Price type AA meter. Engel theoretically derives a set of equations that can be used to determine the error in a velocity reading from a Price meter if the skew of the velocity field, or velocity gradient, is known. The equations are checked using data from an experiment at one velocity with one velocity gradient. In closing, Engel acknowledges that the equations cannot be used for field work because determining the velocity gradient is very difficult to obtain at best.

\section{Turbulence}

The testing of vertical-axis current meters in turbulent flow conditions is very limited. Most of the literature covers situations where the output from one type of current meter is compared to the output of another. The papers covering some aspect of turbulent effects on vertical-axis meters include Groat (1913 and 1916), Yarnell and Nagler (1931), Schubauer and Mason (1937), Hjalmarson (1965), Kallio (1966b), Burtsev and Baryshnikova (1973), and Fulford (1990).

The testing covered by Groat (1913) in his first paper deals with the comparison of the velocity measurements between a large Price meter and an uncalibrated Pitot tube taken in the tail-race of power plant turbines. In the 100 direct velocity comparisons, Groat found that, on average, the Price meter registered velocities 6 percent higher than the Pitot tube. In boils the Price meter registered velocities up to 25 percent higher than the Pitot tube velocities. The turbulence at the location of velocity measurements is described by Groat to be very turbulent because the flow was highly agitated by the turbines. Passing the flow through stilling racks only straightened the flow and did not smooth it according to Groat. The velocity readings were taken at a distance of $30 \mathrm{ft}(9.2 \mathrm{~m})$ downstream of the stilling racks. No data from the comparative velocity readings are given.

In his second paper, Groat (1916) takes comparative velocity readings between a small Price meter and two Ott and two Haskell meters. This paper does present data but includes no reference velocity for comparison with the velocity readings. Groat assumes that the small Price meter overregisters by $6 / 7$ of the difference between its velocity and the velocity determined by an Ott or Haskell meter. The Ott and Haskell meters are assumed to underregister by $1 / 7$ of the velocity difference.

Yarnell and Nagler (1931) tried to create turbulence in a flume by placing paddles in the flow. There are two major problems with this method of creating turbulence. The first is that the paddles create largely oblique flows instead of a purely turbulent flow. The second problem with this test is that there was no reference for the correct velocity. Yarnell and Nagler assumed the average velocity in the flume, discharge divided by cross-sectional area, to be the reference velocity for comparison with the meter's velocity reading. The meters used by Yarnell and Nagler were a small Price meter, acoustic Price meter, and the USGS-improved Price meter.

As part of an investigation on the effects of changing fluid density on the performance of the small Price current meter, Schubauer and Mason (1937) calibrated two small Price meters in a wind tunnel under two turbulence intensities, 0.85 percent and 2.7 percent. (Turbulence intensity, in percent, is equal to 100 times the root-mean-square of the turbulence velocity fluctuations divided by the mean velocity of the measured fluid.) The higher turbulence value was generated by placing a screen rack $7.6 \mathrm{ft}$ $(2.32 \mathrm{~m})$ upstream of the meters. The change in the turbulence intensity resulted in no change in the meters response. Extreme care should be taken in interpreting the results presented in this paper because the change in turbulence intensity is quite small.

Hjalmarson (1965) theoretically derives a set of equations to predict the output from a Price-type meter when subjected to turbulent flows. There are no data given to prove the equations.

Kallio (1966b) compares the discharge of a river obtained using a Price-type meter to the discharge obtained from rated turbines located just upstream of the measuring section. Kallio describes the conditions of the river as turbulent. The discharge measurements were conducted in order to check the turbine ratings. Kallio states that the discharge obtained by the cable-suspended Price meter was consistently within 2.4 percent of the discharge as determined by the turbines. 
Burtsev and Baryshnikova (1973) make a blanket statement that vertical-axis current meters will overregister by as much as 40 percent in highly turbulent flows. The authors base this claim on field and experimental work. The conditions in which the field and experimental work were conducted are not given. Also, the meter type being used for the tests is not given.

Fulford (1990) presents the analysis of the data collected from a large number of paired discharge measurements using Price type AA current meters equipped with standard metal rotors and solid polymer rotors. Without being able to state which type of rotor gives the correct discharge measurement, Fulford used the standard metal-rotor-equipped meter as the reference meter. The comparison of the discharge measurements taken in streams described as having high turbulence levels indicated that the polymer-rotor-equipped Price type AA meter, on average, yielded mean velocities 3.1 percent lower than those yielded by a standard metal-rotorequipped Price type AA meter.

\section{Pulsation of Flow}

In determining the behavior of vertical-axis current meters to pulsations in flow, all experiments described in the literature oscillate the meter being tested parallel to the flow. This type of work is described by Groat (1916), Yarnell and Nagler (1931), Horton (1931), Kolupaila (1958), and Bean (1971).

As part of a set of tests on a small Price meter, Groat (1916) oscillated the meter at various rates of oscillation and travel distances while being towed in a tow tank. All of the results are given graphically in a very cluttered graph and are therefore of little value. Additionally, Groat describes the meter's induced oscillatory movement as "including a vertical component, the effects of which are unknown."

Yarnell and Nagler (1931) report on a set of tests where a small Price meter and a USGSimproved Price meter were subjected to oscillations parallel to the test flume's flow. The oscillations were conducted with a constant stroke distance (amplitude) of $2 \mathrm{ft}(0.6 \mathrm{~m})$ and induced speeds up to three times the average flume velocities. The results, which are shown graphically, are briefly discussed by the authors and indicate that if the maximum additional longitudinal speed of the meter is less than 50 percent of the average stream velocity, the meter's response will not deviate from a steady stream response. The indicated average flume velocities used in the testing are cited by the Yarnell and Nagler as being 2,3 , and $5 \mathrm{ft} / \mathrm{s}(0.6,0.9$, and $1.5 \mathrm{~m} / \mathrm{s})$.

In his discussion of the Yarnell and Nagler (1931) paper, Horton (1931) derives equations and correction factors for the Price-type meter's response to pulsations in flow. Horton describes the equations as accurate when the induced added velocity is equal to or greater than the average stream velocity.

Kolupaila (1958) references other reports to draw conclusions as to the effect of pulsating flow on vertical-axis current meters. The conclusions drawn by Kolupaila are of value only for cases where there is reversal of flow.

The paper by Bean (1971) mainly covers the theory of the design and workings of mechanical current meters, both vertical- and horizontal-axis. As a blanket statement covering the response of both vertical- and horizontal-axis meters to velocity fluctuations, the author states that, if the fluctuations are slow enough for the meter to follow the fluctuations, the meter will correctly register the average velocity. On the other hand, Bean states that if the velocity fluctuations are too fast for the meter to respond, the meter will overregister because of what the author states as the square-law relation between hydrodynamic torque and velocity.

\section{Temperature}

The effects of varying water temperature on the rating of a Price type AA current meter is reported on by Robson (1954) and Frazier (1954). Both of these papers report on the same tests. The meter used in the test was calibrated in water temperatures of $36.9^{\circ} \mathrm{F}, 44.3^{\circ} \mathrm{F}, 55.6^{\circ} \mathrm{F}$, and $62.5^{\circ} \mathrm{F}\left(2.7^{\circ} \mathrm{C}, 6.8^{\circ} \mathrm{C}\right.$, $13.1^{\circ} \mathrm{C}$, and $16.9^{\circ} \mathrm{C}$ ) in a rating facility in Canada. The ratings at the various temperatures are described by Frazier as being "virtually identical and indicating no effects due to temperature change."

\section{Repeatability}

There were three articles located that covered the evaluation of vertical-axis current meters at repeating their calibrations when calibrated in tow tanks. Rohwer (1931 and 1933) and Dickman (1951) discuss this type of work. 
In a discussion of the paper by Yarnell and Nagler (1931), Rohwer (1931) presents a table with the derived calibration equations for a small Price meter that was calibrated 14 times between 1919 and 1929. With the exception of a low velocity calibration equation, all derived calibration equations fell within 1.5 percent of the average equation. The lowvelocity calibration equation, which is for velocities less than $2.4 \mathrm{ft} / \mathrm{s}(0.73 \mathrm{~m} / \mathrm{s})$, falls within 6 percent of the average.

In his second paper, Rohwer (1933) conducted tests in which a pair of small Price meters were calibrated five times each to determine if the meters would respond differently in individual calibrations. Results from the repeated calibrations of the meters show that for the two meters tested, the derived calibration equations for each calibration run did not vary more than \pm 0.5 percent from the mean of the equations.

Dickman (1951) reports on an extended study where one Price type A current meter was calibrated yearly over a 10 -year period. The results presented indicated that the meter's calibration varied by no more than 3 percent at $0.56 \mathrm{ft} / \mathrm{s}(0.171 \mathrm{~m} / \mathrm{s}), 1$ percent at $2.2 \mathrm{ft} / \mathrm{s}(0.67 \mathrm{~m} / \mathrm{s})$, and 1 percent at $10 \mathrm{ft} / \mathrm{s}$ $(3 \mathrm{~m} / \mathrm{s})$.

\section{Miscellaneous Testing}

In addition to the testing already discussed, Rohwer (1933) conducted a group of miscellaneous tests on small Price meters to determine the change in a meter's response when subjected to rotor damage, pivot miss-adjustment, and various mounting changes. To determine the effects of damage to the meter's rotor, Rohwer tested rotors with damaged cups, filling one cup with $5.73 \mathrm{~g}(0.20 \mathrm{oz})$ of a lead and wax mixture, greasing the rotor, and roughening the surface of the cups with shellac and sand. Results as described by Rohwer indicated that for the damaged rotor with one cup crushed approximately 0.25 in. $(6.35 \mathrm{~mm})$, there was a "significant" effect on the rating. The coating of the rotor cups with sand had a "slight" effect on the rating, while the greasing of the rotor cups and the weighting of a cup had "little, if any," effect on the rating.

To test for the effects of miss-adjustment of the meter's lower pivot on a meter's calibration, Rohwer calibrated two small Price meters at various pivot settings. The lower pivots on the meters were unscrewed in quarter turns for each calibration until a maximum of 1.75 turns. The actual distance between the bearing and the pivot at each of the settings is not given. The results, which are shown graphically, show that, for the two meters tested, there was very little effect on the meter's calibrations when the meter's lower pivot was out of adjustment.

The tests dealing with various methods of mounting small Price meters consisted of testing the effects of guy wires, cable suspensions, and varioussized wading rods. Of the three sets of tests, change in the meter calibrations was found in two of the tests - the guy wire tests and the wading rod tests. When a meter with a guy wire attached to the meter suspension was calibrated, the meter was only slightly affected. The change in the meter's calibration was approximately 1 percent. The effect of the change in wading rods was more pronounced. On average, an increase of the wading rod's diameter from 0.5 in. $(12.7 \mathrm{~mm})$ to 1 in. $(25.4 \mathrm{~mm})$ changed the meter's calibration by -1.5 percent, and changing the rod's diameter from 0.5 in. $(12.7 \mathrm{~mm})$ to 2 in. $(50.8 \mathrm{~mm})$ changed the meter's calibration by -3.5 percent.

\section{Horizontal-Axis Meters}

Horizontal-axis meters, unlike the vertical-axis meter, comprise a wide range of meters. These meters include, but are not limited to, the Ott, Hoff, Haskell, Amsler, and Neyrpic "Dumas" meters.

\section{Obllque Flows}

Horizontal-axis current meters respond to oblique flows in the vertical and horizontal planes in the same manner because of the meter's symmetry about it's axis. For this reason there are no subsections needed in this oblique flows section for vertical and horizontal oblique flows.

The testing of horizontal-axis meters in oblique flows has been carried out for as long as the testing on vertical-axis meters. Much of the early testing on horizontal-axis meters has been carried out in conjunction with testing on vertical-axis meters. Most of the later work, 1960's and later, covers the testing of only horizontal-axis meters. The papers and reports reviewed in this section include Lippincott (1902), Miller (1902), Groat (1913 and 1916), Yarnell and Nagler (1931), Leach (1931), Ott (1931), 
Nagler (1931), Rohwer (1931 and 1933), Frazier (1941), Addison (1949), Kolupaila (1949 and 1958), Leonard (1965), Fischer (1966), Johnson (1966), Kallio (1966a), Alming (1967), Jepson (1967), Kulin and Compton (1975), and Smith (1978).

As part of a discussion of a paper by Murphy (1902), Lippincott (1902) very briefly describes his work with a Haskell meter. The author states that a Haskell meter can be moved vertically in a stream when taking a discharge measurement (integration method) without the vertical movement affecting the performance of the meter. No test data pertaining to the Haskell meter's response to oblique flows are given in this paper.

Miller (1902), in a discussion to Murphy's (1902) paper, states that a Haskell meter will underregister when rocked in a vertical direction when placed in a flowing stream. The very brief description of the testing indicates that a Haskell meter and a Price meter were suspended from a skiff in a stream with a current flowing between 2 and $3 \mathrm{ft} / \mathrm{s}(0.6$ and $0.9 \mathrm{~m} / \mathrm{s})$ and rocked in a vertical direction for a distance of 1 to $2 \mathrm{ft}(0.3$ to $0.6 \mathrm{~m})$ by rocking the skiff. No quantitative data are given.

Groat (1913 and 1916) discusses testing on a Haskell meter in 1913 and two Haskell and two Ott meters in 1916 . The 1913 tests described by Groat (1913) have a Haskell meter moving in the vertical direction by rocking the boat used to calibrate the meter. Without any information on the rate of vertical movement, the author states that the Haskell meter's rate of rotation decreased by 2.5 percent over the rate of rotation with no vertical oscillations. There are no quantitative data given in this paper regarding meter testing.

In his second paper, Groat (1916) briefly describes the testing of two Haskell and two Ott meters. These tests consisted, in part, of oscillating the meters in vertical and horizontal directions perpendicular to the direction in which the meters were being towed in a tow tank. The results are given in graphical form and show the deviation of the number of revolutions per foot of travel that the meter's rotor revolves for each of the different oscillation magnitudes and rates. The data presented in the graphs show that all four meters tested underregister for oblique flows caused by oscillating the meter perpendicular to the flow.

As part of an extensive set of tests, Yarnell and Nagler (1931) conducted oblique flow tests on several horizontal-axis current meters. The meters tested were a three-bladed Hoff, a four-bladed Hoff, a small Ott, a medium Ott, a two-bladed Mensing-Ott, a three-bladed Mensing-Ott, a high-pitch Haskell, and a low-pitch Haskell. The tests were conducted in a flowing flume at velocities of approximately 2,3 , and $5 \mathrm{ft} / \mathrm{s}(0.6,0.9$, and $1.5 \mathrm{~m} / \mathrm{s})$ at angles of 10,20 , $25,30,35,40$, and 45 degrees. Results are shown graphically and in tabular form. The graphical data shows the averaged response of each meter tested for all velocities used in the testing. The data presented in tabular form are for the $5 \mathrm{ft} / \mathrm{s}(1.5 \mathrm{~m} / \mathrm{s})$ test only. All of the meters tested underregistered in relation to the ideal cosine response.

Accompanying Yarnell and Nagler's paper was an extensive collection of discussion letters by other writers. As stated previously, most of these discussions are comments about the work done by Yarnell and Nagler with a few presenting results of their own experiments or re-analyzing other people's data. Leach (1931) is an example of someone re-analyzing data. In the area of oblique flows on horizontal-axis meters, Leach replots the Haskell meter data collected by Groat (1916) and Yarnell and Nagler (1931). As with the presentation of the data by the original authors, Leach's presentation shows that the Haskell meter underregisters oblique flows in relation to the theoretical cosine response. The data from both data sets plot together and show a common trend.

In a discussion of the Yarnell and Nagler (1931) paper, Ott (1931) presents an equation that he has derived to determine the percent error in an Ott meter's response to oblique flows. The results of the tests used to derive the equation indicate that for an angle of 15 degrees and a velocity of $6.4 \mathrm{ft} / \mathrm{s}$ $(1.95 \mathrm{~m} / \mathrm{s})$ the meter will overregister by 1 percent. At a velocity of $2.1 \mathrm{ft} / \mathrm{s}(0.64 \mathrm{~m} / \mathrm{s})$ the meter will respond correctly, and for a velocity of $1.3 \mathrm{ft} / \mathrm{s}$ $(0.40 \mathrm{~m} / \mathrm{s})$ the meter will underregister by 1 percent.

The discussion of the Yarnell and Nagler (1931) paper by Nagler (1931) includes the analysis of tests on Ott and Haskell meters conducted by Nagler in a 42-inch-diameter $(1.1 \mathrm{~m})$ pipe. The tests consisted of rotating each meter 360 degrees in a flow of approximately $4 \mathrm{ft} / \mathrm{s}(1.2 \mathrm{~m} / \mathrm{s})$ in 5-degree increments. The limited results are presented graphically and show that both the Ott and Haskell meters tested underregistered the ideal cosine response of the flow. 
Rohwer (1931 and 1933) in his two papers describe three sets of tests. The first of his papers (Rohwer 1931) is his discussion of the Yarnell and Nagler (1931) paper in which Rohwer very briefly describes the results of taking a discharge measurement by tilting a small Ott meter 10 degrees into the flow. The discharge obtained using the tilted meter was compared to the discharge obtained by a weir and was found to be off by -0.24 percent to +3.56 percent, depending on the method used for the meter discharge determination.

In his second paper, Rohwer (1933) presents the results of two sets of tests where horizontal-axis meters are subjected to oblique flows. The first of these tests were conducted on three Ott meters to determine the effect of moving the meters in the vertical direction while being towed in a tow tank to simulate an integration velocity measurement. The meters were moved vertically at approximately $3 \mathrm{ft} / \mathrm{s}$ $(0.9 \mathrm{~m} / \mathrm{s})$ at various towing speeds. The graphically presented results show very little, if any, deviation from the curves obtained with no vertical movement.

The second set of tests described by Rohwer (1933) covers the testing of two Ott, one Fteley and Stearns, one Haskell, and one two- and one threebladed Hoff meter to simulated oblique flows. The meters were towed at angles to the towing direction of $5,10,15,30$, and 45 degrees to the left and right at towing speeds ranging up to $8 \mathrm{ft} / \mathrm{s}(2.4 \mathrm{~m} / \mathrm{s})$. The graphically presented final results show that with the exception of the three-bladed Hoff meter, all of the horizontal-axis meters tested underregistered in relation to the ideal cosine response. The three-bladed Hoff meter is shown to overregister.

Frazier (1941) describes a Gettner horizontalaxis meter and the results of a set of oblique angle tests on the meter. The meter, which was not a commercially available meter, was tested at angles of 5,10 , and 15 degrees to the direction at which it was being towed. The results show that this meter gave a velocity that deviated from the ideal cosine velocity by 1.5 percent at 5 degrees, by 5.5 percent at 10 degrees, and by 11 percent at 15 degrees. Frazier did not give the velocities of the test nor did he say whether the meter underregistered or overregistered.

Addison (1949) does not present any test results, only general statements on the response of horizontal-axis meters to oblique flows. The most noteworthy statement is that a "spoked" rotor registers less of an error in cosine response than does a "screw" rotor. The statement by Addison reflects the meters in use before the 1950's.

Kolupaila (1949) presents the results of oblique flow tests on the Ott component rotor (later designated as the "A" component rotor) for the Ott horizontal-axis meters. For the one set of data presented, the Ott meter with the component rotor was within \pm 1.4 percent of the ideal cosine response for angles of 40 degrees or less and within \pm 2.7 percent for angles of 70 degrees or less. The velocities at which the data were collected were not given.

In another paper, Kolupaila (1958) details the important aspects of the Ott component rotor. Kolupaila states that, when dealing with oblique flows, the pitch of the rotor blades is the most important factor under consideration, with the area of the projection of the blades on a plane normal to the direction of the flow also being important. As proof of the importance of the rotor's blade pitch, a graph showing the response of rotors with varying blade angles to oblique flows is given.

Leonard (1965), in a discussion of a paper by Dodge (1965), very briefly describes problems encountered when tests were conducted on turbine intakes using the Neyrpic horizontal-axis meters. The conclusion reached by the researchers was that the Neyrpic meters used underregistered the axial velocity when subjected to oblique flows. No quantitative data are presented.

As part of a set of tests to determine the effects of oscillating meters in the vertical and axial directions, Fischer (1966) conducted one set of tests in which a current meter was towed at various oblique angles ranging form 0 to 30 degrees. The meter tested was an Ott meter with an "R" component rotor. The results of the tests are shown graphically and indicate that at angles of 20 and 30 degrees, the meter tested overregistered by 3.2 and 5.7 percent, respectively.

Johnson (1966) presents the results of a large set of tests conducted on a group of Neyrpic "Dumas" current meters. One of the tests involved rating several of the Neyrpic meters at oblique angles of $10,20,30$, and 40 degrees. The graphically presented results show that at an angle of 10 degrees, all of the meters overregistered the true cosine component of the flow for meter revolutions per second, $N$, less than 4 revolutions per second (rev/s) and generally underregistered by less than 1 percent for $N$ greater than $6 \mathrm{rev} / \mathrm{s}$. At 20 degrees, all of the meters 
calibrated underregistered by 1 to 2 percent for $N$ greater than 4 rev/s. At 30 degrees, all meters underregistered by 2 to 3 percent for $N$ greater than $8 \mathrm{rev} / \mathrm{s}$. At 40 degrees, the maximum angle tested, both meters calibrated at this angle started underregistering at $N$ equal to $2 \mathrm{rev} / \mathrm{s}$ and reached a maximum underregistration of 6 to 7 percent at $N$ equal to 10 $\mathrm{rev} / \mathrm{s}$. Each of the individual calibration equations derived during the oblique flow tests are also given in tabular form in the report. A set of additional tests were conducted using an Ott current meter with an "A" component rotor calibrated at an angle of 40 degrees. The results presented show the meter underregistering by up to 3 percent at $N$ equal to $15 \mathrm{rev} / \mathrm{s}$.

In addition to testing vertical-axis meters on the effects of vertical motion, Kallio (1966a) tested an Ott meter with an "A" component rotor and a standard rotor. Most of the testing of the Ott meter was with the meter cable suspended. The meter was allowed to rotate in the vertical direction making the data collected with the meter cable suspended of little use for determining the meter's reaction to oblique flows. Kallio did, however, conduct a limited test on a rod-mounted meter equipped with an "A" rotor. The graphically presented results indicate that, for vertical velocities greater than the horizontal velocity (oblique flow angles greater than 45 degrees), the Ott meter tested overregistered. A maximum registration error of approximately 40 percent occurred at a tow speed of $0.5 \mathrm{ft} / \mathrm{s}(0.15 \mathrm{~m} / \mathrm{s})$ with an equivalent oblique flow angle of 65 degrees.

Alming (1967) reports on the results of tests conducted on two Amsler type 505 current meters subjected to oblique flows. The flow angles tested ranged up to maximum values of \pm 30 degrees.

Alming reports that the meters underregister the true cosine velocity for all angles tested. The curve fit through the data points indicates that the meter reading is equal to the horizontal velocity multiplied by cosine $1.33 \alpha$, where $\alpha$ is equal to the oblique flow angle.

As part of a set of experiments dealing with the effects of pulsations, both axial and lateral, on the performance of current meters, Jepson (1967) reports on the effects of oblique flows caused by lateral movement of four Ott rotor types. Each rotor was tested on the same meter body to eliminate any possible errors caused by using different meter bodies. The graphically presented results showed that when three of the four rotor types were oscillated in the lateral direction the meters underregistered the correct flow velocity. The amount of the underregistration is directly proportional to the frequency of the oscillations. The fourth rotor showed little effect of the lateral oscillations, less than 1 percent overregistration at the maximum oscillation rate.

Kulin and Compton (1975) rely on referencing Johnson (1966) to warn the reader that not all meter rotors are created equal when oblique flows are concerned. The authors point out that even component rotors do not necessarily guarantee a true cosine response to oblique flows.

Smith (1978) describes the characteristics of a current-meter system that consists of a cluster of three small banded horizontal-axis meters, each oriented to face a major flow direction (X, Y, and Z directions). (A banded meter is a ducted meter with the duct length shorter than the meter's rotor.) The author explains that with the oblique flow characteristics of each meter in the cluster known, an iterative technique can be used to determine the true threedimensional flow at the meters location. Smith presents a pair of graphs showing a correction factor for angles of attack in the vertical and horizontal planes for a meter cluster system.

\section{Proximity to Boundaries}

The testing of horizontal-axis meters to determine the effect of placing this type of meter in close proximity to boundaries has been reported on by Murphy (1902), Rumpf (1914), Rohwer (1933), Pierce (1941), Dodge (1965), Johnson (1966), and Staubli and Hegland (1982). Proximity to boundaries includes placing the meter close to side boundaries, surface boundaries, bottom boundaries, and mounting assemblies. As with the tests conducted on vertical-axis meters next to boundaries, some of the tests reported in the literature are flawed because of the methods used in the testing, because of the lack of a true reference velocity, or both. The tests that do have reference velocities or pertain only to mounting assemblies are Murphy (1902), Pierce (1941), Dodge (1965), Johnson (1966), and Staubli and Hegland (1982).

Murphy (1902) reports on a set of tests in which he compares the velocity measurements of a Haskell meter to that of a 6-in. $(152 \mathrm{~mm})$ cubical float in the upper $1 \mathrm{ft}(0.3 \mathrm{~m})$ of an irrigation canal. Murphy concludes that the Haskell meter measures, within 
reason, the same velocity as the float when the meter is placed in the upper $1 \mathrm{ft}(0.3 \mathrm{~m})$ of the stream.

Rumpf (1914) reports on a set of tests where a Fteley and Stearns meter is towed next to the towtank surface, sides, and bottom. Without presenting any quantitative data, Rumpf states that the meter tested underregistered when towed closer than $1 \mathrm{ft}$ $(0.3 \mathrm{~m})$ to the tank surface and overregistered when towed closer than 6 in. $(152 \mathrm{~mm})$ to the tank bottom or the tank walls. As stated in the proximity to boundaries section in the report on the tests of the vertical-axis meters, the results with the meter being towed are of little value because towing a meter next to a stationary boundary is not the same as placing a meter next to a boundary in a flowing stream. In a flowing stream, there will be a boundary development zone that does not exist when both the water and the boundary are stationary as in a tow tank.

Rohwer (1933), like Rumpf, reports on a set of proximity tests conducted in a tow tank where the meters were towed next to fixed boundaries. The meters tested were an Ott meter and a Hoff meter. As with Rumpf's results, Rohwer's results should not be considered good results because the data were obtained by towing the meters next to fixed boundaries in still water.

The data presented by Pierce (1941) cover work done using an Ott $\mathrm{Xb}$ current meter. The results presented by Pierce for proximity to side wall tests are in graphical form. These graphs show that for measurements within 4 in. $(102 \mathrm{~mm})$ of a side wall, the meter tested registered a velocity slightly higher ( 2 to 3 percent) than the velocity obtained by a Pitot static tube.

The test described by Dodge (1965) is different from most previous tests. Dodge's test was conducted to determine how far in front of the test frame a Neyrpic "Dumas" meter had to be mounted so that the frame did not influence the meter's performance. The results showed that the meters had to be mounted 44 in. $(1.11 \mathrm{~m})$ in front of the test frame used in his study in order to be out of the breaking influence of the frame.

As part of the calibration procedure of the Neyrpic current meters used by Dodge, the meters were tested for the effects of the meter's mounting method and reported on by Johnson (1966). The results arrived at and reported by Johnson were that the Neyrpic meters should be mounted at least 34 in. $(0.86 \mathrm{~m})$ in front of the meter mounting frame.
Additional tests were conducted on a Neyrpic meter by towing the meter in close proximity to the bottom of the tow tank. The data obtained from this set of tests are flawed because of the missing boundary layer in these tests that is found in a flowing flume. An Ott meter with an "A" component rotor was also towed next to the tow tank's wall to determine the meter's response next to a boundary. This test is also flawed for the same reasons stated above.

Staubli and Hegland (1982) present a derivation of a theoretical equation for the determination of the effects of a meter's mount on its calibration equation. The major effect looked at during the tests was the distance the meter mount extended below the meter itself. Using an Ott meter with an " $\mathrm{R}$ " component rotor, the authors ran a set of tests at one velocity, $1.5 \mathrm{~m} / \mathrm{s}(4.9 \mathrm{ft} / \mathrm{s})$, to determine some of the coefficients in their equations. Results of the testing and equation verification lead to the suggestion of mounting the meter at least $0.3 \mathrm{~m}(0.98 \mathrm{ft})$ from the bottom of the mounting rod. Because the towing tank dimensions affect the meters response, the authors pointed out that if the towing tank's width was at least $3 \mathrm{~m}(9.8 \mathrm{ft})$ wide an error of less than 0.1 percent would occur if the meter mount extended less than the suggested $0.3 \mathrm{~m}(0.98 \mathrm{ft})$ below the meter.

\section{Turbulence}

The testing of horizontal-axis current meters in turbulent flow conditions is very limited. Most of the literature covers situations where the output from one type of current meter is compared with the output from another. The papers covering some aspect of turbulent effects on horizontal-axis meters include Groat (1913 and 1916), Yarnell and Nagler (1931), Leach (1931), Buchanan (1963), Szigyarto (1965), Fischer (1966), and Kallio (1966b).

The testing covered by Groat (1913) in his first paper deals with the comparison of velocity measurements between a Haskell current meter and an uncalibrated Pitot tube taken in the tail-race of power plant turbines. In the 120 direct-velocity comparisons, Groat found that, on average, the Haskell meter registered velocities 1 percent lower than the Pitot tube. In boils the Haskell meter registered up to 5 percent lower than the Pitot tube. The turbulence at the location of the velocity measurements is described by Groat as being "very turbulent" because the flow was highly agitated by the turbines. Passing 
the flow through stilling racks only straightened the flow and did not smooth it according to Groat. The velocity readings were taken at a distance of $30 \mathrm{ft}$ $(9.2 \mathrm{~m})$ downstream of the stilling racks. A table showing the individual meter and Pitot tube readings is presented by Groat.

In his second paper, Groat (1916) takes comparative velocity readings between four horizontalaxis meters and a small Price meter. The four horizontal-axis meters were two Ott meters and two Haskell meters. This paper does have data presented, but there is no reference velocity with which to compare the meter velocity readings. Groat assumes that the four horizontal-axis meters underregister by $1 / 7$ of the difference between this type of meter's velocity readings and the Price meter's velocity readings. The Price meter is assumed to overregister by $6 / 7$ of the velocity difference.

Yarnell and Nagler (1931) tried to create turbulence in a flume by placing paddles in the flow. There are two major problems with this method of creating turbulence. The first is that the paddles create mostly oblique flows instead of purely turbulent flow. The second problem with this test is that there was no reference for the correct velocity. Yarnell and Nagler assumed the average velocity in the flume, discharge divided by cross-sectional area, to be the reference velocity with which to compare the meter's velocity reading. The horizontal-axis meters used by Yarnell and Nagler were a threebladed Hoff, a four-bladed Hoff, a small Ott, a medium Ott, a two-bladed Mensing-Ott, a threebladed Mensing-Ott, a high-pitch Haskell, and a lowpitch Haskell meter.

In a discussion of the Yarnell and Nagler paper, Leach (1931) gives his opinion on ways to take discharge measurements in turbulent streams. The suggestions are (1) use two measuring sections and use the average of the obtained discharges to be the correct discharge; (2) use baffles to eliminate the turbulence; (3) measure the intensity of the turbulence and use the known characteristics of the current meter to turbulent flow to correct the discharge measurement; (4) incline (rotate) the meter in the flow until the maximum velocity is obtained and adjust the reading according to the meter's angle; (5) use two current meters, one which overregisters and one which underregisters in turbulent flow and use the known characteristics of the two meters to determine the correct velocity; and (6) use a cable- suspended meter so that the meter will automatically point in the direction of highest velocity. Of the six suggestions given by Leach, item 3 appears to be the only one of much practical use.

The paper by Buchanan (1963) is an edited translation of a report of the International Current Meter Group, Report no. 13, written by L. Castex and $\mathrm{E}$. Carounas. The original report entitled "Influence of turbulence on current meter flow measurements in a free-flowing channel" briefly covered tests conducted on two Ott-meter rotors when the Ott meters are placed downstream of a grill. Without stating which rotor was used in determining the discharge, the report shows errors in the calculated discharge as high as 13 percent above the reference discharge when the meters are placed $1 \mathrm{ft}(0.3 \mathrm{~m})$ downstream of the grill. The error in the calculated discharge reduces to less than 2 percent when the meters were moved $39 \mathrm{ft}(12 \mathrm{~m})$ downstream of the grill. The reference discharge measurement was obtained from a weir at the discharge end of the test flume. Because there are no reference-point velocities, the limited data presented are of little or no value for determining the meter's response to turbulent flow conditions.

The report by Szigyarto (1965) mostly covers the theoretical response of a horizontal-axis current meter to turbulent flow. Szigyarto concludes that horizontal-axis current meters will register the correct mean velocity provided that there is a small degree of turbulence, the velocity fluctuations within the meter's field of flow (area of the meters rotor) are uniform, the turbulence conditions are uniform, and the mean velocity distribution across the rotor is uniform. As part of his conclusions, Szigyarto also states that a horizontal-axis meter should not be used in a cable suspension if "reliable measurements are required." Additional work on determining the standard deviation of measurements of fixed duration in turbulent flow was conducted. Results of this additional work show that for measurements taken with a Lange-type current meter just downstream of a sluice gate using a 40-second time interval, a standard deviation of the measurements of approximately 7 percent of the measured mean velocity was determined.

Fischer (1966) reported on a set of tests in which several rotors for an Ott current meter were tested to determine the rotors response to simulated turbulence in a tow tank. The rotors tested were a 
spoked Ott rotor; a slant-edged Ott rotor; an Ott "A" component rotor; an Ott " $\mathrm{F}$ " component rotor; an Ott "R" component rotor; a special aluminum Ott "A" component rotor; an Amsler rotor; and two custom slant-edged rotors, one heavy (made of lead) and one relatively light. The turbulence was simulated by pulsating (oscillating) the meters being tested in several directions, including axially, vertically, and axially with the meter turned at various oblique angles to the towing direction. Although this is a set of tests dealing with pulsating flow, Fischer uses the results to point out that the " $R$ " component and special rotors are best suited for measuring turbulent flows.

In his report, Kallio (1966b) reviewed a set of discharge measurements taken in a turbulent river downstream from a dam power station using a cablesuspended Ott meter with an "A" component rotor. After obtaining a discharge that was 3 percent higher than the discharge obtained from the dam's rated turbines, Kallio conducted tests to determine the reason for the overregistration of the current meter. Results of the testing indicated that a component rotor should not be used in a cable-suspension arrangement.

\section{Pulsation of Flow}

In determining the behavior of horizontal-axis current meters to pulsations in flow, all experiments described in the literature oscillate the meter being tested parallel to the flow. This type of work is described by Groat (1913 and 1916), Yarnell and Nagler (1931), Kolupaila (1958), Fischer (1966), Jepson (1967), and Bean (1971).

Groat (1913) covers testing conducted on a Haskell current meter. The meter tested was oscillated a distance of $5.75 \mathrm{in}$. $(146 \mathrm{~mm})$ parallel to the towing direction with the rate of the oscillations not given. The results of the tests are presented graphically in a plot with the data from 8 other tests. No clear trend can be observed from the cluttered plot.

As part of a set of tests on two Haskell and two Ott meters, Groat (1916) oscillated the meters at various rates and various travel distances while being towed in a towing tank. All of the results are presented graphically in a very cluttered graph. Because of the difficulty in interpreting the cluttered graphs, it is difficult to verify Groat's statement that longitudinal oscillations, pulsations of flow, have very little effect on the performance of the tested current meters. An additional note: Groat describes the meter's induced oscillatory movement as including a vertical component as the meters swung back and forth, the effects of which were unknown to Groat.

Yarnell and Nagler (1931) report on a set of tests where a three-bladed Hoff, a four bladed-Hoff, a small Ott, a medium Ott, a two-bladed Mensing-Ott, a three-bladed Mensing-Ott, a high-pitch Haskell, and a low-pitch Haskell meter were subjected to oscillations parallel to a flume's flow with a constant stroke distance of $2 \mathrm{ft}(0.6 \mathrm{~m})$ and induced speeds of up to three times the average flume velocities. The results, which are shown graphically and briefly discussed by the authors, indicate that if the maximum additional longitudinal speed of the meter is less than 50 percent of the average stream velocity, the meter's response will not deviate from a steady stream response. The indicated flume velocities used in the testing are cited by Yarnell and Nagler as being 2, 3, and $5 \mathrm{ft} / \mathrm{s}(0.6,0.9$, and $1.5 \mathrm{~m} / \mathrm{s})$.

Kolupaila (1958) references other reports to draw conclusions as to the effect of pulsating flow on horizontal-axis current meters. The conclusions drawn by Kolupaila are of value for cases when there is a reversal of flow and when the meter being used can distinguish between forward and reverse flow. For current meters that do not distinguish between forward and reverse flow, the conclusions presented by Kolupaila do not hold true.

As part of a set of tests to determine the effect of simulated turbulence on several rotor types for an Ott current meter, Fischer (1966) conducted some tests in which the current meter was oscillated in the axial direction, parallel to the towing direction. The rotors being tested by Fischer were a spoked Ott rotor; a slant-edged Ott rotor; an Ott "A" component rotor; an Ott "F" component rotor; an Ott "R" component rotor; a special aluminum Ott "A" component rotor; an Amsler rotor; and two custom slant-edged rotors; one heavy (made of lead) and one relatively light. Limited results are presented in Fischer's report. The results of tests on an "F" component rotor are presented, however, and these results show that for axial pulsations of the meter and rotor at less than 20 percent of the average tow speed, the meter generally overregistered by 5 percent or less. Test results also show that the length of the pulsation cycle and the magnitude of the oscillation frequency affect the performance of the current meter and rotor. 
Jepson (1967) reported on a set of tests where an Ott meter with several different rotor types and a Gloster mini flow meter were oscillated in the axial direction in a flowing flume to simulate the pulsation of flow. A set of four tests was conducted to determine what effect, if any, there would be; (1) if different meter rotor types were tested under the same conditions; (2) if the mass of the rotor was changed with all other physical conditions remaining the same; (3) if the frequency of the pulsations was changed; and (4) if the mean velocity was changed. For different rotor types, it was found that the rotor configuration/design does have a large bearing on the amount of registration error that occurs with pulsating flows. The results presented by Jepson show a that the rotor's diameter and the number of blades affect the characteristics of the rotor's performance. There is no clear indication as to what the pitch of the rotor blades does for the meter. The mass of the rotor was found to be a large contributor to the performance of the rotor. The lower the mass of the rotor, the better the response of the meter to fluctuations in velocity. Also, the higher the frequency of the pulsations, the larger the registration error. Changing the average water velocity while keeping the frequency of oscillation constant is the same as changing the intensity of the flow pulsation. The results of this type of test are predictable; increase the intensity of the pulsations and increase the deviation in meter registration. All registration errors presented by Jepson were overregistration errors.

In the second part of his report, Jepson uses the principles of simple aerodynamics to theoretically explain the results of the conducted tests. The theoretical work reaches the same conclusions as the flume tests; that is, the rotor should be of low mass, small diameter, and have a large aspect ratio. These features will reduce the overregistration of the rotorequipped current meter.

The paper by Bean (1971) mainly covers the theory of the design and workings of mechanical current meters, both vertical- and horizontal-axis meters. As a blanket statement covering the response of both vertical- and horizontal-axis meters to velocity fluctuations, the author states that if the fluctuations are slow enough for the meter to follow the fluctuations, the meter will correctly register the average velocity. On the other hand, Bean states that if the velocity fluctuations are too fast for the meter to respond, the meter will overregister because of what the author states as the square-law relation between hydrodynamic torque and velocity.

\section{Temperature}

The effects of water temperature on oil-filled horizontal-axis current meters are briefly discussed by Dodge (1965) and Johnson (1966). Dodge very briefly discusses the temperature effects that were encountered during his tests at a dam's power station. The effects were virtually nonexistent because of the very small temperature range encountered during the testing. Johnson, on the other hand, determined that for a group of six Neyrpic "Dumas" current meters a temperature variation of $30.5^{\circ} \mathrm{F}\left(16.9^{\circ} \mathrm{C}\right)$ produced a maximum underregistration error of 6.2 percent at a rotational speed of $2 \mathrm{rev} / \mathrm{s}$.

\section{Repeatability}

All of the articles pertaining to the repeatability of calibrations of horizontal-axis current meters, Raffel (1965), Dodge (1965), and Johnson (1966), talk about the tests fully described by Johnson. According to Johnson, one Neyrpic current meter was rated at five tow tanks across the United States between April 1962 and October 1962. At the lower end of the rating curves, $N$ less than $6 \mathrm{rev} / \mathrm{s}$, the obtained rating curves varied as much as 5.5 percent while at the upper end of the rating curves, $N$ greater than $6 \mathrm{rev} / \mathrm{s}$, the curves varied less than 1 percent. Caution should be used when interpreting this information because the meter was not always mounted in the same manner for all calibrations and there was also varying water temperatures at the towing facilities.

\section{ELECTRONIC CURRENT METERS}

The term electronic current meter in this paper covers the meter types of electromagnetic current meters and acoustic, or ultrasonic, current meters. Unlike the mechanical-type current meters, the written history of testing electronic current meters is short and very limited. 


\section{Electromagnetic Meters}

Electromagnetic current meters come in one-, two-, and three-dimensional varieties. The threedimensional version of this meter type, however, has not gained full acceptance for general use and is not covered in the literature. The predominant brand of electromagnetic current meter in the United States is the Marsh-McBirney current meter. Papers covering the testing of electromagnetic current meters in oblique flows, performance in close proximity to boundaries, performance in turbulent flow, reaction to flow pulsations, effects of icing on the meter's probe, and effects of biological fouling of the current meter's probe have been found. Most meter probe shapes tested are cylindrical probes, spherical probes, and discus shaped probes.

\section{Oblique Flows}

The effects of oblique flows on electromagnetic current meters are reported on by Cushing (1976), Engel and DeZeeuw (1980), Aubrey, Spencer, and Towbridge (1984), and Marsh-McBirney (1988). Engel and DeZeeuw report on work conducted on a one-dimensional meter while Cushing; Aubrey, Spencer, and Towbridge; and Marsh-McBirney report on work conducted on two-dimensional meters.

Most of the work presented by Cushing (1976) is theoretical dealing with the response of both cylindrical and spherical probes of two-dimensional electromagnetic current meters. In theory and in the experimental data presented, Cushing points out that a cylindrical meter with a long magnet and flush sensors is the best overall probe design when horizontal angles are involved. Cushing also points out that the sensitivity of the probe to horizontal angles is dependent on the Reynolds number of the flow around the probe. Experimental results are presented that show that as the Reynolds number increases, the boundary layer around the probe decreases and the meter's response increases. For vertical angles, the spherical probe is reported to have very good cosine response because of the probe's shape and the probe's magnetic orientation. The cylindrical probe is very dependent on the location and orientation of the meter's housing when vertical angles are involved.
Engel and DeZeeuw (1980) conducted a limited number of oblique flow tests on a Marsh-McBirney 201 one-dimensional current meter as part of a larger set of tests on the calibration of current meters at extreme low flows. The oblique-flow portion of the testing consisted of rotating the meter sensor to angles of 5 and 15 degrees out of alignment in the horizontal plane while being towed in a tow tank. The results of the tests are presented in both tabular and graphic form and show that the tested meter consistently underregistered the correct velocity. The cosine corrected velocity reading of the meter was off by as much as 20 percent for the 15-degree angle at a tow speed of $0.6 \mathrm{~m} / \mathrm{s}(2 \mathrm{ft} / \mathrm{s})$.

Aubrey, Spencer, and Towbridge (1984) use a combination of laboratory tests and cited references to describe the behavior of spherical-probed electromagnetic current meters in oblique flows. The authors, citing Cushing (1976), contend that a spherical probed meter's cosine response is a function of the Reynolds number, $R e$, of the flow around the probe. As the $R e$ increases, the boundary layer around the probe decreases and the cosine response improves. Laboratory towing tests conducted by the authors with the meter's probe rotated roughly 45 degrees showed that for the meter tested, the obtained meter reading was as much as 10 percent off in comparison to the manufacturer's calibration. The authors do not make it clear whether the meter read higher or lower than the manufacture's calibration.

The report by Marsh-McBirney (1988) presents the results of tests to determine the response of an electromagnetic current meter with a 4-inch-diameter $(102 \mathrm{~mm})$ spherical probe in oblique flows in both the horizontal and vertical directions. The results of the oblique-flow tests are presented graphically. For horizontal-oblique flows, the meters response was off by -4.4 percent at a velocity of $8.4 \mathrm{ft} / \mathrm{s}(2.56 \mathrm{~m} / \mathrm{s})$ and an angle of approximately 45 degrees, and +10.7 percent at a velocity of $1.5 \mathrm{ft} / \mathrm{s}(0.46 \mathrm{~m} / \mathrm{s})$ at an angle of approximately 20 degrees. The meter's response to vertical-oblique flows is shown to be better than the response to horizontal-oblique flows. The figure presented in the report shows the meter's response tracing almost directly on top of an ideal cosine curve. Marsh-McBirney calculates that, on average, the meter tested will overregister by no more than 1 percent when subjected to vertical-oblique flows. 


\section{Proximity to Boundaries}

The reports on testing of electromagnetic current meters to determine their response to being placed in close proximity to boundaries is limited. Cushing (1976) reports on theoretical and laboratory tests of placing electromagnetic current meters next to boundaries. Theoretically, a meter will register correctly if the boundary material is a better conductor than the water being measured. If the boundary has the same conductance as the water, the meter is likely to be minimally affected by the boundary. The final case looked at by Cushing is that of the boundary being an insulator. For this last case, the meter's sensitivity will be degraded by a factor of two times that of a neutral boundary. A set of test data presented by Cushing shows that when a cylindrical probe is placed near the water surface, an insulating boundary, the meter underregistered by 15 percent.

Aubrey, Spencer, and Towbridge (1984) reference Cushing (1976) when recommending that an electromagnetic current meter's probe be placed at least three probe diameters from a boundary when taking a velocity measurement. The three probe diameter limit can be bypassed if the boundary material is a good conductor.

\section{Turbulence}

The performance of electromagnetic current meters subjected to turbulent flow is reported on by Bivins (1976); Mero, Appell, and McQuivey (1977); Griffiths (1979); and Aubrey, Spencer, and Towbridge (1984). The majority of the tests reported on used meters with cylindrical and spherical probes.

Bivins (1976) reports on a set of tests conducted on a Marsh-McBirney model 750 electromagnetic current meter with a cylindrical probe to determine the effects of grid-induced turbulence on the meter's performance. The tests were conducted in a submerged jet facility with several grids used to induce small scale turbulence with levels up to 11 percent. The turbulence intensity was measured with a hot film anemometer and the mean velocity was measured using the hot film anemometer and a Delft horizontal-axis current meter. Results of the tests show that the electromagnetic meter tested overregistered by as much as 20 percent when the turbulence intensities were at 11 percent.

The paper by Mero, Appell, and McQuivey (1977) briefly describes the results of turbulent flow testing on several probe designs of electromagnetic current meters. The probes tested were a $25-\mathrm{mm}$ (1 in.) diameter cylindrical probe with protruding electrodes, a $90-\mathrm{mm}(0.38 \mathrm{in}$.) spherical probe with protruding electrodes, a $38-\mathrm{mm}$ (1.6 in.) spherical probe with protruding electrodes, a streamlined elliptical probe, an "open" design probe, and a 100 -mm-diameter (3.9 in.) spherical probe. All of the meters were tested under turbulent flow conditions except for the 100-mm-diameter (3.9 in.) probe, which was tested under macro-scale dynamic conditions only.

The turbulence conditions for the Mero, Appell, and McQuivey tests were generated in the same submerged jet facility and in the same manner as described by Bivins (1976). The results presented in the Mero, Appell, and McQuivey report are for a test run with a turbulence scale of $20 \mathrm{~mm}$ ( $0.79 \mathrm{in}$.) with an intensity of 4 percent. The graphically presented results show that the cylindrical probe overregistered by 5 percent at a mean velocity $(U)$ of $0.65 \mathrm{~m} / \mathrm{s}$ $(2.1 \mathrm{ft} / \mathrm{s})$ and by up to 10 percent at a $U$ of $1.1 \mathrm{~m} / \mathrm{s}$ $(3.6 \mathrm{ft} / \mathrm{s})$. The $90-\mathrm{mm}(0.38 \mathrm{in}$.) spherical probe was shown to be relatively unaffected by the induced turbulence. Its maximum overregistration of 1.5 percent occurred at a $U$ of $0.65 \mathrm{~m} / \mathrm{s}(2.1 \mathrm{ft} / \mathrm{s})$. The $38-\mathrm{mm}$ (1.6 in.) spherical probe was shown to overregister by as much as 16 percent at a $U$ of $0.65 \mathrm{~m} / \mathrm{s}$ $(2.1 \mathrm{ft} / \mathrm{s})$ and 6 percent at a $U$ of $1.1 \mathrm{~m} / \mathrm{s}(3.6 \mathrm{ft} / \mathrm{s})$. The streamlined elliptical probe was shown to overregister by 4 percent at a $U$ of $0.65 \mathrm{~m} / \mathrm{s}(2.1 \mathrm{ft} / \mathrm{s})$ and to reduce to zero error in registration at $1.1 \mathrm{~m} / \mathrm{s}$ $(3.6 \mathrm{ft} / \mathrm{s})$. The "open" design probe was unaffected by the induced turbulence.

The macro-scale dynamics test consisted of towing a meter through a tow tank while the meter was moved through an orbital motion. With a tow speed of $0.72 \mathrm{~m} / \mathrm{s}(2.4 \mathrm{ft} / \mathrm{s})$ and orbital velocities of $0.32 \mathrm{~m} / \mathrm{s}(1.0 \mathrm{ft} / \mathrm{s})$ and $0.77 \mathrm{~m} / \mathrm{s}(2.5 \mathrm{ft} / \mathrm{s})$, the 100 -mm-spherical (3.9 in.) probed meter was reported to register in error of less than 5.5 percent of the mean (tow-cart) velocity.

Griffiths (1979) reports on a set of tests where the turbulence was generated by towing a pipe $3.3 \mathrm{~m}$ $(10.8 \mathrm{ft})$ in front of the current-meter probes being tested. The turbulence generated by this method was calculated to have an intensity of approximately 7 percent. The probe designs tested by Griffiths were a 111-mm-diameter (4.4 in.) discus probe, a 50-mmdiameter (2.0 in.) discus probe, a $160-\mathrm{mm}$-diameter 
(6.3 in.) annular probe, and a 134-mm-diameter

(5.3 in.) spherical probe with protruding electrodes.

The output from the meters was compared to the tow speed after adjusting the tow speed using a theoretically derived adjustment based on turbulence generated behind circular pipes and tubes. Griffiths reports that all of the probe designs tested measured the mean flow with "no significant errors."

In discussing turbulence effects on electromagnetic current meters, Aubrey, Spencer, and Towbridge (1984) give their recommendations as to where to locate a meter probe to avoid problems from grid-induced turbulence. The authors recommend that the meter probe be located at least 40 meshlengths back.

\section{Pulsation of Flow}

Reports found covering the effects of pulsation of flow testing on electromagnetic current meters are limited to those by Aubrey, Spencer, and Towbridge (1984) and Aubrey, Towbridge, and Spencer (1984). The second of these reports is a shortened version of the more comprehensive first report.

The results presented in the two reports are for tests conducted in a tow tank on two different-sized spherical probes with protruding electrodes. The probe diameters tested were $105 \mathrm{~mm}(4.1 \mathrm{in}$.) and $40 \mathrm{~mm}$ (1.6 in.). Results of the tests indicate that errors in registration can be as high as 10 to 20 percent depending on the magnitude and rate of oscillations and orientation of the probe to the flow. The authors attribute the majority of the error obtained to be caused by the constantly changing boundary layer around the spherical probe and the constantly changing pattern of vortex shedding.

\section{Ice}

Reports covering the effects of ice on the performance of electromagnetic current meters are limited to one by Derecki and Quinn (1987). The authors report on the effects of frazil ice on the performance of a Marsh-McBirney model 585 electromagnetic current meter located on the bottom of a river. The magnitude of the frazil-ice effects are not known and only the statement that the frazil ice occurrence "drastically affect" the performance of the current meter is given by the authors. The frazil ice is described as "coating" the meter and its sensor, thus reducing the flow in the area around the probe that is measured by the meter.

\section{Fouling}

The fouling of a current meter can be caused by biological growth on the meter's sensor or by a buildup of trash, debris, and (or) weeds growing up around the meter's location. Aubrey, Towbridge, and Spencer (1984) discuss the first of these fouling types while Derecki and Quinn (1987) discuss the second.

Aubrey, Towbridge, and Spencer (1984) report on an electromagnetic current meter that was calibrated with biological growth on the meter's probe and again after the probe was cleaned. The meter's response was changed by 25 percent with the fouling growth on the probe. The authors do caution that the effect of the growth is dependent on the type of biological growth.

Derecki and Quinn (1987) report on problems encountered when weeds drifting in the river in which the meter was installed got caught on the meter. The authors also report on problems with weeds growing up around the meter. The authors reported that the weed accumulation reduced the meter-registered velocities by more than 50 percent.

\section{Acoustic Meters}

Acoustic current meters used for point-velocity measurements have less written on their testing than electromagnetic current meters. Both of the articles found cover only the testing of the current meters in oblique flows. The two reports are by Appell (1978) and Botma (1990).

The report by Appell (1978) covers horizontaland vertical-oblique angle testing of three twodimensional acoustic current meters. The meters tested were Neil Brown acoustic current meters. Results of the horizontal-angle testing indicated that the readings of the meters tested generally deviated from the correct reading when the meter's major axis were not pointed into the flow. This deviation ranged from a slight overregistration to an underregistration of as high as 14 percent. The two velocities used in the testing were $0.13 \mathrm{~m} / \mathrm{s}(0.42 \mathrm{ft} / \mathrm{s})$ and $0.51 \mathrm{~m} / \mathrm{s}(1.7 \mathrm{ft} / \mathrm{s})$.

The results of the vertical-angle oblique flow tests show that for vertical angles of \pm 15 degrees the 
meters tested deviated very little from the true velocity reading. All three of the meters tended to overregister the correct component of the flow when the meter was tilted by \pm 60 degrees. The overregistration was as much as 50 percent at angles of -60 degrees. The plots of the meters' responses to the vertical angled flows are almost identical and show the same trend for all of the angles tested.

The paper by Botma (1990) briefly covers some tow-tank testing of a three-dimensional VEKTORAKWA acoustic current meter. The meter was rotated in the vertical and horizontal directions during testing. The limited results presented show that when the $\mathrm{X}$-axis is rotated to 45 degrees, the meter's error will generally be larger than 20 percent. All of the other positions of the $\mathrm{X}$-axis tested, with a few exceptions, produced errors of less than 5 percent. (The X-axis runs parallel to the probe's support rod.) With few exceptions, all of the data points were collected with the current meter being towed at $0.6 \mathrm{~m} / \mathrm{s}$ $(2.0 \mathrm{ft} / \mathrm{s})$.

\section{COMPARISONS OF DISCHARGE MEASUREMENTS}

In this section, those papers and reports that discuss tests and experiments in which discharge measurements made with different equipment will be identified. Because the comparisons of the measured discharges are subjective evaluations, no attempt to determine the correct discharge will be undertaken. Only the equipment used, the location of the comparisons, when known, and the percent difference between discharges will be reported here. It will be left up to the reader to determine the usefulness of the individual reports listed.

Early comparison work is reported on by Murphy in reports from the early 1900's (Murphy 1901, 1902, 1904). Murphy (1901) briefly describes two sets of tests, one in irrigation canals and one in a laboratory flume. The work conducted in the irrigation canals used float rods and a small Price current meter to determine the discharge in the canals. The meter determined discharges ranged from 7 percent below the rod discharges to 6.5 percent higher than the rod discharges. The tests conducted in the laboratory flume again used float rods and a small Price meter to determine the discharge in the Cornell hydraulics laboratory flume. The reference discharge for the flume was determined using a sharp-crested weir. For the laboratory studies, the Price meter underregistered the discharge as compared to the weir discharge.

Murphy's 1904 report (Murphy, 1904) is an updated and expanded presentation of the 1901 report.

The 1902 paper by Murphy (1902) presents a set of tests conducted at the Cornell Hydraulics Laboratory. This set of tests consisted of comparing the discharge in a flume as determined by two small Price current meters and one Haskell meter. The reference discharge was determined using a sharpcrested weir. Both the Price meters and the Haskell meter overregistered the discharge as referenced to the weir discharge for almost all the cases. Also, in all but a few cases, the Haskell meter's determined discharge was more in error than the Price meter's determined discharge.

In a discussion of Murphy's 1902 paper, Lippincott (1902) lists several tests in which the discharge of streams was determined using different methods. Lippincott lists (1) four tests in which the discharge as determined by a large Price meter was compared to the discharge determined by weirs (types of weirs not specified); (2) two tests in which the discharges determined by a large Haskell meter and a large Price meter were compared; (3) one test in which the discharges of a large Price meter, a small Price meter, and a weir were compared; (4) one test in which the discharges determined by a large Price meter and a volumetric measurement were compared; (5) one test in which the discharges determined by a small acoustic Price meter and a weir were compared; (6) one test in which the discharges determined by two large Price meters and one small Price meter were compared; and (7) one test in which the discharges as determined by two large Price meters were compared. The results of these tests are as follows: (1) the meter's discharge differed by less than \pm 1 percent of the weir's discharge; (2) the large Haskell meters registered a discharge 9 percent higher and 1 percent higher than the large Price meter; (3) the small Price meter registered a 2 percent higher discharge than the weir; (4) the discharge of the two methods differed by less than 1 percent; (5) the discharge determined by the acoustic Price meter differed by less than 2 percent high and low of the weir discharge; (6) both large and small Price meters registered the same discharge; and (7) the 
determined discharges by the two large Price meters varied by less than 1 percent.

As part of an extensive list of discussions to a paper by Yarnell and Nagler (1931), Grover (1931), Nettleton (1931), and Van Vliet (1931) include discharge comparisons in their discussions. Grover (1931) talks about a test conducted in a canal where the discharge in the canal as determined by a small Price current meter was compared to the discharge as determined by the salt-velocity method. The meter's discharge was 1 percent higher than the discharge determined by the salt-velocity method. Nettleton (1931) very briefly discusses a comparison of discharge measurements determined by a "cup" and a "screw" meter. Both meter types generally gave the same discharge. Nettleton does not give the meter types used. Van Vliet (1931) describes several sets of tests where the discharge determined by a large or a small Price meter was compared to the discharge determined from a calibrated sluice gate. The meter discharges were always less than that of the sluice gates by 1 to 3.5 percent. The sluice gates were on the Assuan Dam on the Nile River and were volumetrically calibrated.

The USGS Portland District Office reports on a set of tests using a Price meter and a four-bladed Hoff meter (USGS 1931). The discharges determined by both of the meters were compared to the discharge determined using the rated gage site. The Hoff meter registered a discharge 2 percent higher than the Price meter and both meters registered a discharge higher than determined from the rated gage. This meter work was conducted in the Columbia River at the Dalles gaging site.

In 1933 there were four reports by USGS district offices on comparing discharge measurements. The Hartford District Office reported on comparing the discharge in a small brook using a Price current meter and an orifice-weir control structure (USGS 1933b). The discharges of the meter and the orificeweir were always within 0.5 percent of each other. The tests were conducted in Burlington Brook near Burlington, Conn.

The Columbia office reported on a comparison of discharge measurements using a Price meter and a Hoff meter (USGS 1933c). The discharges obtained using the Price meter were 1 percent less than the discharges obtained using the Hoff meter. The site used for the Columbia study was not given.
The report by the Madison office describes some discharge comparison tests conducted in the headrace of a power plant (USGS 1933d). The meters used in this study were a Price meter and an Ott meter. The Price meter discharges were usually 3 percent less than the Ott meter discharges.

The fourth report was by Woster of the Tacoma District Office (Woster, 1933). A small Price type 622 current meter and a four- and a three-bladed Hoff meter were used to determine the discharge of the Clark Fork of the Columbia River. The meter determined discharges were compared to the discharge from an established rating curve for the site. On average, the Price meter discharge was 8 percent higher than the Hoff meter discharge.

As part of an extensive set of tests on current meters, Rohwer (1933) compares the discharge measured by a large number of current meters to the discharge determined by a Francis-weir. The current meters used in the discharge comparison tests were a small Price meter, a Lallie cup meter, two Ott meters, a Hoff meter with a rubber rotor, and a small Price meter with a special four-cup rotor, five-cup rotor, six-cup rotor, seven-cup rotor, and eight-cup rotor. All of the meters were used to determine the discharge in a flume using the integration method, a multipoint method, the 0.2-0.8 depth method, and the 0.6 depth method. The small Price meter underregistered the discharge by 3.0 percent for the integration method, and by 2.5 percent for the multipoint method and overregistered by 0.5 percent for the $0.2-0.8$ depth method and by 1.5 percent for the 0.6 depth method. The Lallie cup meter underregistered the discharge by 1.0 percent for the integration method, determined roughly the correct discharge for the multipoint method, and overregistered by 1.0 percent for the $0.2-0.8$ depth method and 3.0 percent for the 0.6 depth method. The two Ott meters always overregistered the discharge. The overregistration was by 1.3 and 2.5 percent for the integration method, 2.5 and 0.5 percent for the multipoint method, 2.5 and 1.0 percent for the $0.2-0.8$ depth method, and 4.2 and 2.0 percent for the 0.6 depth method. The Hoff meter overregistered the discharge by 1.5 percent for the integration method, 1.0 percent for the multipoint method, 2.0 percent for the $0.2-0.8$ depth method, and 3.2 percent for the 0.6 depth method. The small Price meter with the special rotors always overregistered the discharge. This overregistration ranged from a low of a 1.0 percent with the five-cup rotor 
using the integration method to a high of 5.2 percent with the four-cup rotor using the 0.6 depth method.

Hoyt (1934) briefly describes five sets of discharge comparison tests involving Price meters. The first set of tests consists of comparing the discharge determined using a Price meter and a volumetric tank. This first set of tests was conducted at the Assuan Dam in Egypt. On average, the meter determined discharge was 2 percent lower than the discharge determined from the dam's sluice gates. The second set of tests compares the discharge determined using a Price meter and a volumetrically calibrated weir. For these measurements, the Price meter determined discharge, on average, was 2 percent less than the weir-determined discharge. The second set of tests was conducted in a flume at the Worcester Polytechnic Institute in 1927. The third set of tests compared the discharge determined using a Price meter to the discharge determined using the salt-velocity method. The Price meter determined discharge was, on average, 0.7 percent low. This third set of tests was conducted while calibrating turbines at a power plant. The fourth set of tests compared the discharge determined using a Price meter to the discharge obtained from power plants rated by the Gibson method. The Price meter determined discharge was 2 percent higher than the power plant discharge. This fourth set of tests was conducted on the Sacandaga River and the Spokane River. The fifth set of tests compared the discharge determined by a Price meter to the discharge determined by a Hoff meter. The fifth set of tests was conducted in the James River at Reusens, Va., and Clark Fork of the Columbia River at Metal Falls, Wash. On the James River, the Price meter determined discharge was 6 percent higher than the discharge determined by the Hoff meter. On the Columbia River, the Price meter determined discharge was 1 percent higher than the discharge determined by the Hoff meter.

McDonald (1940) reports on a set of tests in which the discharge in a tailrace of a power plant as determined using a Price current meter is compared to the discharge determined using the salt-velocity method and a sharp-crested weir. The location of the meter measurement section is located between the power plant and the weir location. The meter determined discharge was 3 percent higher than the discharge determined using the salt-velocity method.
Wood (1946) briefly describes several examples of comparing discharge measurements using USGS current meters (Price-type) and rated gaging stations to discharge determined by other methods. Most of the examples cited by Wood are comparing the discharge obtained from a gaging station's rating to the discharge obtained using other methods. These other methods include determining the discharge using weirs, Venturi meters, and using the salt-velocity method. In the examples given, the Price meter determined discharges were lower in comparison to the discharge determined by a weir by 1 percent, lower by 2 percent in comparison to that determined by a Venturi meter, and higher by 0.7 percent in comparison to the discharge determined using the salt-velocity method.

Dreher (1957) describes a set of tests where the discharge flowing over the top of a broad-crested dam was measured with both a pygmy meter and a Pitot static tube. On average, the pygmy meter determined discharge was 20 percent less than the discharge determined using the Pitot tube. The conditions at the location of the discharge measurement were described by Dreher as not being an ideal measuring section.

In the paper by Kolupaila (1958), the author briefly describes an occasion when two discharge measurements were taken in parallel on the Mississippi River at Vicksburg, Miss. Both discharge measurements were taken using cable-suspended Price current meters. One measurement was taken from a bridge over the river while the second measurement was taken from a boat. The measurements were also taken by two different government agencies. The discharge determined from the bridge was 9 percent higher than the discharge determined from the boat.

Townsend and Blust (1960) briefly present results of a test where the discharge in the lower Niagara River was determined simultaneously using three current meters. The current meters used were a Price meter, an Ott meter, and a Neyrpic meter. All three current meters were cable suspended on a special meter mounting frame placing the meters at the same vertical position in the river and $3 \mathrm{ft}(0.9 \mathrm{~m})$ horizontally apart. The meter's relative horizontal positions on the mounting frame were constantly changed so that the meter's position on the mounting frame would not bias the meter readings. All three of 
the meters gave discharges within 0.3 percent of each other.

As a discussion of the Townsend and Blust paper, Golden and Trotter (1960) present data obtained on the Mississippi River near Vicksburg, Miss. The data presented show discharges of the Mississippi River as determined with a Price meter and an Ott meter. On average, the Price meter determined discharges were 1 percent lower than the discharges determined using the Ott meter.

As part of a larger discussion on the accuracy of current meter measurements, Carter and Anderson (1963) present a set of data collected on the Mississippi River using a Price current meter and an Ott current meter. The data presented are the same as presented by Golden and Trotter (1960).

The report by Bruck (1965) differs from the other reports and papers listed in this section. Bruck's report covers a set of tests in which three vertical-axis meter types were used to obtain velocity profiles of flow under ice cover. The meters used in the tests were three Price 623 type meters, one pygmy meter, and one vane ice meter. On average, the Price meter's determined velocities were 6 percent lower than the vane ice meter determined velocities. The averaged velocities of the pygmy meter and the vane ice meter were the same.

The paper by Dodge (1965) very briefly describes a test in which a Price meter and a set of 10 Neyrpic "Dumas" meters are used to determine the discharge through electric turbines of a dam power station. The Price meter determined discharge averaged less than 2 percent more than the discharge from the dam. The Price meter was used in the river downstream of the dam and the Neyrpic meters were located in the intakes of the electric turbines.

The paper by LaCornu, Hanson, and Cruff (1965) covers work where the discharge of the Eel River near Scotic, Calif., was measured using three types of current meters and three methods of taking the measurements. The meters and methods used were a Price meter using the point-velocity method; an Ott meter using the vertical velocity-integration and vertical-horizontal velocity-integration methods; and a four-vane vertical-axis meter using the vertical velocity-integration and vertical-horizontal velocityintegration methods. All three meters were used in a cable-suspension arrangement. The Price meter determined discharge was 1.5 percent less than that determined using the Ott meter and 3 percent less than the discharge determined using the vane meter.

In his paper, Kallio (1966b) describes a test in which the discharge from a power station is compared to the discharge determined by two different current meters. The two current meters were a Price meter and an Ott meter with a component rotor. The discharge determined by the Ott meter was 3 percent higher than the discharge determined by the Price meter. The meter discharge measurements were taken from a boat in what Kallio called a "swift and very turbulent" river.

Carter (1973) briefly discusses and presents the results of six tests in which the discharge from dam powerhouses was compared to the discharge calculated from stage-discharge ratings of the river downstream of the dam or from discharge measurements made downstream of the dam. The discharge of the powerhouses was determined using Neyrpic current meters. In those tests in which the discharge was measured simultaneously downstream of the dam, Price current meters were used to make the downstream discharge measurements. The stated averaged difference in the discharges was 1.5 percent.

Located in Rantz and others (1982) is a very brief description of a long-term (2-year) test in which the discharge in the Mississippi River was measured using two types of current meters. The meter types used were Price and Ott meters. This same series of discharge measurements is also covered by Golden and Trotter (1960) and Carter and Anderson (1963).

Fulford (1990) briefly presents the results of tests where Price type AA current meters with different rotors were used to make comparison discharge measurements in rivers. The rotors used were a standard open-cup metal rotor and a solid-cup polymer rotor. Averaging all of the measurements, the solidcup polymer-rotor-equipped meter registered 2 percent higher discharges than the standard open-cup metal-rotor-equipped meter.

\section{SUMMARY}

The results of the U.S. Geological Survey's literature review on the testing of point-velocity current meters revealed that there has been extensive reporting of the testing of mechanical current meters and relatively little reporting on the testing of electronic current meters. Testing of mechanical type 
meters was extensive in the early to mid-twentieth century and has slowed in recent decades. This reduction in the number of tests indicates that the modern versions of the mechanical meters have not been tested as extensively as the older versions of meters.

Of the two types of electronic meter types, the electromagnetic meters have been tested much more extensively than the acoustic meters, although not as extensively as the mechanical-type meters. Unlike the mechanical-type meters, both the electromagnetic and acoustic meter probe designs are still evolving.

Comprehensive testing of a group of current meters under the same conditions has not been done since the late 1920 's. In addition, there has never been a set of comprehensive tests conducted that included both mechanical and electronic current meters.

\section{REFERENCES CITED}

Addison, Herbert, 1949, Hydraulic measurements (2d ed.): New York, John Wiley \& Sons, Inc., 327 p.

Alming, Knut, 1967, Measurements on current meters in skew and rotating flow: International Current Meter Group - Report 28, 20 p.

Appell, G.F., 1978, A review of the performance of an acoustic current meter in Proceedings of a Working Conference on Current Measurement, January 11-13, 1978, University of Delaware, Newark, Del.: The National Oceanic and Atmospheric Administration and University of Delaware, p. 35-58.

Aubrey, D.G., Spencer, W.D., and Towbridge, J.H., 1984, Dynamic response of electromagnetic current meters: Woods Hole Oceanographic Institution Technical Report Number WHOI-84-20, 150 p.

Aubrey, D.G., Towbridge, J.H., and Spencer, W.D., 1984, Dynamic response of spherical electromagnetic current meters: Institute of Electrical and Electronic Engineers, p. 242-248.

Bean, H.S., ed., 1971, Fluid Meters-Their theory and applications, Report of ASME Research Committee on fluid meters (6th ed.): New York, American Society of Mechanical Engineers, p. 91-97.

Bivins, L.E., 1976, Turbulence effects on current measurement: Coral Gables, Fla., M.S. thesis, University of Miami, 102 p.
Botma, H.C., 1990, The VEKTOR-AKWA, an acoustic current meter for use in 3-dimensional dynamic flows, in Appell, G.F. and Curtin, T.B., eds., Proceedings: IEEE Fourth Working Conference on Current Measurement, 1990, Clinton, Md., Institute of Electrical and Electronics Engineers, p. 120-128.

Brown, E.H., and Nagler, F., 1914, Preliminary report of current meter investigations, in Discussion on Measurement of the velocity of flowing water, by Moody, L.F. (1914): Engineers' Society of Western Pennsylvania, 1914, Proceedings, v. 30 , no. 5, p. 415417.

Bruck, P.J., Jr., 1965, Vertical velocity curves under ice - a comparison of Price current meter with vane ice meter: Water-Resources Bulletin, May 1965, p. 2831.

Buchanan, T.J., 1963, Translation of "Influence of turbulence on current meter flow measurements in free-flowing channel": Water-Resources Bulletin, Aug. 1963, p. 18-20.

Burtsev, P.N. and Baryshnikova, M.M., 1973, The analysis of the possibilities of current meter operation in turbulent streams, in Hydrometry-Proceedings of the Koblenz Symposium, Paris, September 1970: Paris, UNESCO, v. 1, p. 79-85.

Carter, R.W., 1973, Accuracy of current meter measurements, in Hydrometry-Proceedings of the Koblenz Symposium, Paris, September 1970: Paris, UNESCO, v. 1, p. 86-98.

Carter, R.W., and Anderson, I.E., 1963, Accuracy of current meter measurements: Journal of the Hydraulics Division-Proceedings of the American Society of Civil Engineers, v. 89, no. HY4, p. 105115.

Chappell, C.J., 1939, Effect of vertical movement of meter on registered velocities: Water-Resources Bulletin, Aug. 1939, p. 435-437.

Cushing, Vincent, 1976, Electromagnetic water current meter: Oceans '76, Institute of Electrical and Electronic Engineers, p. 25C-1, 25C-17.

Derecki, J.A., and Quinn, F.H., 1987, Use of current meters for continuous measurement of flows in large rivers: Water Resources Research, v. 29, no. 9, p. 1751-1756.

Dickinson, W.T., 1967, Accuracy of discharge determinations: Colorado State University Hydrology Paper 20, $54 \mathrm{p}$.

Dickman, R.H., 1951, The rating of water-current meters: Water Power, v.3, no. 9, p. 330-334, 341.

Dodge, N.A., 1965, Flow measurements at Columbia River power plants: Journal of the Hydraulics Division-Proceedings of the American Society of Civil Engineers, v. 91, no. HY2, p. 125-147. 
Dreher, F.C., 1957, Comparing velocities by Pygmy meter and Pitot tube: Water-Resources Bulletin, Feb. 1957, p. 3-7.

Engel, Peter, 1983, The effect of transverse velocity gradients on the performance of the Price current meter: Environmental Canada, National Water Research Institute, $16 \mathrm{p}$.

1990 , On the vertical transit method of determining the mean velocity in open channel flow:

Environmental Canada, National Water Research Institute, NWIS Contribution 90-133, 24 p., 16 fig.

Engel, P. and DeZeeuw C., 1978, The effect of horizontal alignment on the performance of Price 622AA current meter: Environmental Canada, National Water Research Institute, $14 \mathrm{p}$.

1979, The effect of vertical alignment on the performance of the Price 622AA current meter: Environmental Canada, National Water Research Institute, 10 p., 9 fig., 6 tables.

1980, Performance of the Price 622AA, Ott C-1, and Marsh-McBirney 201 current meters at low speed Environmental Canada, National Water Research Institute, Report Number 80-14, 25 p., 4 fig.

Fischer, M. 1966, Versuche über den Einfluss der turbulenten Strömung auf hydrometrishe Flügel durch Nachahmung der Turbulenz im Schlepptank [Experiments on the influence of turbulence on propeller current meters by means of reproducing the turbulence in the tow tank]: International Current Meter Group Report 19, 6 p., 10 fig. [In German.]

Frazier, A.H., 1941, Current meter, Gettner: WaterResources Bulletin, May 1941, p. 94-96.

1954, Effect of temperature on the ratings of Pricetype current meters: Water-Resources Bulletin, Feb. 1954, p. 11-13.

1967, William Gunn Price and the Price current meter, in Contributions from the Museum of History and Technology: United States National Museum Bulletin 252, p. 37-68.

1974, Water current meters in the Smithsonian collections of the National Museum of History and Technology: Washington, D.C., Smithsonian Institution Press, 95 p.

Fulford, J.M., 1990, Effect of turbulence on Price AA meter rotors, in Chang, H.H. and Hill, J.C., eds., Hydraulic Engineering-Proceedings of the 1990 National Conference July 30 - Aug. 3, 1990, San Diego: New York, American Society of Civil Engineers, p. 909-914.

1992, Characteristics of U.S. Geological Survey discharge measurements for water year 1990: U.S. Geological Survey Open-File Report 92-493, 79 p.
Golden, H.G. and Trotter, I.L., 1960, Discussion of A comparison of stream velocity meters, by F.W. Townsend and F.A. Blust: Journal of the Hydraulics Division-Proceedings of the American Society of Civil Engineers, v. 86, no. HY9, p. 155-156.

Griffiths, G., 1979, The effect of turbulence on the calibration of electromagnetic current sensors and an approximation of their spatial response: Institute of Oceanographic Sciences Report No. 68, (unpublished manuscript), $14 \mathrm{p}$.

Groat, B.F., 1913, Characteristics of cup and screw current meters-Performance of these meters in tailraces and large mountain streams-Statistical synthesis of discharge curves, with discussions: American Society of Civil Engineers Transactions, v. 76, p. 819-870.

1916, Chemi-hydrometry and its applications to the precise testing of hydro-electric generators, part 5 of 5, with discussions: American Society of Civil Engineers Transactions, v. 80, p. 1231-1271.

Grover, N.C., 1931, Discussion of Effect of turbulence on the registration of current meters, by D.L. Yarnell and F.A. Nagler, 1931: American Society of Civil Engineers Transactions, v. 95, p. 806-811.

Hjalmarson, H.W., 1965, Price current meter and instrument characteristics: Water-Resources Bulletin, May 1965, p. 20-23.

1967, Effect of transverse velocity on the Price current meter: Water-Resources Bulletin, April-June 1967, p. 26-27.

Horton, R.E., 1931, Discussion of Effect of turbulence on the registration of current meters, by D.L. Yarnell and F.A. Nagler, 1931: American Society of Civil Engineers Transactions, v. 95, p. 840-854.

Hoyt, J.C., 1910, The use and care of the current meter, as practiced by the United States Geological Survey, with discussions: American Society of Civil Engineers Transactions, v. 66, p. 70-134.

1934, Tests of current velocity meters and their performance: The Canadian Engineer, v. 67, no. 17, p. 3-7.

Jepson, P., 1967, Currentmeter errors under pulsating flow conditions: Journal of Mechanical Engineering Science, v. 9, no. 1, p. 45-54.

Johnson, R.L., 1966, Laboratory determination of current meter performance, Technical Report No. 843-1: Bonneville, Oregon, Division Hydraulic Laboratory, North Pacific U. S. Army Engineering Division, Corps of Engineers, 33 p.

Kallio, N.A., 1966a, Effects of vertical motion on current meters: U.S. Geological Survey Water-Supply Paper 1869-B, 20 p. 
1966b, Some precautions to the use of the component propeller with the Ott current meter: Water-Resources Bulletin, Oct.-Dec. 1966, p. 5-8.

Kolupaila, Steponas, 1949, Recent developments in current-meter design: Transactions of the American Geophysical Union, v. 30, no. 6, p. 916-918. 1958 , Use of current meters in turbulent and divergent channels in Proceedings and Reports of the International Association of Scientific Hydrology, General Assembly at Toronto 1957, Gentbrugge, 1958: Toronto, International Association of Scientific Hydrology, p. 437-444.

1960, Early history of hydrometry in the United States: Journal of the Hydraulics DivisionProceedings of the American Society of Civil Engineers, v. 86, no. HY1, p. 1-51.

1961, Bibliography of hydrometry: Notre Dame, Ind, University of Notre Dame Press, 975 p.

Kulin, Gershon, 1977, Some error sources in Price and Pygmy current meter traverses, in Irwin, Lafayette K., ed., Flow measurement in open channels and closed conduits, v. 1 and 2: National Bureau of Standards Special Publication 484, p. 123-144.

Kulin, Gershon, and Compton, P.R., 1975, A guide to methods and standards for the measurement of water flow: National Bureau of Standards Special Publication 421, $89 \mathrm{p}$.

LaCornu, E.J., Hanson, R.L., and Cruff, R.W., 1965, Comparison of discharge measurements made by integration- and point-velocity methods: WaterResources Bulletin, Aug. 1965, p. 17-19.

Leach, H.R., 1931, Discussion of Effect of turbulence on the registration of current meters, by D.L. Yarnell and F. A. Nagler, 1931: American Society of Civil Engineers Transactions, v. 95, p. 816-826.

Leonard, R.W., 1965, Discussion of Flow measurements at Columbia River power plants, by N.A. Dodge, 1965: Journal of the Hydraulics DivisionProceedings of the American Society of Civil Engineers, v. 91, no. HY6, p. 194-200.

Lippincott, J.B., 1902, Discussion of Current meter and weir discharge comparisons, by E.C. Murphy, 1902: American Society of Civil Engineers Transactions, v. 47 , p. $383-387$.

Marsh-McBirney, 1988, Directional sensitivity of oceanographic flow sensors: Marsh-McBirney Technical Note 5, 9 p.

McDonald, C.C., 1940, Salt-velocity method, comparison with current-meter measurements and weir formula: Water-Resources Bulletin, August 1940, p. 147-151.
Mero, Thomas; Appell, Gerald; and McQuivey, R.S., 1977, Marine dynamics and its effects on current measuring transducers, in Irwin, L.K., ed., Flow measurement in open channels and closed conduits, v. 1 and 2: National Bureau of Standards Special Publication 484, p. 109-122.

Miller, C.H., 1902, Discussion of Current meter and weir discharge comparisons, by E.C. Murphy, 1902: American Society of Civil Engineers Transactions, v. 47 , p. $379-380$.

Murphy, E.C., 1901, Tests to determine the accuracy of discharge measurements of New York state canals and feeders, in Operations at river stations, 1900: Water-Supply and Irrigation Papers of the United States Geological Survey, no. 47, p. 18-29.

1902, Current meter and weir discharge comparisons, with discussions: American Society of Civil Engineers Transactions, v. 47, p. 371-391.

1904, Accuracy of stream measurements: WaterSupply and Irrigation Papers of the United States Geological Survey, no. 95.

Nagler, Forrest, 1931, Discussion of Effect of turbulence on the registration of current meters, by D.L. Yarnell and F.A. Nagler, 1931: American Society of Civil Engineers Transactions, v. 95, p. 834-840.

Nettleton, G.H., 1931, Discussion of Effect of turbulence on the registration of current meters, by D.L. Yarnell and F.A. Nagler, 1931: American Society of Civil Engineers Transactions, v. 95, p. 812-814.

Newell, F.H., 1899, Rating the meters: U.S. Geological Survey nineteenth annual report, 1897-98, Part IVHydrology: United States Geological Survey, p. 2730.

Ott, Ludwig A., 1931, Discussion of Effect of turbulence on the registration of current meters, by D.L. Yarnell and F.A. Nagler, 1931: American Society of Civil Engineers Transactions, v. 95, p. 826-829.

Pelletier, P.M., 1988, Uncertainties in the single determination of river discharge-A literature review: Canadian Journal of Civil Engineering, v. 15 , no. 5 , p. $834-850$.

Pierce, C.H., 1941, Investigations of methods and equipment used in stream gaging, Part 1Performance of current meters in shallow depth: U.S. Geological Survey Water-Supply Paper 868-A, 35 p.

Raffel, D.N., 1965, Discussion of Spillway discharge coefficients for Rock Island Dam, by C.C. Lomax, 1965: Journal of the Hydraulics DivisionProceedings of the American Society of Civil Engineers, v. 91, no. HY6, p. 214-217. 
Rantz, S.E. and others, 1982, Measurement and computation of streamflow, Volume 1Measurement of stage and discharge: U.S. Geological Survey Water-Supply Paper 2175, $284 \mathrm{p}$.

Robson, A.D., 1954, The effect of water temperature upon the calibration of a current meter: Transactions of the American Geophysical Union, v. 35, p. 647648.

Rohwer, Carl, 1931, Discussion of Effect of turbulence on the registration of current meters, by D.L. Yarnell and F.A. Nagler, 1931: American Society of Civil Engineers Transactions, v. 95, p. 797-800. 1933, The rating and use of current meters: Colorado Agricultural College Technical Bulletin 3, $133 \mathrm{p}$.

Rumpf, C.P., 1914, An investigation of the use and rating of the current meter: Engineering News, v. 71, no. 20, p. 1083-1084.

Schubauer, G.B., and Mason, M.A., 1937, Performance characteristics of a water current meter in water and in air: Journal of Research of the National Bureau of Standards, Research Paper RP981, v. 18, p. 351- 360.

Scobey, F.C., 1914, Behavior of cup current meters under conditions not covered by standard ratings: Journal of Agricultural Research, v. 2, no. 2, p. 77-83.

Smith, J.D., 1978, Measurement of turbulence in ocean boundary layers in Proceedings of a Working Conference on Current Measurement, January 11-13, 1978, University of Delaware, Newark, Del.: The National Oceanic and Atmospheric Administration and University of Delaware, p.95-128.

Staubli, T., and Hegland, M., 1982, Current meter calibration and three-dimensional displacement effects: Journal of Hydraulic Research, v. 20, no. 5, p. 453-464.

Szigyarto, Z., 1965, Current meter investigations at the Research Institute for Water Resources, Budapest, Hungary, Part 1-Effect of turbulence on velocity measurements with current meters: International Current Meter Group Report 14, 27 p.
Thibodeaux, K.G., and Futrell, J.C., Jr., 1987, The effects of vertical motion on the performance of current meters: U.S. Geological Survey Water-Resources Investigations Report 87-4147, $53 \mathrm{p}$.

Townsend, F.W. and Blust, F.A., 1960, A comparison of stream velocity meters: Journal of the Hydraulics Division-Proceedings of the American Society of Civil Engineers, v. 86, no. HY4, p. 11-19.

U.S. Geological Survey, 1931, Discharge measurements with Price and Hoff current meters: Water-Resources Bulletin, Sept. 1931, p. 20. 1933a, Comparison of Price and Hoff current meters: Water-Resources Bulletin, Jan. 1933, p. 5152.

1933b, Discharge by current meter and orifice-weir: Water-Resources Bulletin, Jan. 1933, p. 29-30. 1933c, Simultaneous discharge measurements using Price and Hoff current meters: Water-Resources Bulletin, April 1933, p. 32-33.

1933d, Comparison between Price meter and Ott propeller-type meter: Water-Resources Bulletin, Aug. 1933, p. 34.

Van Vliet, Richard, 1931, Discussion of Effect of turbulence on the registration of current meters, by D.L. Yarnell and F.A. Nagler, 1931: American Society of Civil Engineers Transactions, v. 95, p. 854-856.

Wood, G.K., 1946, Stream-flow records, accuracy of: Water-Resources Bulletin, May 1946, p. 92-96.

Woster, H.C., 1933, Comparison of Price and Hoff current meters: Water-Resources Bulletin, April 1933, p. 57-61.

Yarnell, D.L. and Nagler, F.A., 1931, Effect of turbulence on the registration of current meters, with discussions: American Society of Civil Engineers Transactions, v. 95 , p. $766-860$. 
APPENDIX 


\section{APPENDIX. ADDITIONAL PHOTOGRAPHS}

Included in this appendix are photographs of some of the meter types described in the literature. These photographs are not of the actual meters tested, but are examples of the tested meters. Figure 3 (Hoyt 1910) is a collection of Price-type meters of the early 1900's. In the photograph, the meter labeled as a meter number 1 is a large Price meter; number 2 is an acoustic Price meter; number 3 is an original small Price meter; and numbers 4, 5, and 6 are small Price meters. Figure 4 (Murphy 1902) is a close-up view of a large Haskell meter and a small Price meter. Figure 5 (Hoyt 1910) is a collection of various Haskell meters used in the early 1900's. The various meter types shown are not known by the author. Figure 6 is a close-up view of a large Haskell meter. Figure 7 (Hoyt 1910) is a photograph of an Ott meter used in the early 1900 's. Included in this photograph are three types of rotors. Figure 8 is a photograph of a Hoff meter with a four-bladed rotor attached and a three-bladed rotor near by. Figure 9 is a photograph of a Price type Lallie meter. Figure 10 is a collection of current meters from the 1920 's. The meters of note are the meters on the top shelf. These meters are, from left to right, a large Haskell meter, a small Haskell meter, a Fteley and Stearns meter, and a small Price 622 type meter. Figure 11 is a photograph of a Price type pygmy meter. Figure 12 is a photograph of a vane Ice meter. Figure 13 is a photograph of a
Neyrpic meter in a cable suspension arrangement. Figure 14 is a photograph of the head of a two-dimensional EG\&G (Neil Brown) acoustic current meter. Figures 15 and 16 are photographs of Marsh-McBirney electromagnetic current meter probes. Figure 15 is the one-dimensional tear-drop shaped probe of the model 201 and newer model 2000. Figure 16 is a two-dimensional spherical probe with protruding electrodes.

Also included in this appendix are photographs of some of the current meter inventors and builders and some of the individuals who conducted tests on current meters. Figure 17 is a photograph of W.G. Price, the inventor of the Price-type current meter. Figure 18 is a photograph of E.E. Haskell, the inventor of the Haskell meter. Figure 19 is a photograph of Albert Ott, founder of the A. Ott company. Figure 20 is Ludwig A. Ott. Figure 21 is a photograph of Stephonas Kolupaila the inventor of the "A" component rotor for the Ott current meters. Figure 22 is a photograph of E.J. Hoff, the inventor of the Hoff meter.

Figure 23 is a photograph of the testing of a small Price current meter under vertical-oblique flow conditions. This photograph was taken in 1897. Figure 24 is a photograph of Frederick H. Newell; Figure 25 is Edward C. Murphy; Figure 26 is Benjamin F. Groat; Figure 27 is F.A. Nagler; Figure 28 is Carl Rohwer; Figure 29 is John C. Hoyt; and Figure 30 is a photograph of Arthur $\mathrm{H}$. Frazier. 


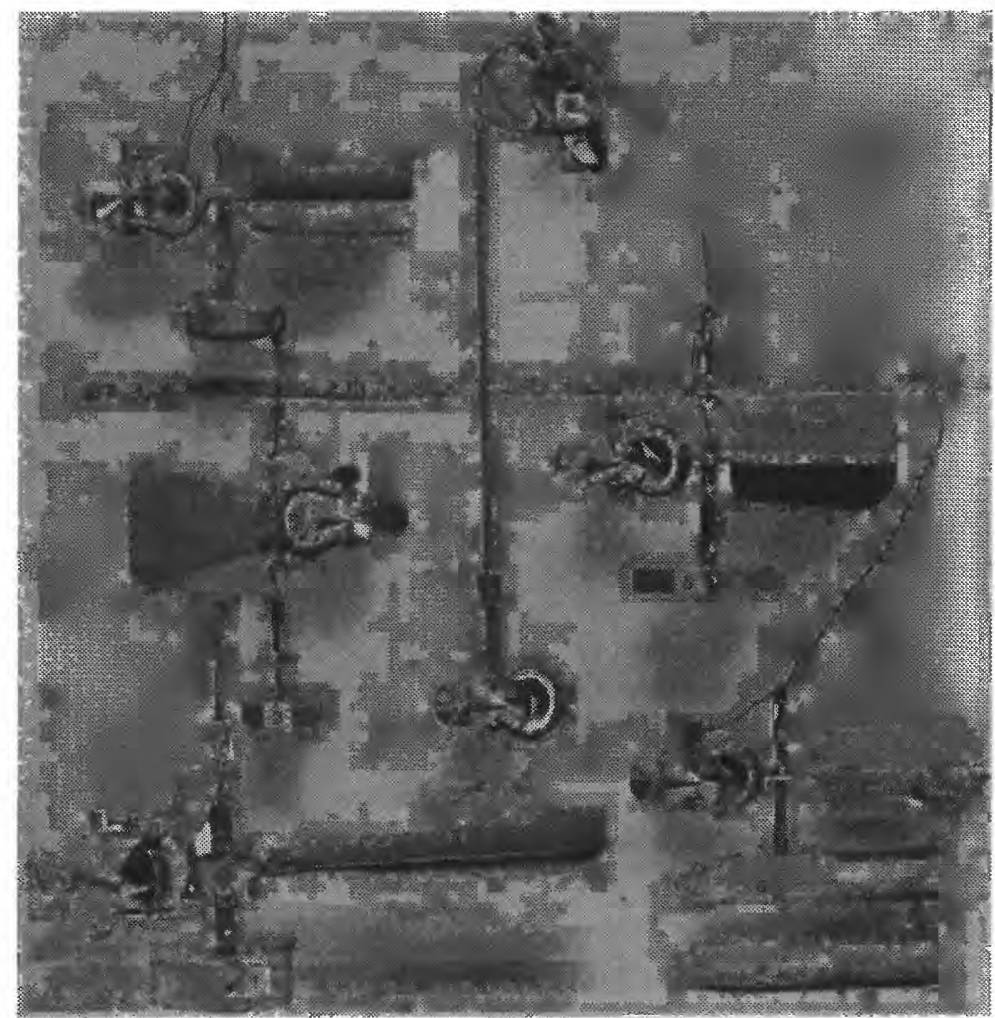

Figure 3. Collection of Price-type current meters from the early 1900's. [From Hoyt, 1910, plate III.]

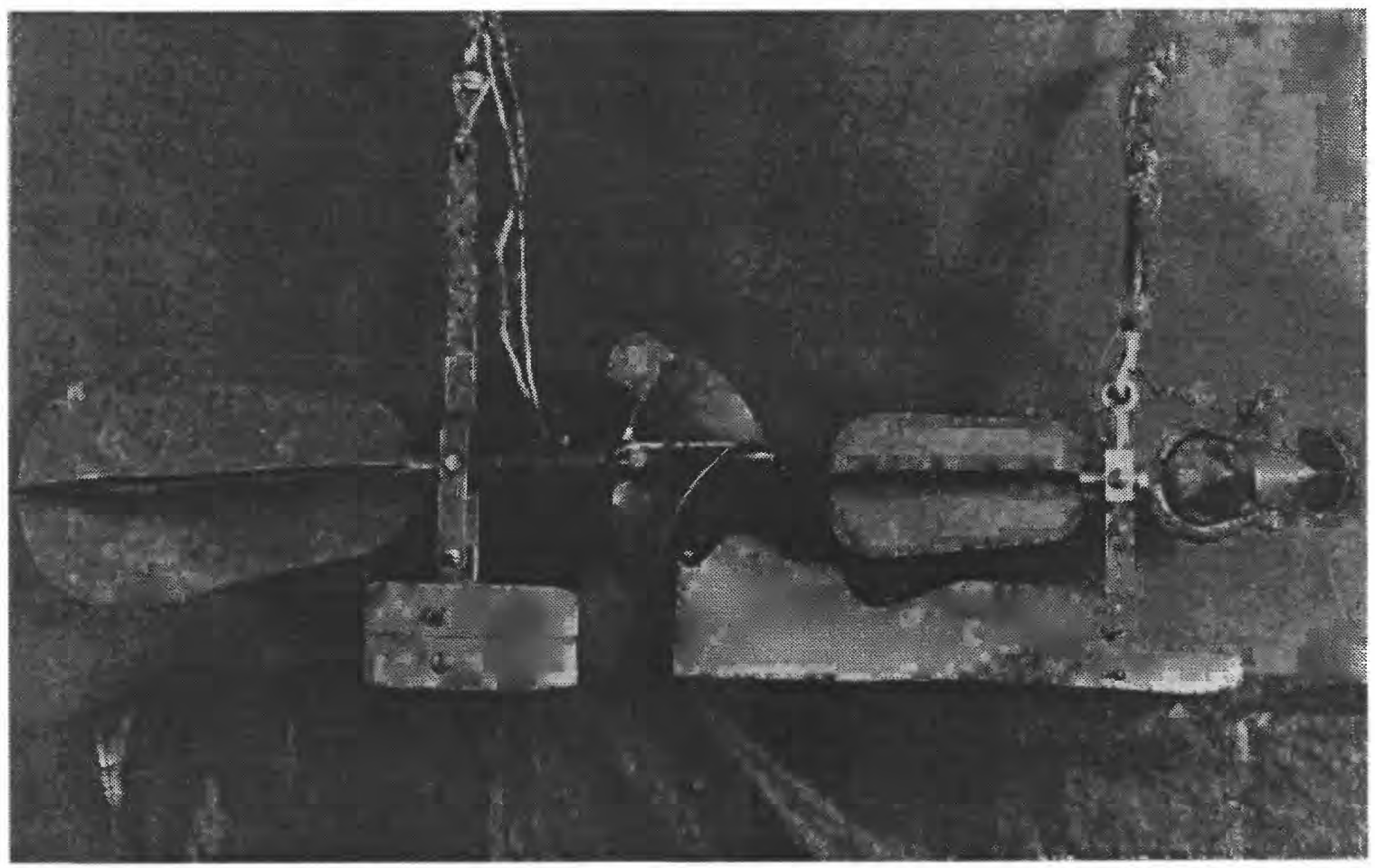

Figure 4. Large Haskell and small Price current meters. [From Murphy, 1902, plate XI.] 


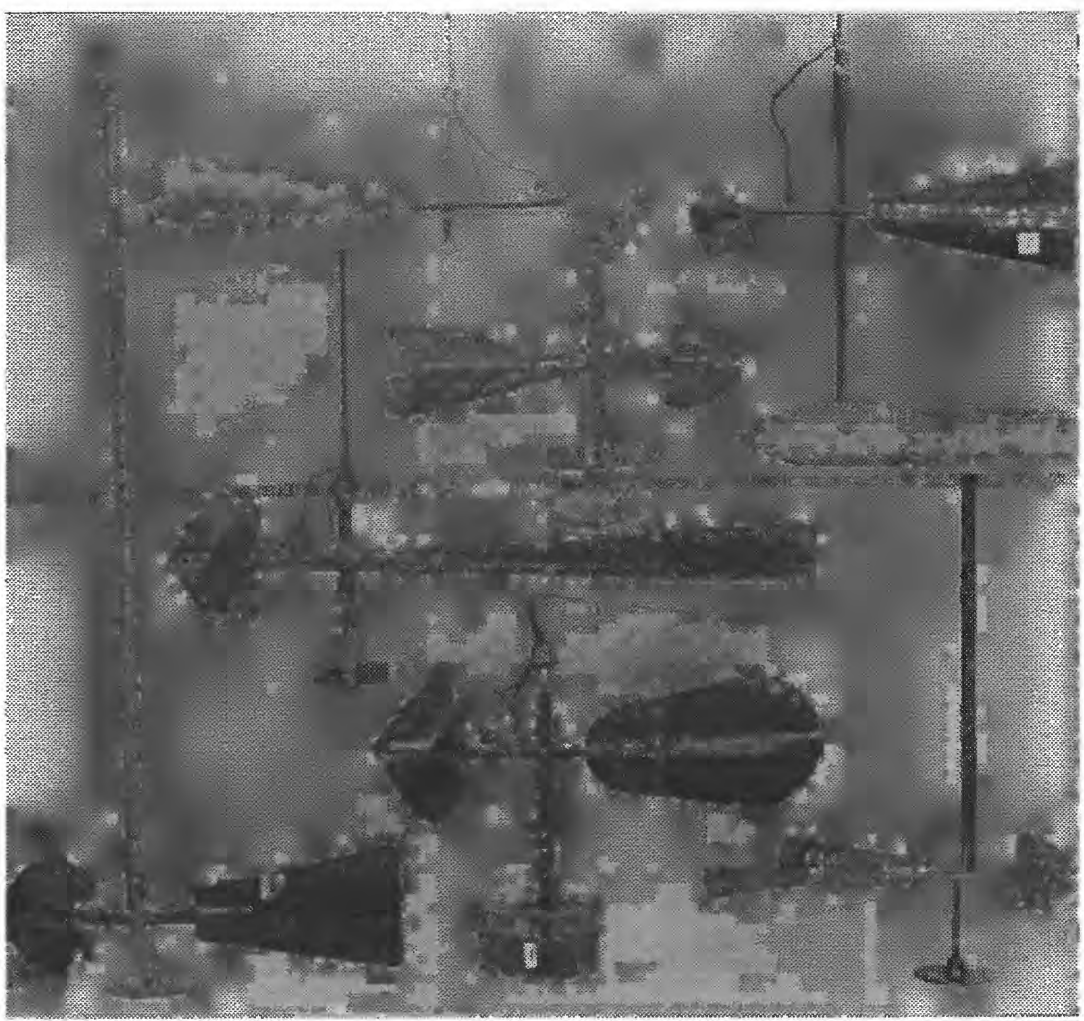

Figure 5. Collection of Haskell current meters from the early 1900's. [From Hoyt, 1910, plate II.]

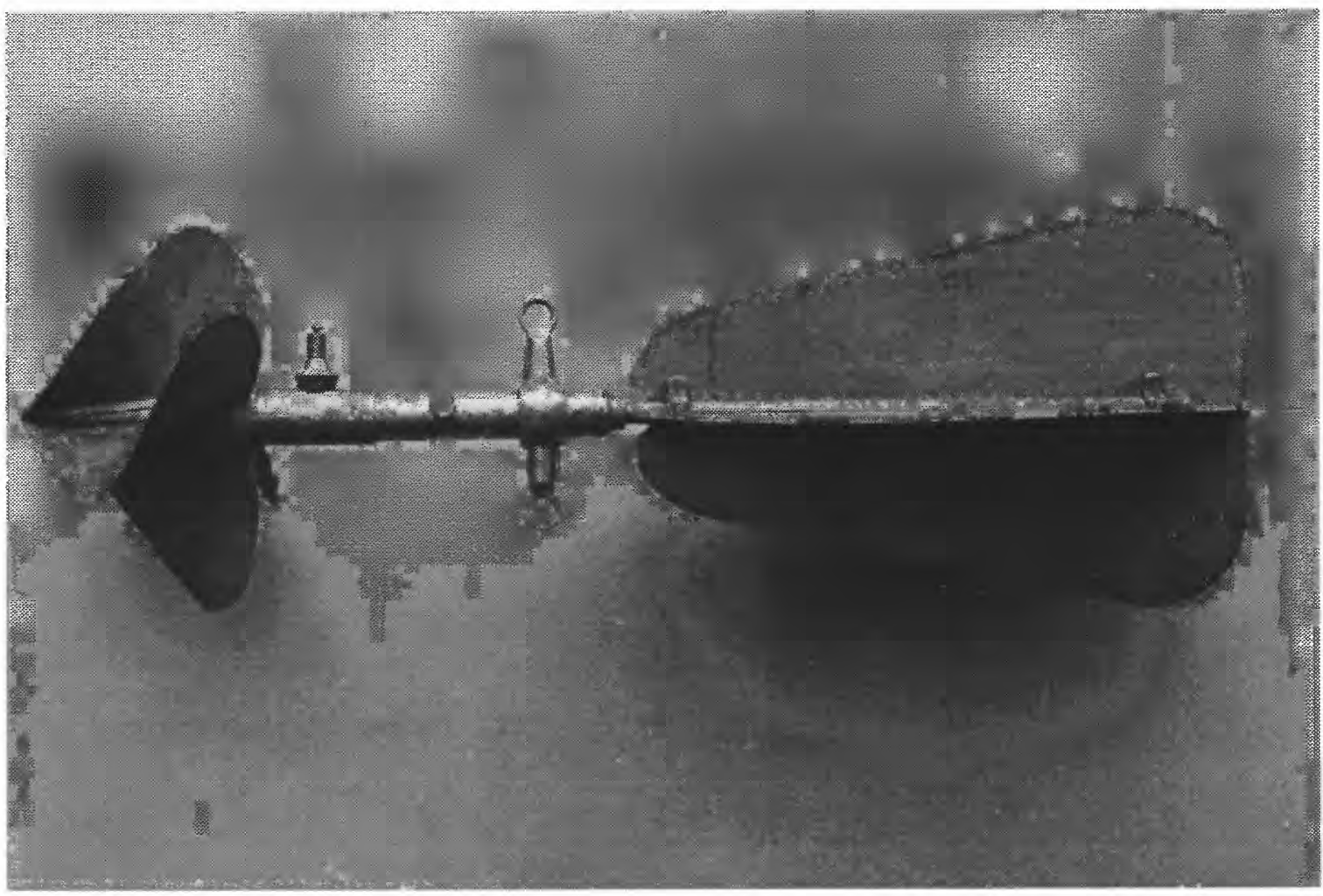

Figure 6. Large Haskell current meter. 

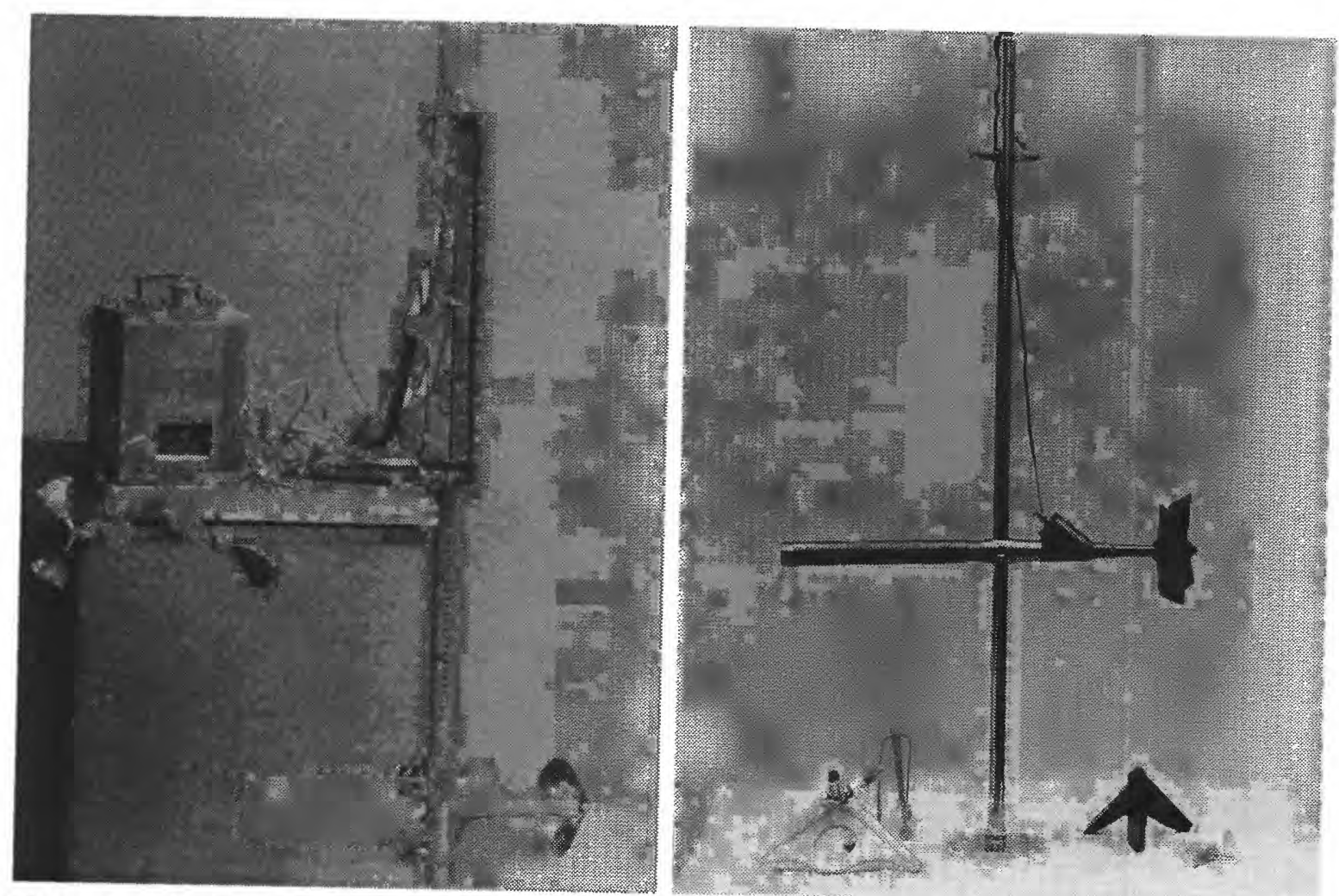

Figure 7. Ott current meter used in the early 1900's. [From Hoyt, 1910, plate VI.]

Figure 8. Hoff current meter with four- and threeblade rotors.

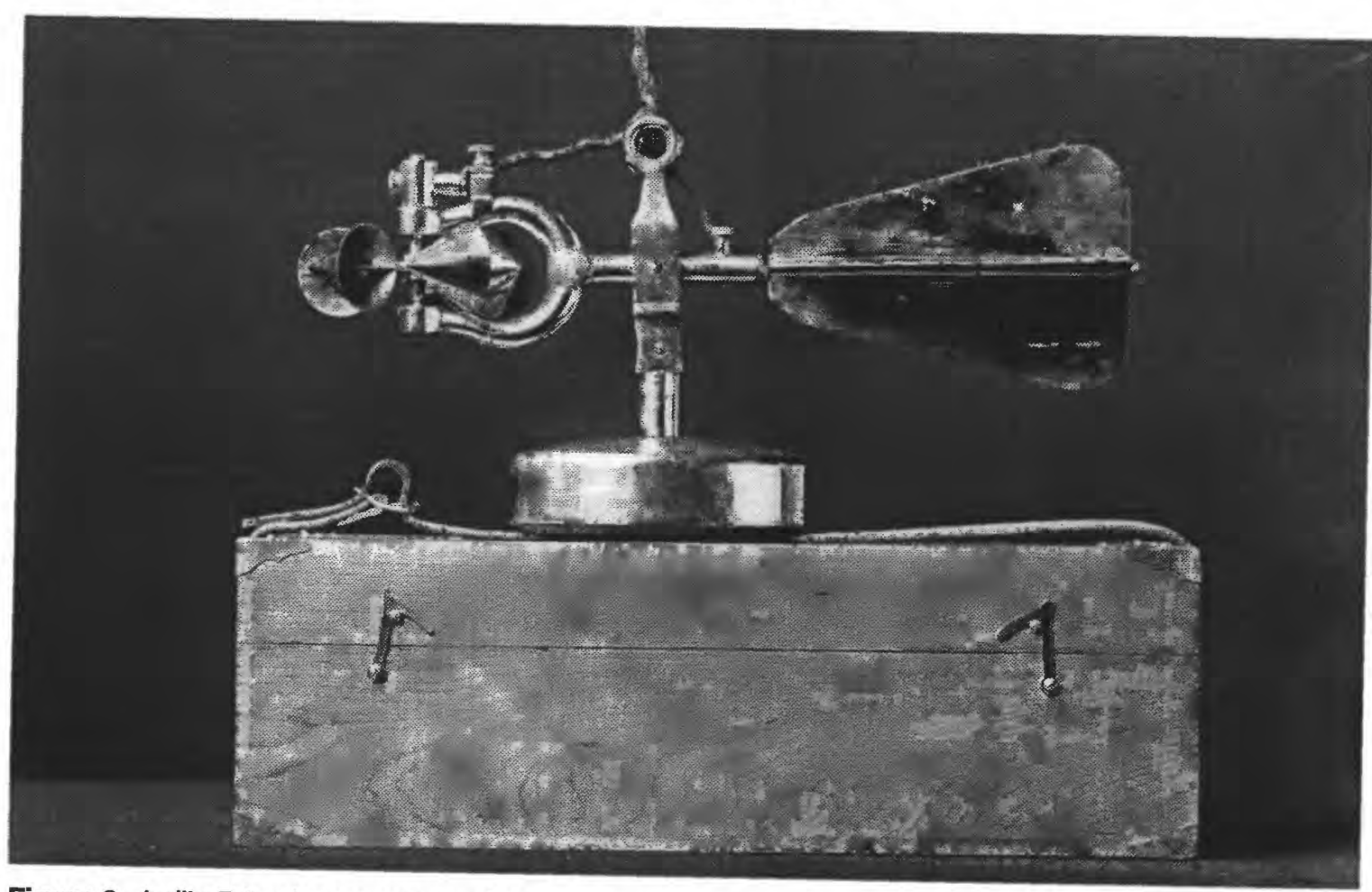

Figure 9. Lallie Price-type current meter. 


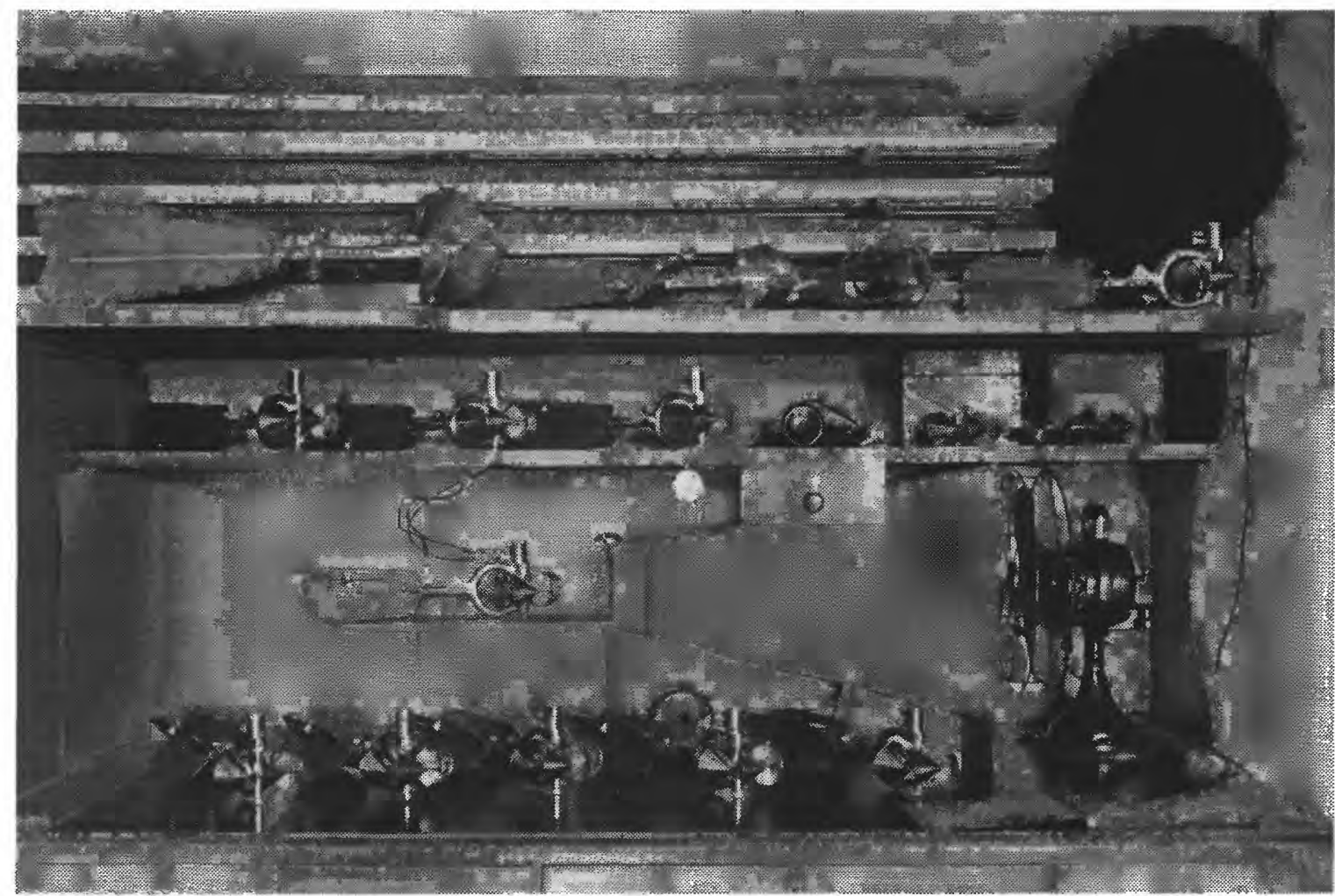

Figure 10. Collection of current meters from the 1920's. Top shelf (L-R) are a large Haskell, small Haskell, Fteley and Stearns, and Price 622 type meters.

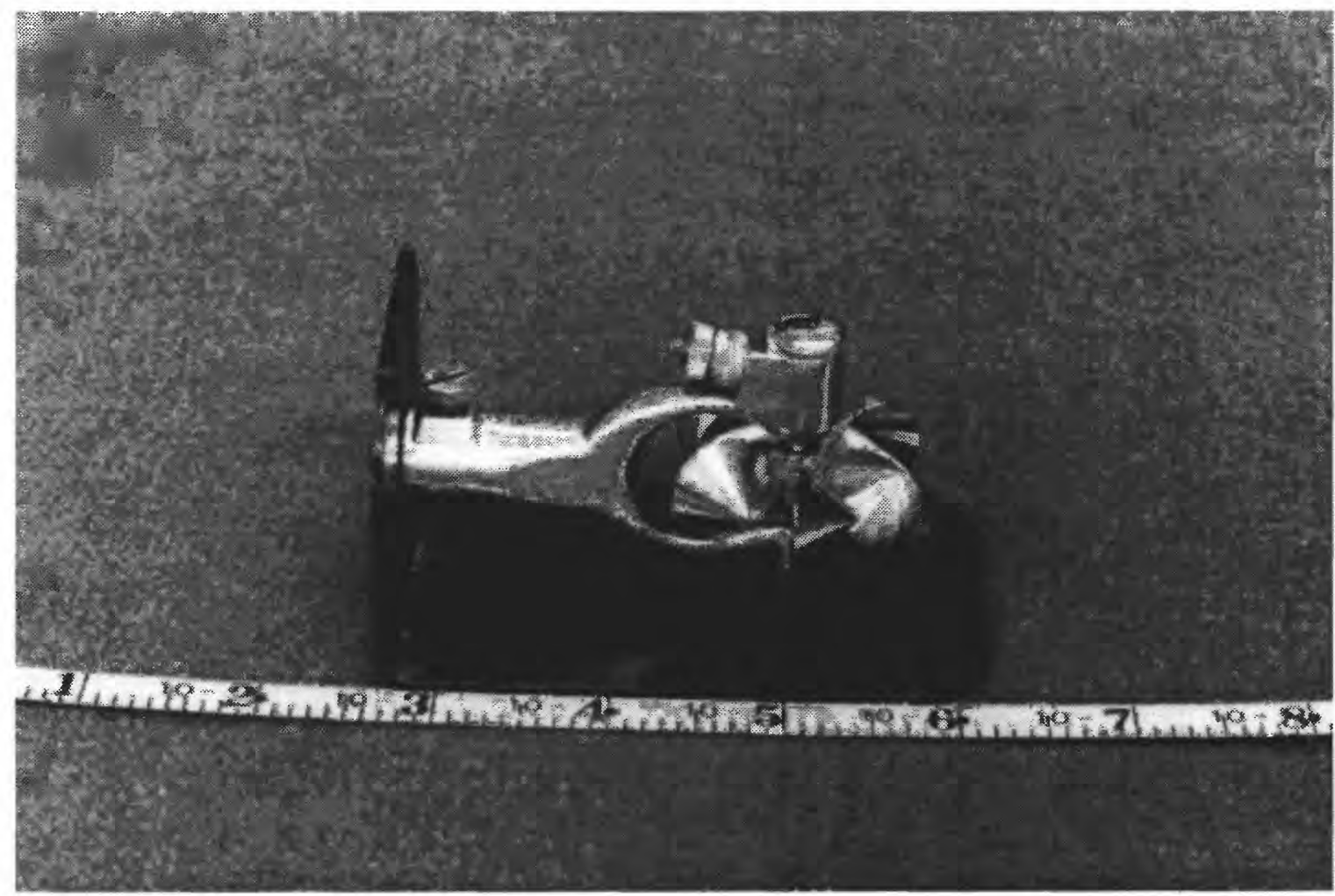

Figure 11. Price type pygmy current meter. 


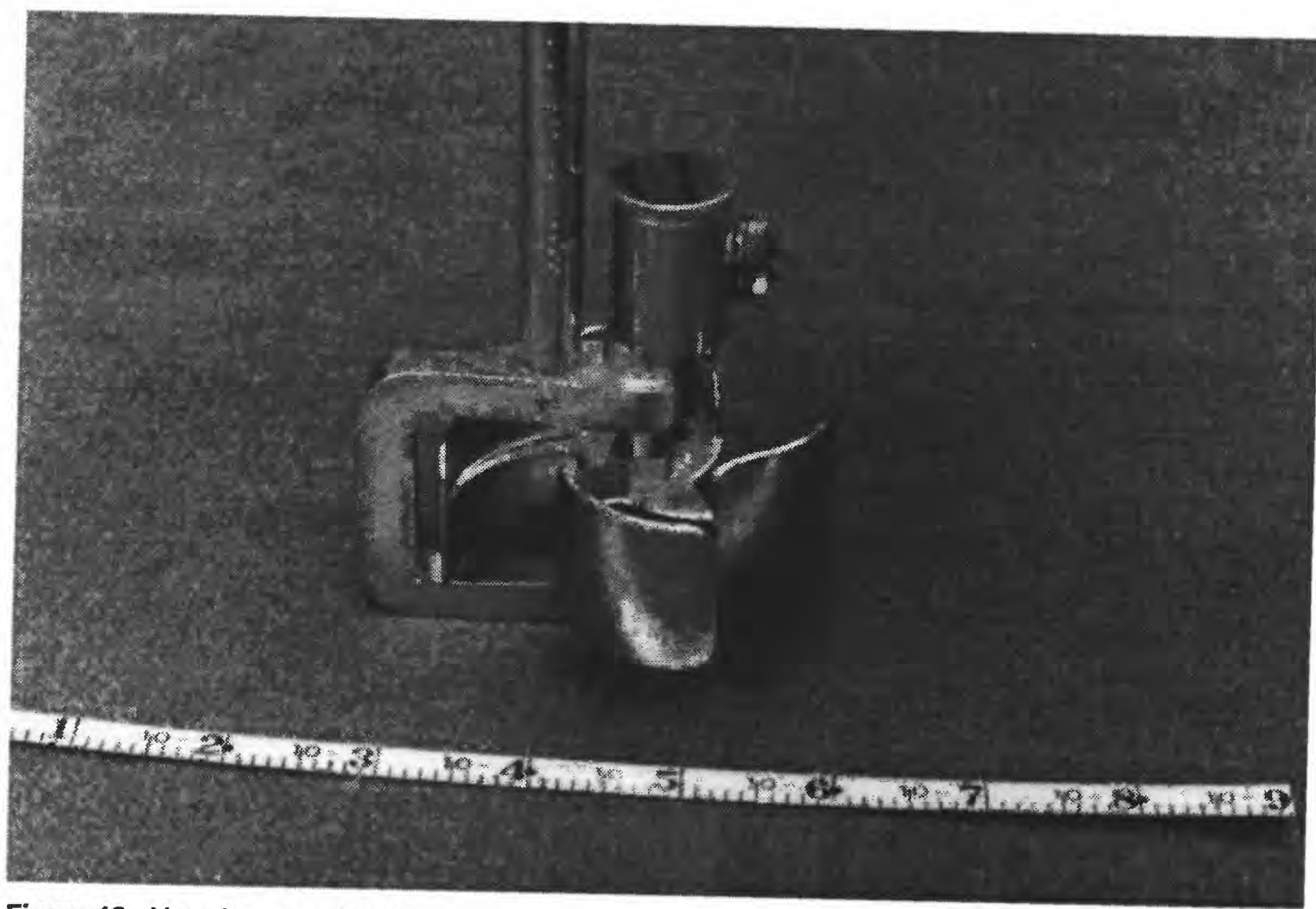

Figure 12. Vane ice current meter.

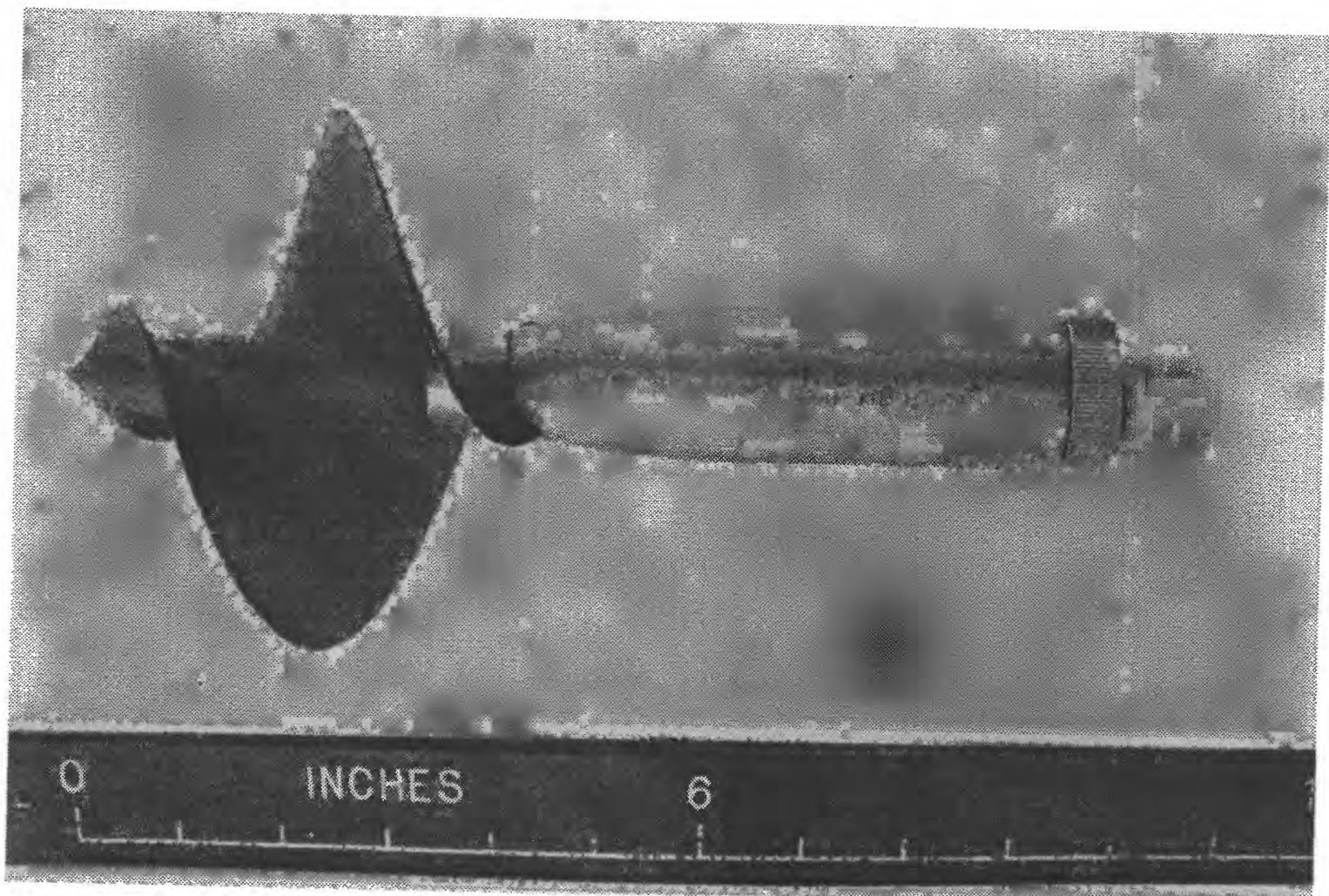

Figure 13. Neyrpic current meter. 


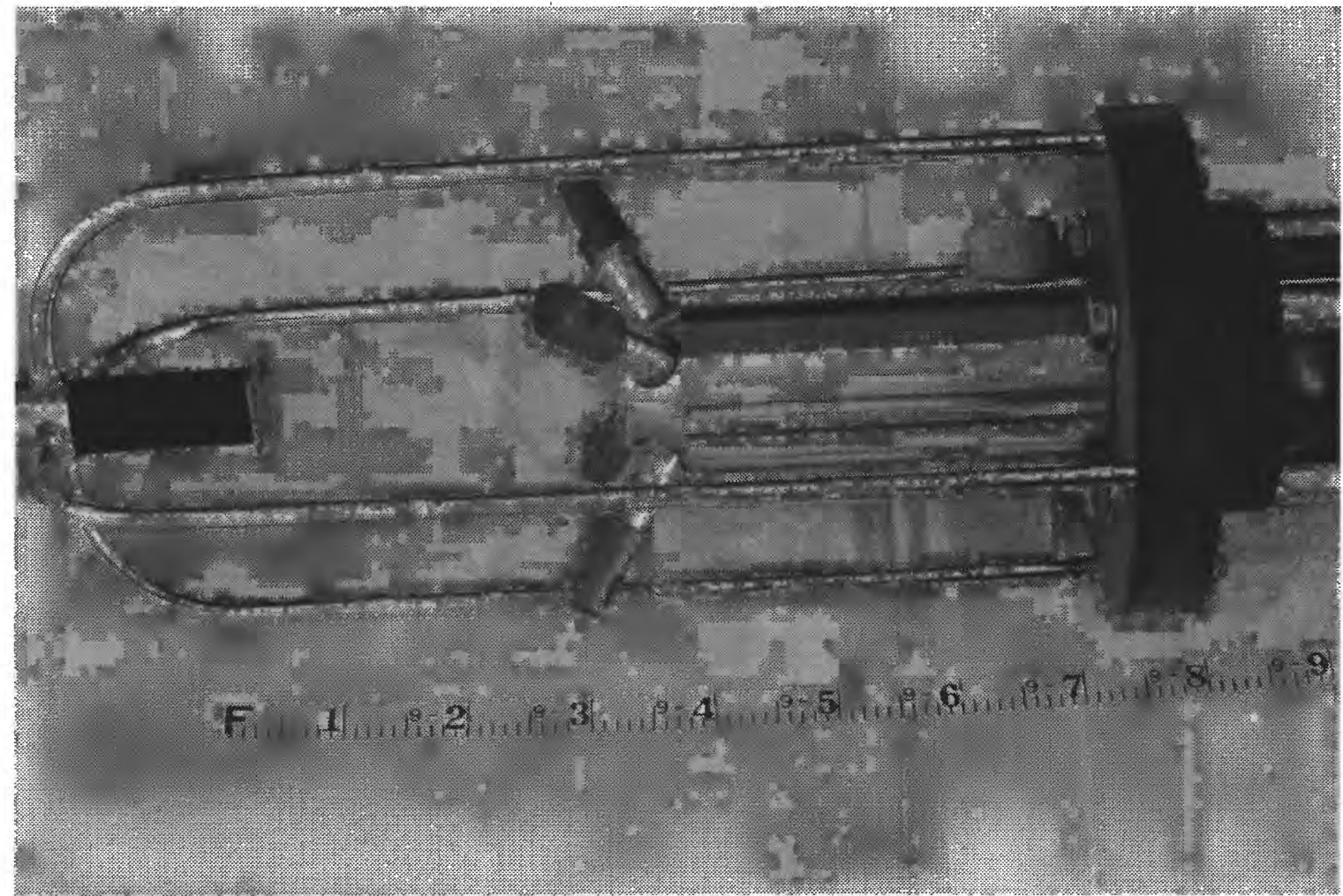

Figure 14. EG\&G (Neil Brown) two-dimensional acoustic current meter.

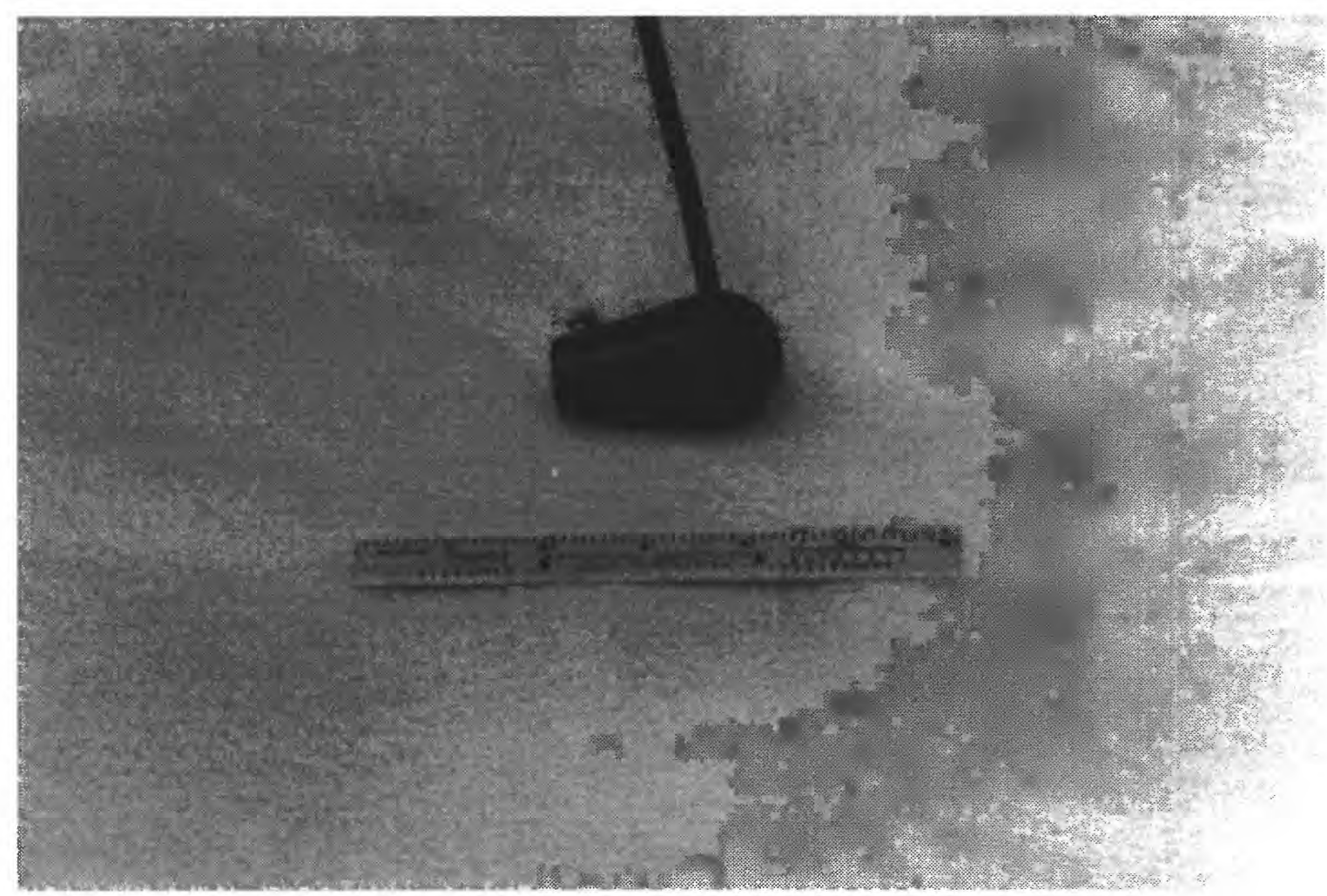

Figure 15. Marsh-McBirney one-dimensional electromagnetic tear-drop probe. 


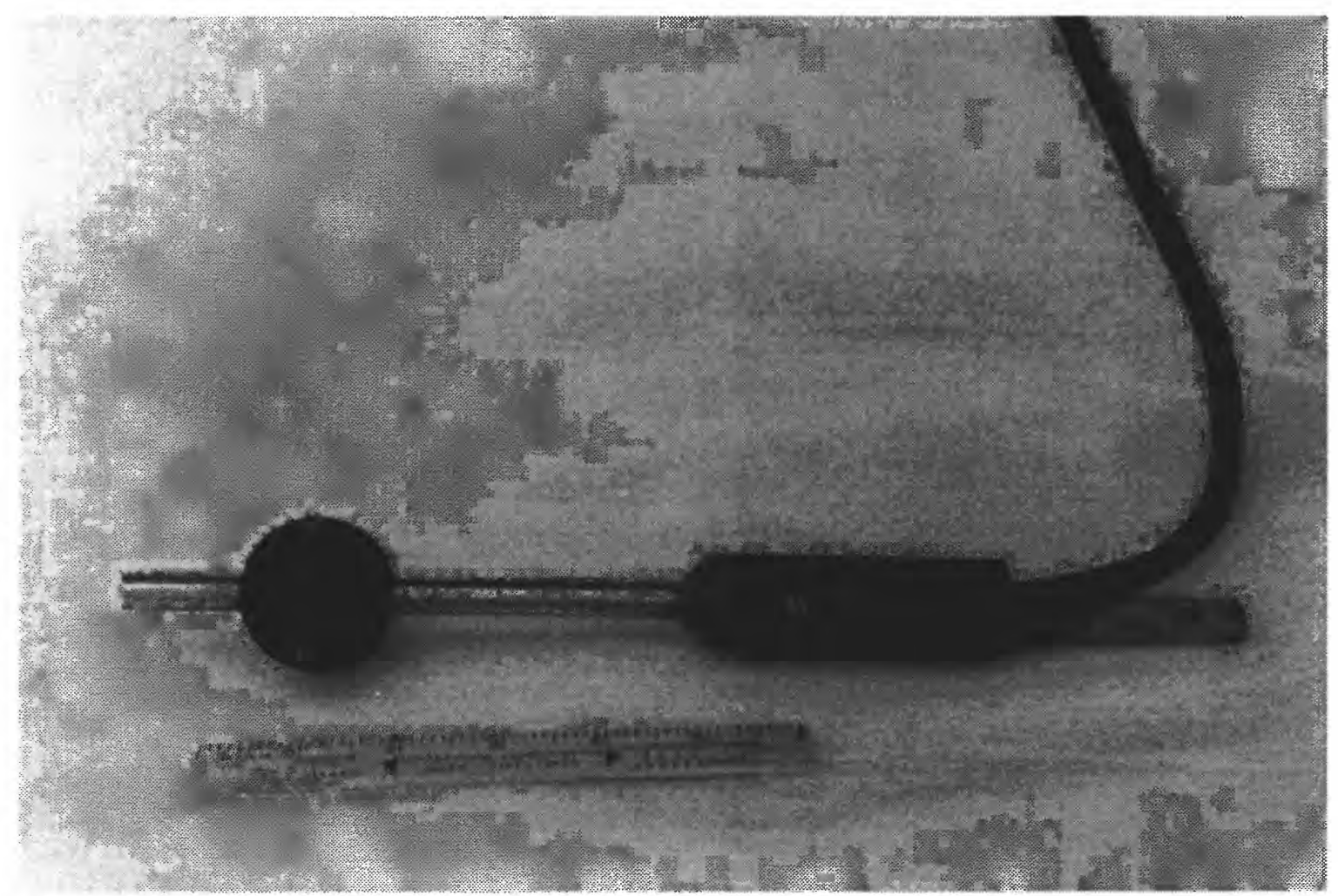

Figure 16. Marsh-McBirney two-dimensional electromagnetic spherical probe.
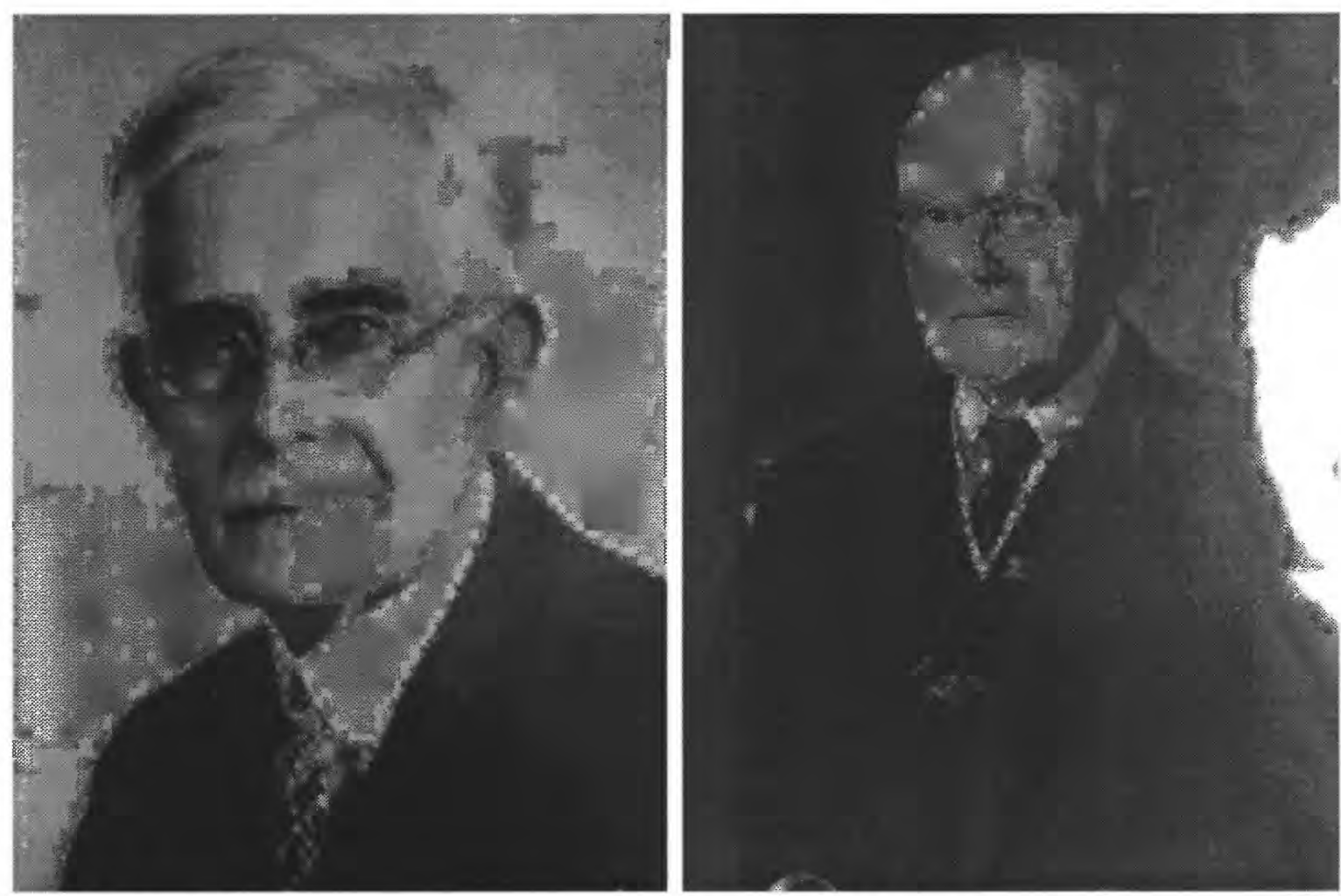

Figure 17. W.G. Price.

Figure 18. E.E. Haskell. 


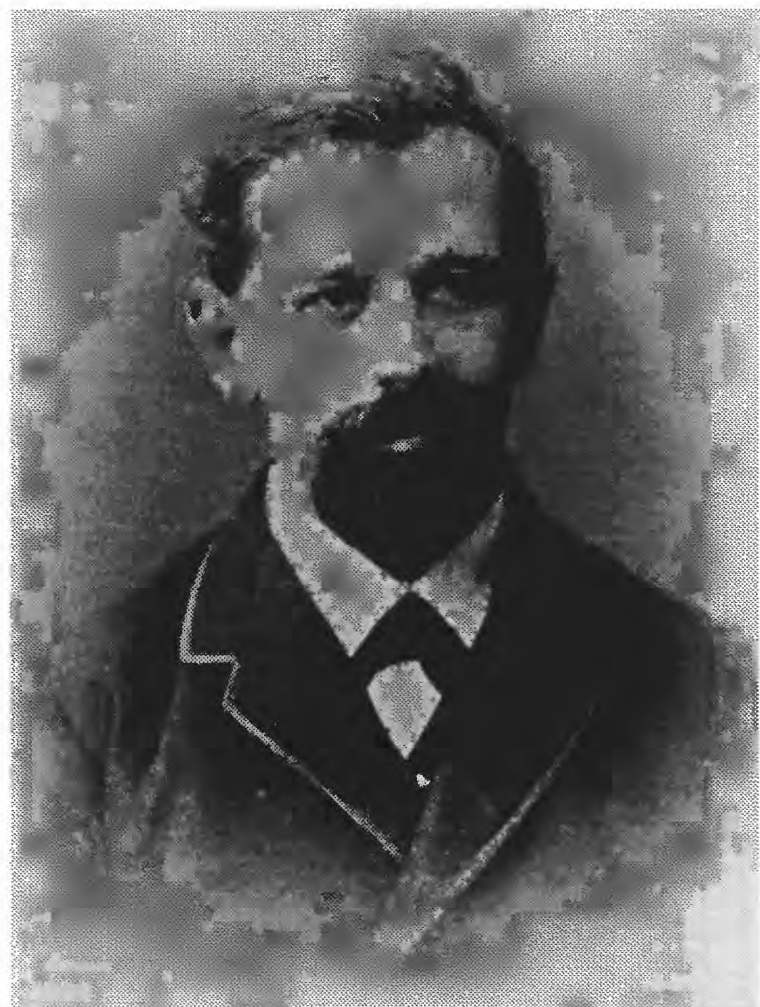

Figure 19. Albert Ott.

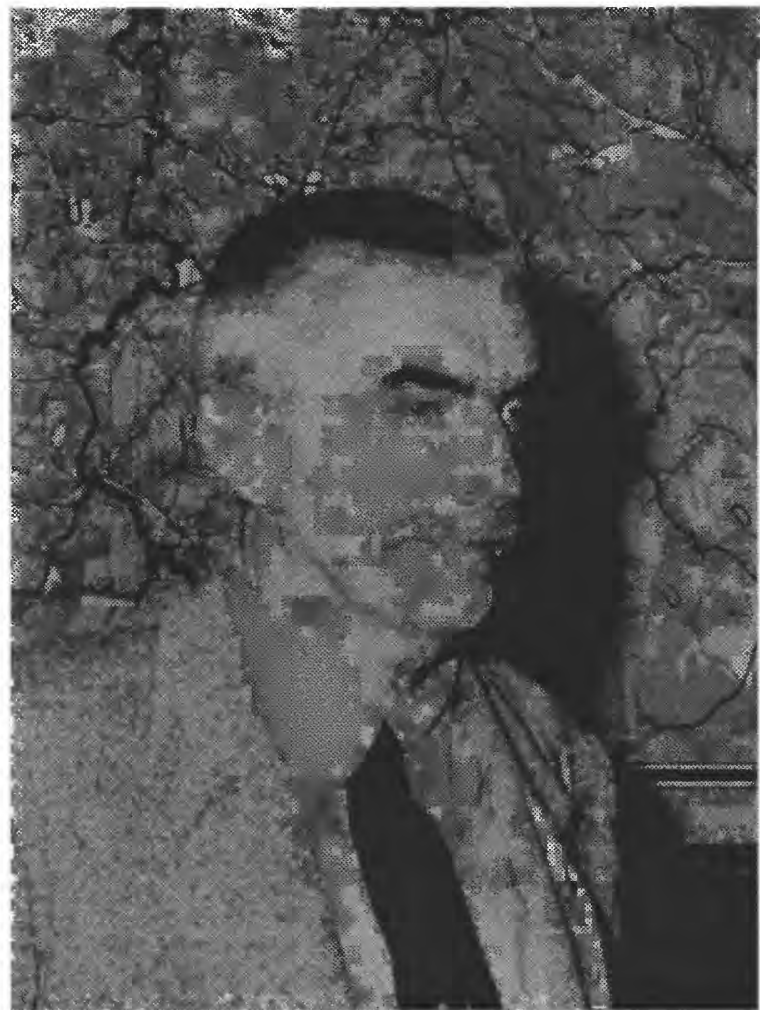

Figure 21. Stephonas Kolupaila.

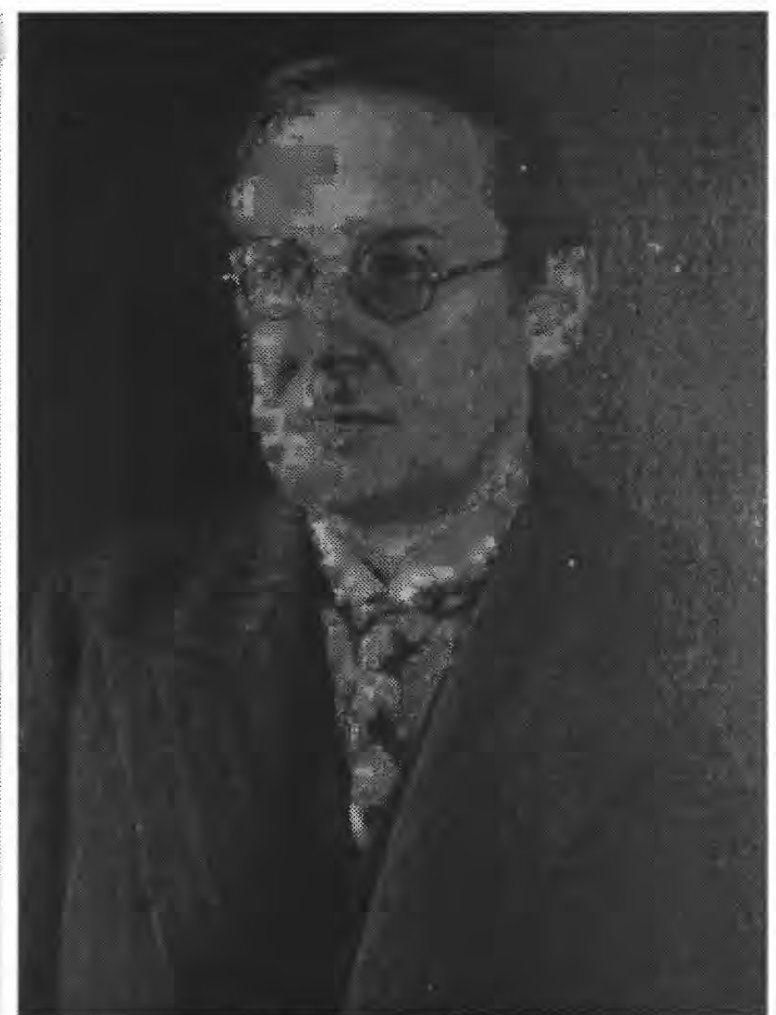

Figure 20. Ludwig A. Ott.

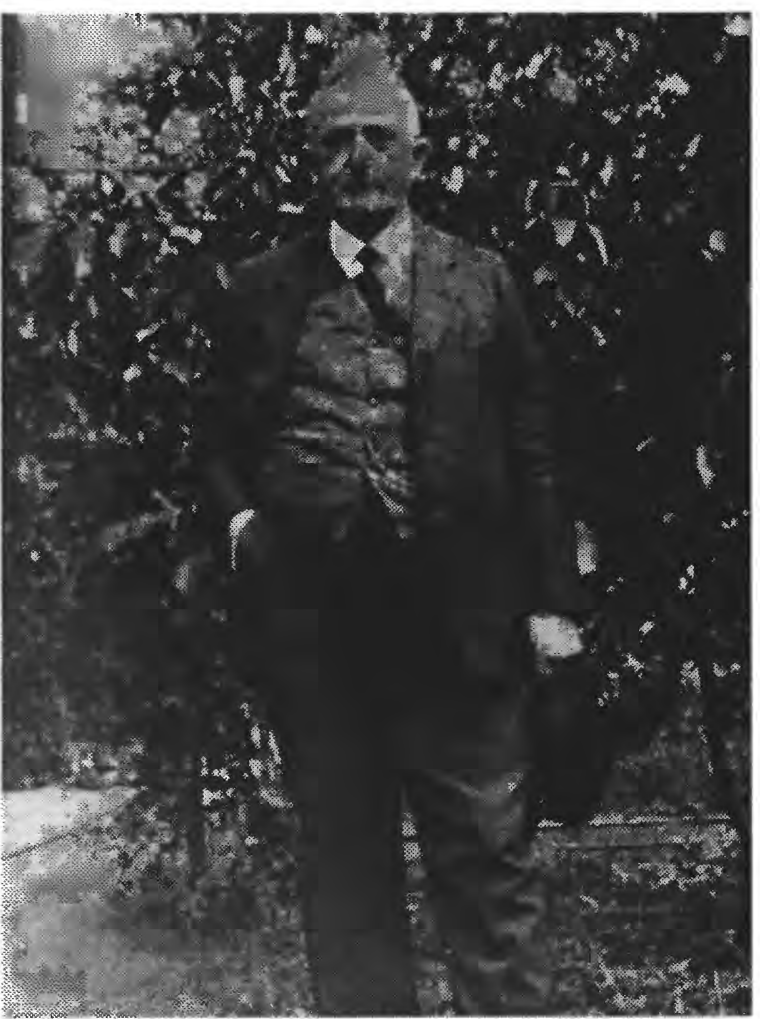

Figure 22. E.J. Hoff. 


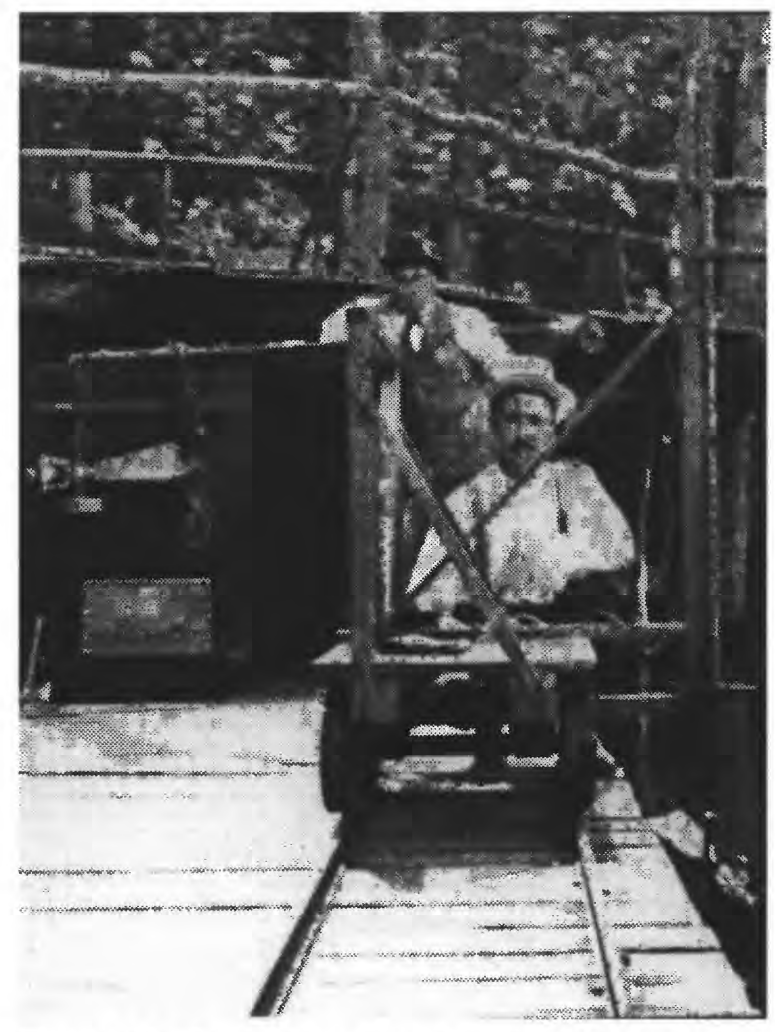

Figure 23. Small Price current meter being tested under vertical-oblique flow conditions.

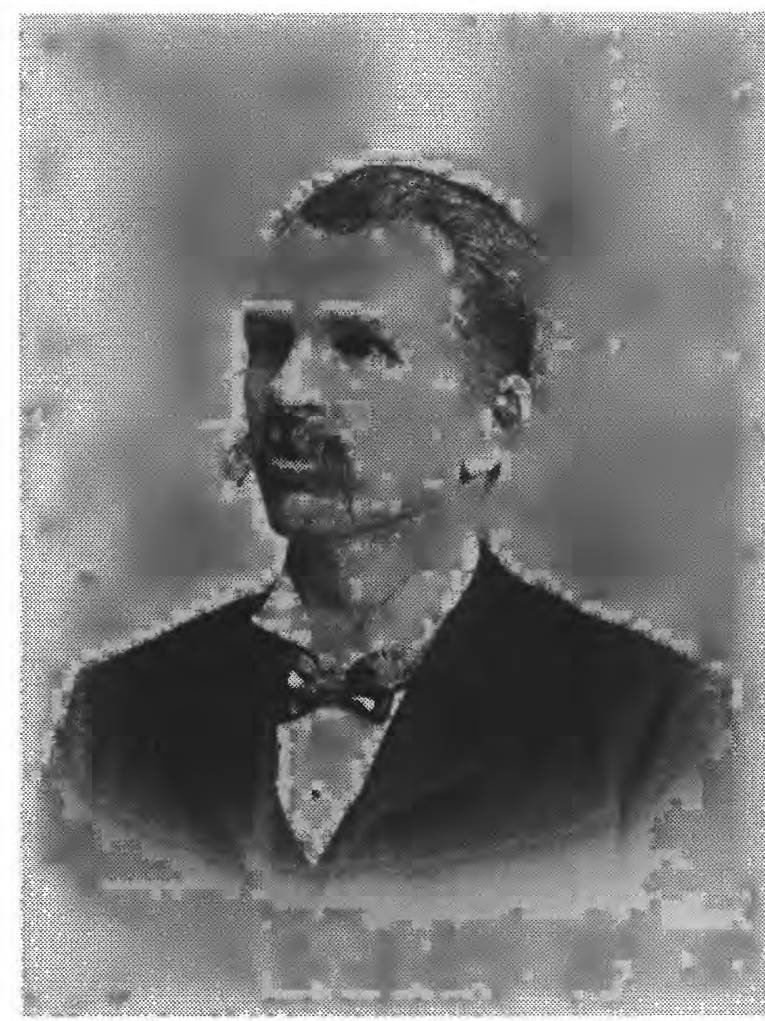

Figure 25. Edward C. Murphy.

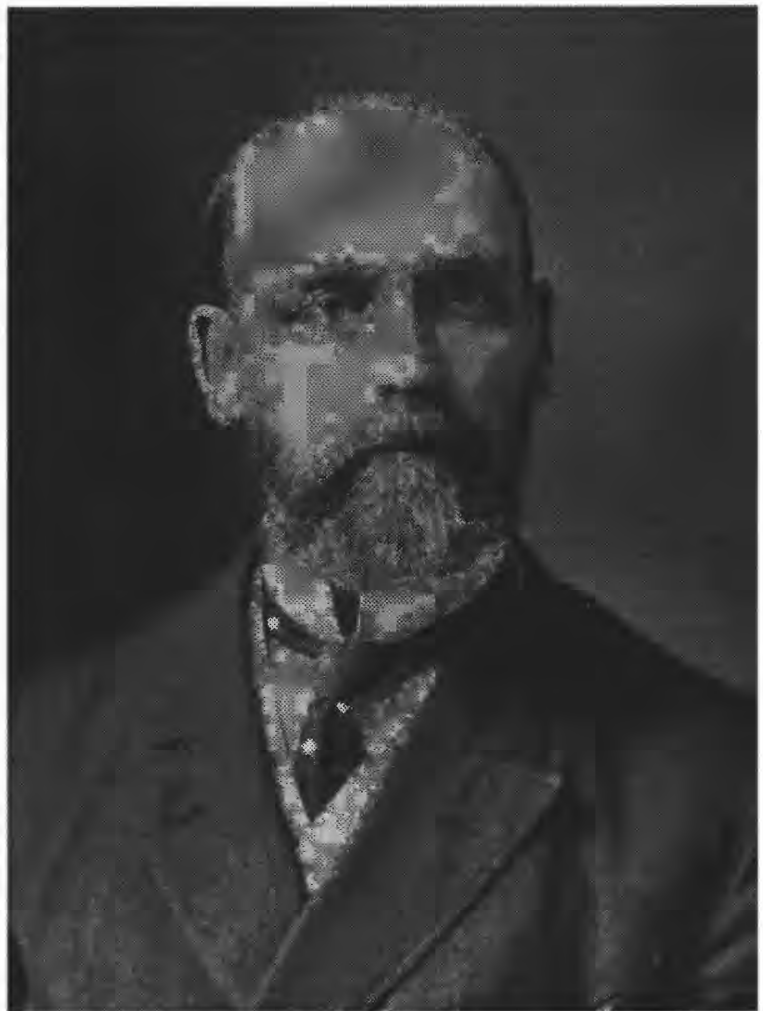

Figure 24. Frederick H. Newell.

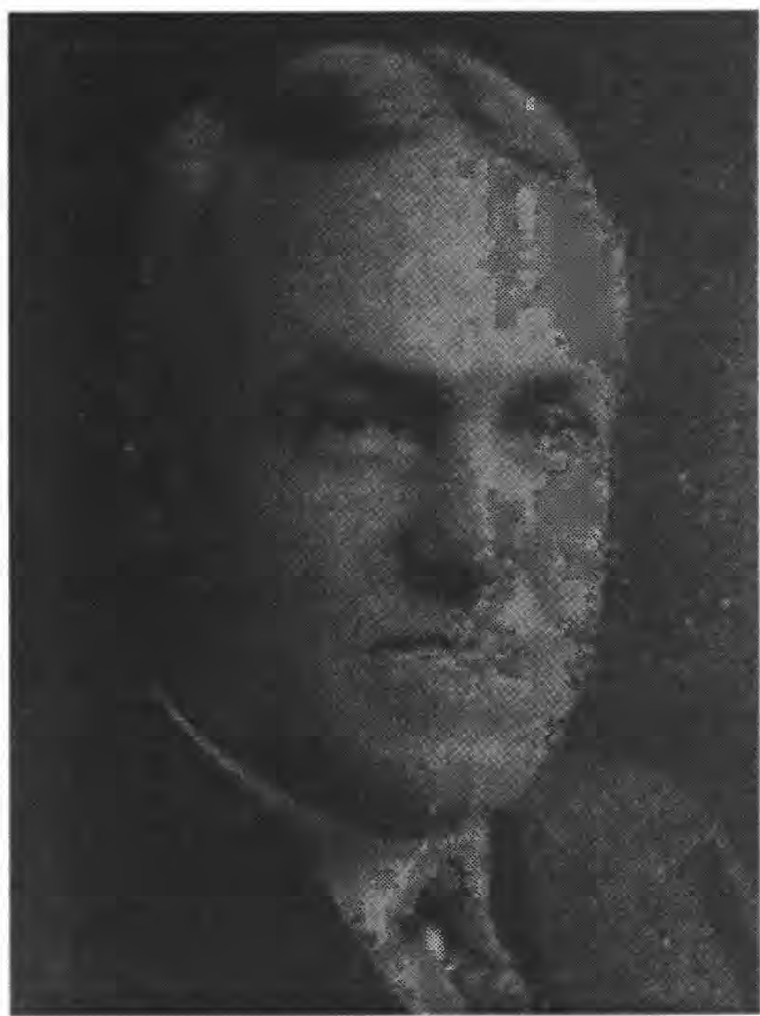

Figure 26. Benjamin F. Groat. 

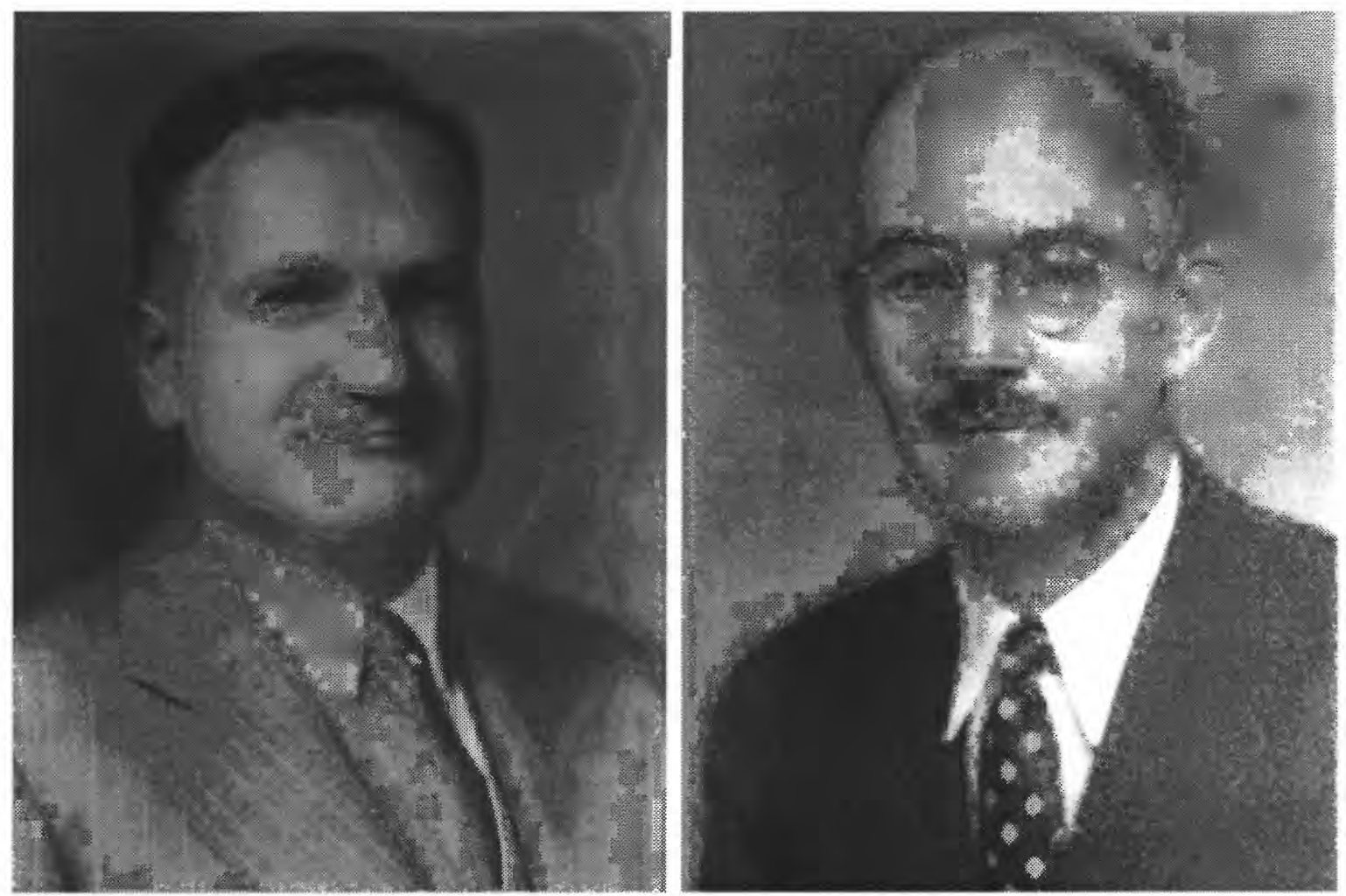

Figure 27. F.A. Nagler.

Figure 28. Carl Rohwer.
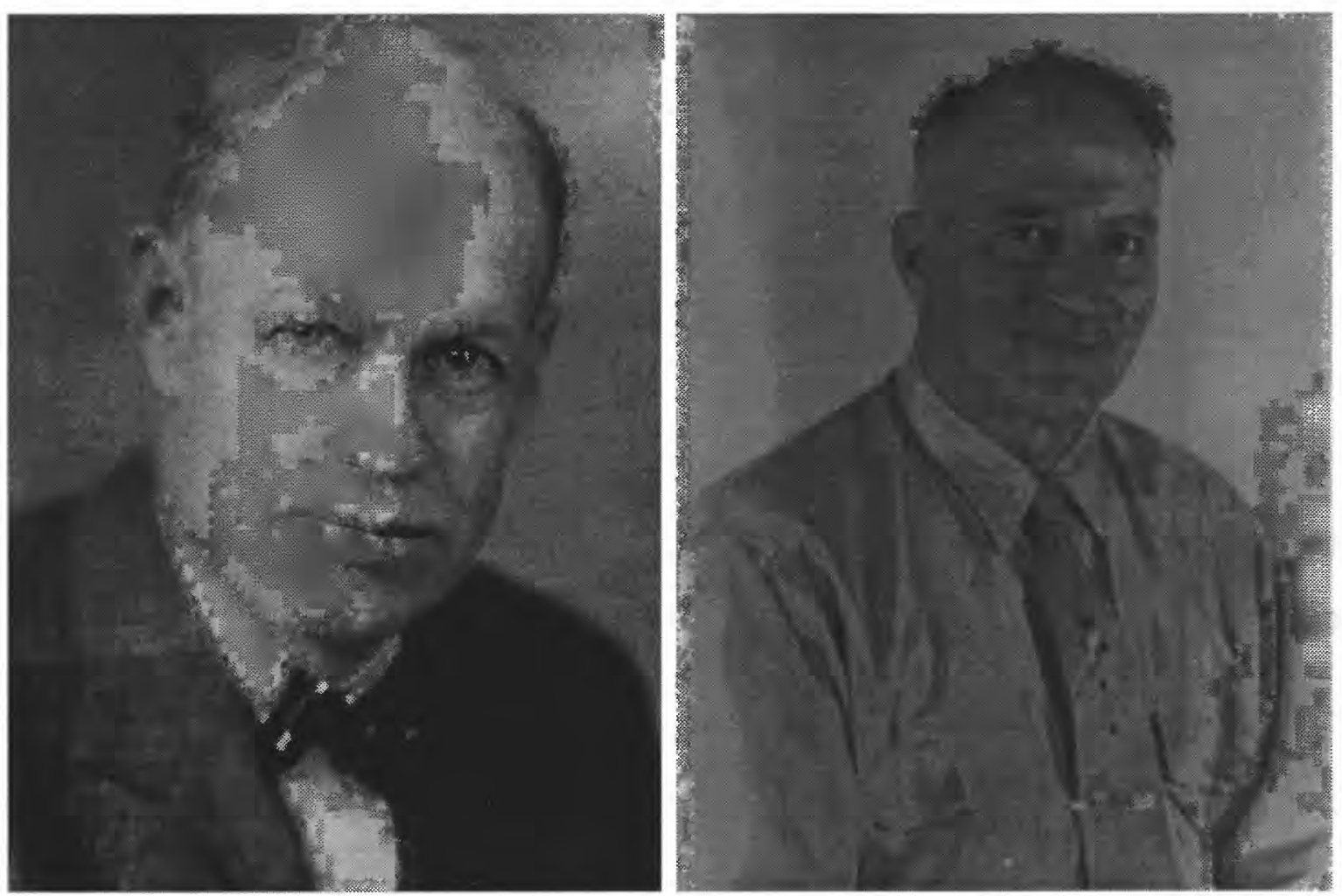

Figure 29. John C. Hoyt.

Figure 30. Arthur H. Frazier. 


\section{INDEX}

Addison, H. 12, 13

Alming, K. 12, 14

Amsler meter

See: Meter, Horizontal-axis

Appell, G.F. 21

Aubrey, Spencer, and Towbridge 19, 20, 21

Aubrey, Towbridge, and Spencer $\mathbf{2 1}$

Bean, H.S. 10, 17, 18

Bivins, L.E. 20

Botma, H.C. 21, 22

Brown and Nagler 2, 4

Bruck, P.J. 25

Buchanan, T.J. 15, 16

Burtsev and Baryshnikova 9,10

Carter and Anderson 25

Carter, R.W. 25

Castex, L. and Carounas, E. 16

Chappell, C.J. 2, 5, 6

Cushing, V. 19, 20

Derecki and Quinn 21

Dickinson, W.T. 1

Dickman, R.H. 10, 11

Dodge, N.A. 13, 14, 15, 18, 25

Dreher, F.C. 24

EG\&G meter

See: Meter, Acoustic

Engel and DeZeeuw 2, 4, 6, 7, 19

Engel, P. 2, 6, 7, 9

Fischer, M. 12, 13, 15, 16, 17

Float(s) 7, 8, 14, 22

Frazier, A.H. 1, 6, 7, 10, 12, 13, 32, 42

Fteley and Stearns meter See: Meter, Horizontal-axis

Fulford, J.M. 1, 2, 4, 6, 9, 10, 25

Gettner meter

See: Meter, Horizontal-axis

Gloster meter

See: Meter, Horizontal-axis

Golden and Trotter 25

Griffiths, G. 20, 21

Groat, B.F. $2,5,6,7,9,10,11,12,15,16,17,32,41$

Grover, N.C. 23

Haskell, E.E. 32, 39

Haskell meter

See: Meter, Horizontal-axis

Hjalmarson, H.W. 2, 4, 9

Hoff, E.J. 32, 40
Hoff meter

See: Meter, Horizontal-axis

Horton, R.E. 10

Hoyt, J.C. 1, 24, 32, 33, 34, 35, 42

Jepson, P. 12, 14, 17, 18

Johnson, R.L. 12, 13, 14, 15, 18

Kallio, N.A. 2, 6, 9, 12, 14, 15, 17, 25

Kolupaila, S. 1, 10, 12, 13, 17, 24, 32, 40

Kulin and Compton $6,7,12,14$

Kulin, G. 7,8,9

LaCornu, Hanson, and Cruff 25

Lallie meter

See: Meter, Vertical-axis

Lange meter

See: Meter, Horizontal-axis

Leach, H.R. 2, 5, 11, 12, 15, 16

Leonard, R.W. 12, 13

Lippincott, J.B. 2, 5, 11, 12, 22

Marsh-McBirney 19

Marsh-McBirney meter

See: Meter, Electromagnetic

McDonald, C.C. 24

Mero, Appell, and McQuivey 20

Meter, Acoustic

EG\&G 32, 38

Neil Brown 21, 32, 38

VEKTOR-AKWA 22

Meter, Electromagnetic Marsh-McBirney 19, 20, 21, 32, 38, 39

Meter, Horizontal-axis Amsler 11, 14, 17

Fteley and Stearns 13, 15, 32, 36

Gettner 13

Gloster 18

Haskell 5, 9, 11, 12, 13, 14, 15, 16, 17, 22, 32, 33, 34, 36

Hoff $11,12,13,15,16,17,23,24,32,35$

Lange 16

Neyrpic 11, 13, 15, 18, 24, 25, 32, 37

Ott $2,3,9,11,12,13,14,15,16,17,18,23,24,25,32,35$

Meter, Venturi 24

Meter, Vertical-axis

Lallie 23, 32, 35

Price 622 type $4,7,9,10,23,32,36$

Price 623 type 25

Price pygmy $2,6,7,8,9,24,25,32,36$

Price type $2,4,5,6,7,8,9,10,12,16,23,24,25,32,33$

Price type A 8, 11

Price type AA $2,3,4,6,7,8,9,10,25$

Price type OAA 6

Price, acoustic 4, 7, 9, 22, 32

Price, large $2,4,5,7,9,22,23,32$ 
Meter, Vertical-axis (cont.)

Price, small 2, 4, 5, 6, 7, 8, 9, 10, 11, 16, 22, 23, 32, 33, 41

Price, USGS-improved 4, 7,9, 10

Vane type $6,25,32,37$

Miller, C.H. 2, 5, 11, 12

Murphy, E.C. $1,5,7,8,12,14,22,32,33,41$

Nagler, F. 2, 4, 6, 7, 12

Nagler, F.A. 32, 42

Neil Brown meter See: Meter, Acoustic

Nettleton, G.H. 23

Newell, F.H. 2, 32, 41

Neyrpic meter

See: Meter, Horizontal-axis

Ott, A. 32, 40

Ott, L.A. 11, 12, 32, 40

Ott meter

See: Meter, Horizontal-axis

Pelletier, P.M. 1

Pierce, C.H. 7, 8, 14, 15

Pitot tube 8, 9, 15, 16, 24

Price, W.G. 32, 39

Price meter

See: Meter, Vertical-axis

Pygmy meter

See: Meter, Vertical-axis
Raffel, D.N. 18

Rantz, S.E. 25

Robson, A.D. 10

Rohwer, C. $2,4,5,6,7,8,10,11,12,13,14,15,23,32,42$

Rumpf, C.P. $6,7,8,14,15$

Schubauer and Mason 9

Scobey, F.C. $2, \mathbf{5 , 7 , 8}$

Smith, J.D. 12, 14

Staubli and Hegland 14, 15

Szigyarto, Z. 15, 16

Thibodeaux and Futrell 2, 6

Townsend and Blust 24, 25

Van Vliet, R. 23

Vane meter See: Meter, Vertical-axis

VEKTOR-AKWA meter

See: Meter, Acoustic

Venturi meter

See: Meter, Venturi

Weir(s) 13, 16, 22, 23, 24

Wood, G.K. 24

Woster, H.C. 23

Yarnell and Nagler 2, 4, 5, 6, 7, 9, 10, 11, 12, 13, 15, 16, 17, 23 